CHEMICAL COMPOSITIONAL ANALYSIS

OF POLYCHROME POTTERY IN THE

NORTHERN CASAS GRANDES AREA (A.D. 1200-1450)

\begin{abstract}
A Dissertation
presented to
\end{abstract}

the Faculty of the Graduate School

at the University of Missouri

In Partial Fulfillment

of the Requirements for the Degree

Doctor of Philosophy

By

CANDACE A. SALL

Dr. Todd VanPool, Dissertation Supervisor

December 2018 
The undersigned, appointed by the dean of the Graduate School, have examined the dissertation entitled

\section{CHEMICAL CHARACTERIZATION OF POLYCHROME POTTERY IN THE NORTHERN CASAS GRANDES AREA (A.D. 1200-1450)}

presented by Candace A. Sall,

a candidate for the degree of doctor of philosophy, and hereby certify that, in their opinion, it is worthy of acceptance.

Michael J. O’Brien (co-chair)

Todd L. VanPool (co-chair)

Christine S. VanPool

Michael D. Glascock 


\section{DEDICATION}

This dissertation is dedicated to my family. Joseph, my husband, never wavered in his support of my graduate work, be it excavating, researching, analyzing, or writing, and he was always there to take care of things at home. Our daughters, Izzy and Beth, were happy to come into the field with me, even though it was always hot! My parents always supported my education and their care kept me going, even after they passed away. My grandparents also helped make sure I had what I needed. My Mom was always my biggest cheerleader and I will always try to make her proud. 


\section{ACKNOWLEDGMENTS}

My sincere thanks are given to many people. Michael J. O’Brien provided guidance since the day we met when I said I wanted to use science to understand the archaeological record. His support throughout this project was unwavering. Todd and Christine VanPool allowed me to come to the field with them and work at 76 Draw. Todd keeps the excavations running, and there are none better than Chris at reading excavations. Thank you to Todd for working with me on my first drafts. Mike Glascock trained me in NAA sample preparations and later in analyzing the data as a graduate student. He never let me lose sight of finishing this dissertation and he always inquired on how it was going.

This research was funded by two grants: National Science Foundation grant 1621158 at the Archaeometry Lab at the University of Missouri Research Reactor funded NAA, and an additional grant to Todd VanPool from the University of Missouri Arts and Science Alumni Foundation also supported NAA.

Thank you to the researchers that allowed me to use their comparative data from across southern New Mexico and western Texas: Katy Putsavage, Darrell Creel, Lori Reed, and Karl Laumbach. My thanks also go to fellow graduate students, especially Matt Boulanger, who showed me the finer points of NAA, and Kyle Waller, who kept me up to date on all the skeletal research in the Casas Grandes area. I also thank Kate Trusler, who helped me walk through all the final graduate school steps in order and as gracefully as possible. 


\section{Table of Contents}

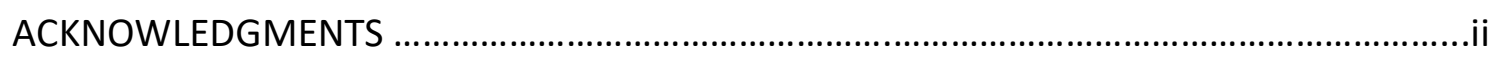

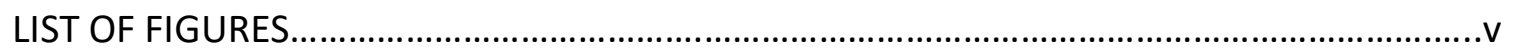

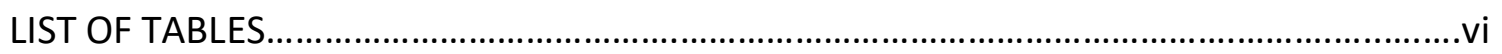

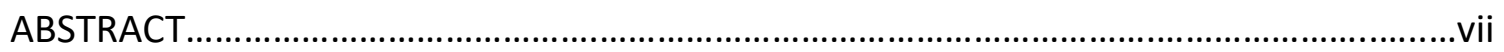

Chapter

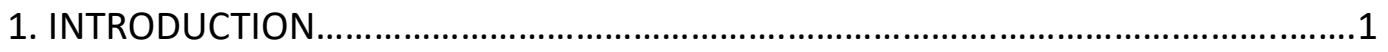

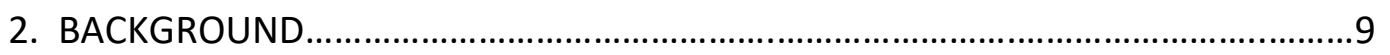

Casas Grandes Medio Period (A.D. 1200-1450)

Chihuahuan Polychrome Pottery

Salado (A.D. 1250-1450)

Salado Polychrome Pottery

Animas Phase (A.D. 1200-1450)

76 Draw

Other Settlements Used for Comparisons

Pottery Production in the Casas Grandes and Salado Regions

3. MATERIALS AND METHODS.

Neutron Activation Analysis

The Samples

Sample Preparation

Multivariate Analysis

Petrographic Analysis

Chapter Summary

4. NAA AND PETROGRAPHIC ANALYSIS AND RESULTS.

NAA Compositional Results

Group R1

Group R2

Group R3

Group G (Gila: Salado wares)

Group P1

Group P2 
Group P3

Group BMP1

Group BMP2

Group BMP3

Petrographic Analysis

Interpreting NAA and Petrographic Results

5. DISCUSSION

Discussion

Conclusions

Future Work

APPENDIX

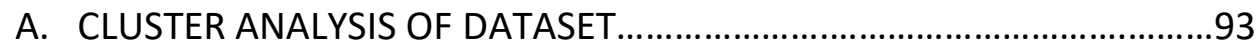

B. MAHALANOBIS DISTANCES FOR NAA GROUPS ......................................

C. ANALYSIS IDENTIFICATION NUMBERS WITH PROVENIENCE

DESGINATION AND NAA GROUP.........................................................102

D. SCATTERPLOTS OF RAMOS GROUPS: FE, EU, LA, CR, HF...................105

E. RAW NAA DATA FROM 76 DRAW SAMPLES....................................109

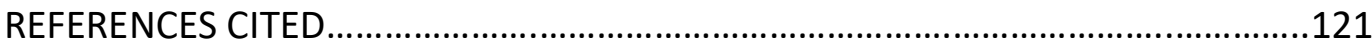

VITA 


\section{LIST OF FIGURES}

Figure

Page

1.1 Map showing the Casas Grandes and Salado regions................................................

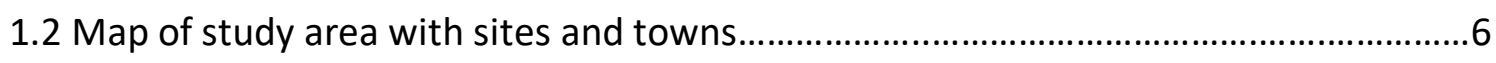

2.1 Macaw pens with stone rings and plugs at Paquimé.................................................12

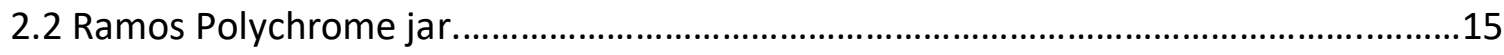

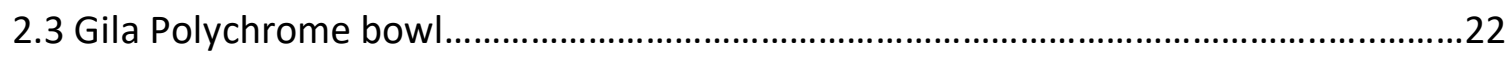

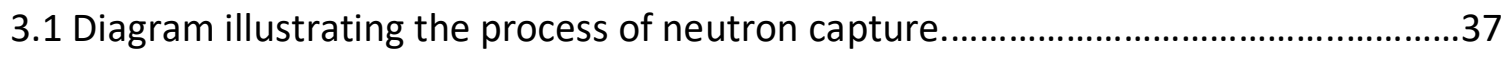

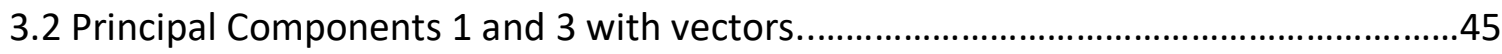

3.3 Principal Components 1 and 4 with all 10 geochemical groups...................................47

3.4 Scatterplot comparing barium and arsenic of Ramos Polychrome groups.................48

4.1 Bar chart of variances explained by each principle component..................................54

4.2 Principal Components scatterplot of Ramos Polychrome groups..............................58

4.3 Scatterplot of barium and arsenic for Ramos Polychrome groups.............................60

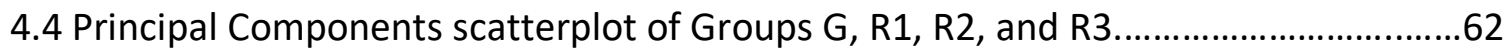

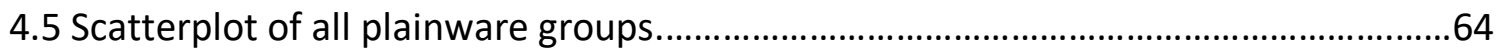

4.6 Scatterplot of vanadium and calcium with plainware Groups $1-3 \ldots \ldots \ldots \ldots \ldots \ldots \ldots \ldots . . . . . . . . .66$

4.7 Principal Components scatterplot of plainware Groups 1-3...................................67

4.8 Scatterplot of ytterbium and barium with Groups P2-3 and BMP1-3......................68

4.9 Scatterplot of ytterbium and neodymium with Groups BMP1-3............................69

5.1 Ramos Polychrome group distribution areas...........................................................85

5.2 Group G (Gila Polychrome) distribution area........................................................... 87 


\section{LIST OF TABLES}

Table Page

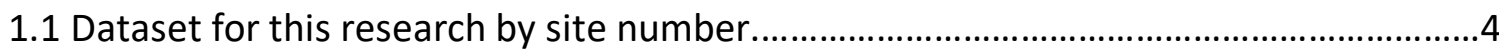

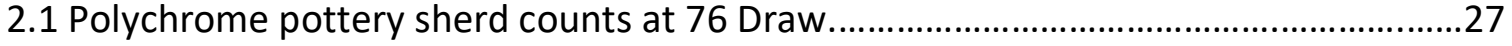

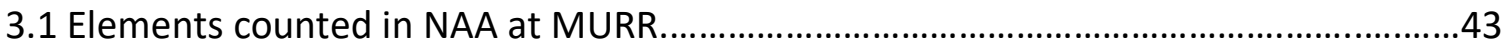

4.1 Sites and pottery types with site names/number......................................................54

4.2 Eigenvalues for the first eight principle components..................................................55

4.3 Sites with sherd counts and clay sample by geochemical group.................................57

4.4 Petrographic analysis of minerals by temper group and NAA group..........................74 


\begin{abstract}
The northern area of the Casas Grandes Medio Period (A.D. 1200-1450) was not well known archaeologically. 76 Draw is on the border of the Casas Grandes and Salado (A.D. 1275-1450) regions and the nature of interaction and integration with both areas at this site was examined through excavation. 76 Draw, an Animas Phase settlement in Luna County, New Mexico, had both Ramos Polychrome vessels, a Casas Grandes polychrome type, and Gila Polychrome vessels, a Salado polychrome type, and neutron activation analysis was conducted to determine if both types were made at 76 Draw. The Ramos Polychrome pottery at the site came from three production locations based on the geochemical groups as well as petrographic analysis of some of the sherds. One of the production locations is at or near Paquimé and one might be at or near 76 Draw. The Gila Polychrome vessels came to 76 Draw from one production location in the Mimbres Valley north of the site. 76 Draw was integrated with Casas Grandes in Chihuahua, Mexico, as it was participating in the religious system that included the production and use of the iconographic Ramos Polychrome pottery. Evidence of roasting ovens, obsidian from southern sources, shell, and bird burial information from 76 Draw, along with Ramos Polychrome data, demonstrates that the Casas Grandes interaction sphere operates as far north as southern New Mexico.
\end{abstract}




\section{Chapter 1 Introduction}

This study seeks to define the nature of late prehistoric borderland dynamics in what is now southern New Mexico in an area where the Casas Grandes culture, centered in Chihuahua, Mexico, and the Salado culture, centered in Arizona, overlapped (Figure 1.1).

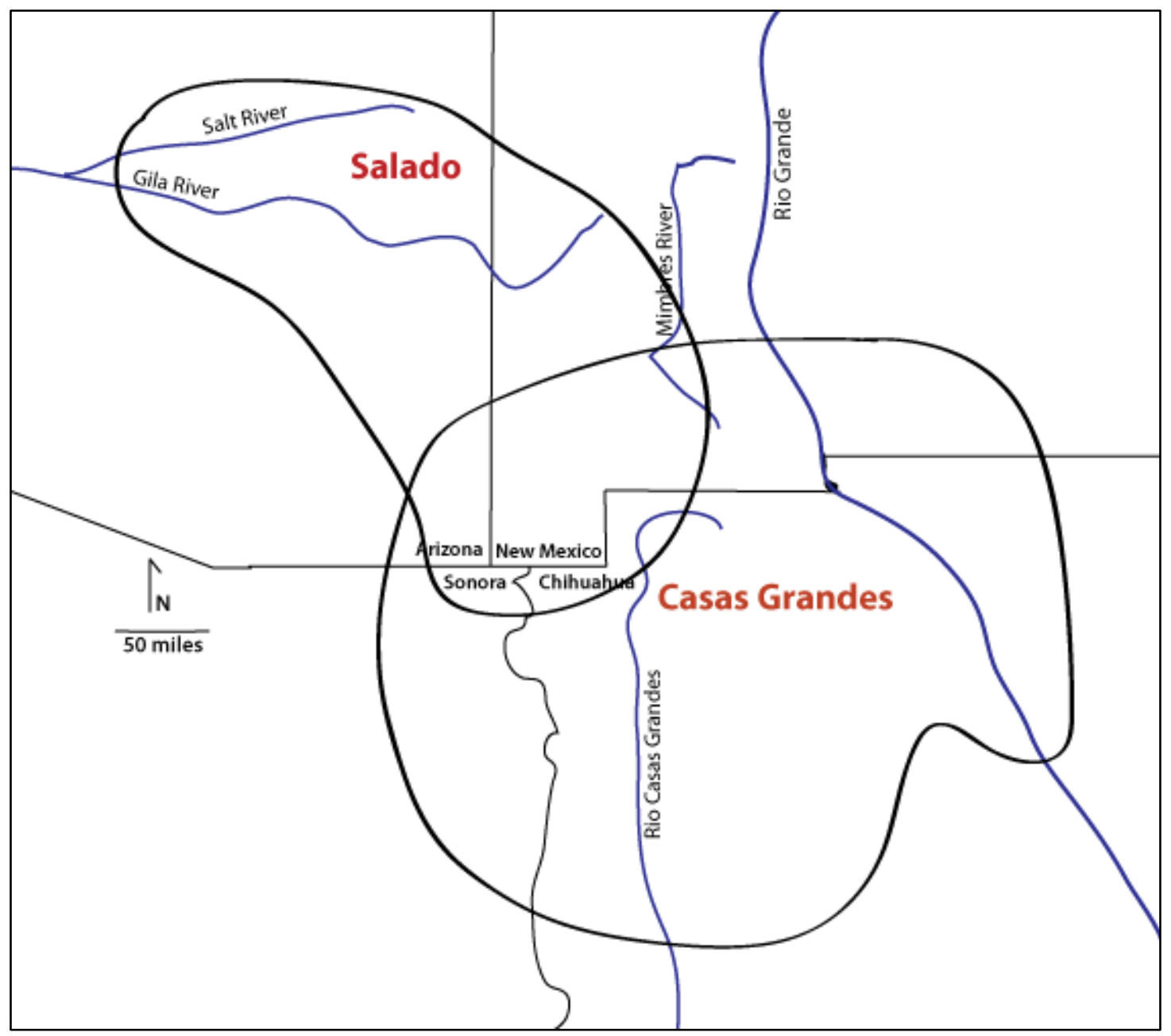

Figure 1.1 Map showing the Casas Grandes and Salado regions.

The Casas Grandes world encompasses a large area of the United States and

Mexico, from southern New Mexico to central Chihuahua and from southwest Texas to southern Arizona and eastern Sonora. This area is delineated most easily by Medio 
Period (A.D. 1200-1450) Chihuahuan polychrome pottery such as Ramos, Babícora, and Villa Ahumada Polychromes. These polychromes, with intricate red and black painted designs on a light-colored surface, have been noted for over a hundred years (Kidder 1916). They were made by farmers who lived in adobe houses. The largest city in the region, Paquimé (formally known as Casas Grandes) served as a ceremonial and economic center that exerted influence across the region and beyond (Di Peso et al. 1974; Schaafsma and Riley 1999a). Northwest of Paquimé, in east-central Arizona and west-central New Mexico, lived people who also were also farmers but were part of a different religious and cultural system (Crown 1994; VanPool et al. 2006). They also made distinctive pottery, called Salado polychrome (A.D. 1275-1450), which is further subdivided into Gila, Tonto, and Pinto Polychromes (Crown 1994; Dean and Woosley 2000; Lekson 2002). This pottery has black paint and red and white slips, and was made at about the same time as the Chihuahuan polychromes. Both groups used similar designs and themes to decorate their pottery, but they took efforts to distinguish between the religious systems; for example, both included horned-serpent images on their pottery, but they made them using different colors and with horns pointing in different directions (VanPool et al. 2006). Salado and Casas Grandes settlements were contemporaneous and often close to one another, and pottery from each tradition is found on settlements throughout the other region (Kidder et al. 1949; Lekson 2002). Paquimé, in fact, had Salado polychrome throughout the site and a stockpile of 49 exceptionally large Gila Polychrome bowls was recovered from a storeroom, Room 81-8 (Di Peso et al. 1974:6; Lekson 2000:282-284). 
The interaction between the two cultures was, overall, generally friendly, given the ubiquity of the pottery, the closeness of the communities, and the lack of an obvious military frontier with fortified settlements in defensive locations. There is evidence of a fire at Paquimé which Di Peso (1974) suggested reflected a final battle during which the city was sacked and many of its inhabitants killed. However, Lally (2006) cautions against labeling a fire intentional without a purposeful fire investigation, and Walker and McGahee (2006) suggest the fire may be part of a ceremonial, peaceful closing of the settlement. Regardless, the pottery was made as part of two distinctive production systems, with local pottery production typical of the Salado region (Crown 1994; Huntley et al. 2013) and specialized manufacture of Ramos Polychrome and perhaps other ceramic types in the Casas Grandes region (Rakita and Cruz 2015; Sprehn 2003; Topi et al. 2018). Were Casas Grandes polychromes and Salado polychromes produced on the same sites in the Casas Grandes region? Were vessels of these pottery types traded far and wide as people moved through the other region? And if so, where was the pottery made? To determine the nature of interaction that existed between the Casas Grandes and Salado people, this study uses neutron activation analysis (NAA) of sherds from along the southern U.S. border to examine both where the polychrome pottery might have been made and trade relationships or other mechanisms that caused it to move across the landscape. The data were derived from pottery from five sites in southern New Mexico and two in west Texas (Table 1.1, Figure 1.2). I was not able to analyze sherds from Chihuahua at this time because of difficulties in getting all of the necessary permits, but hope to do so in the future. 
Table 1.1 The 216 samples analyzed using NAA in this research. The sherds from 76 Draw were analyzed by the author. The remaining samples were analyzed by other researchers who have consented to their use for comparison to the 76 Draw sherds.

\begin{tabular}{|c|c|c|c|c|c|}
\hline & $\begin{array}{l}\text { Plain } \\
\text { ware }\end{array}$ & $\begin{array}{c}\text { Ramos } \\
\text { Polychrome }\end{array}$ & $\begin{array}{l}\text { Gila (Salado) } \\
\text { Polychrome }\end{array}$ & Other Types & Total \\
\hline $\begin{array}{l}6 \text { Draw, } \\
\text { Luna County, NM }\end{array}$ & 31 & 33 & 36 & $\begin{array}{c}1 \text { Tonto (Salado) } \\
\text { Polychrome, } \\
1 \text { Villa Ahumada } \\
\text { (Casas Grandes) } \\
\text { Polychrome }\end{array}$ & 102 \\
\hline $\begin{array}{l}\text { Black Mountain, } \\
\text { Luna County, NM }\end{array}$ & 101 & 2 & 0 & 0 & 103 \\
\hline $\begin{array}{l}\text { Simon Ranch, } \\
\text { Luna County, NM }\end{array}$ & 0 & 3 & 0 & 0 & 3 \\
\hline $\begin{array}{l}\text { LA15062, } \\
\text { Grant County, NM }\end{array}$ & 0 & 4 & 0 & 0 & 4 \\
\hline $\begin{array}{l}\text { LA26788, } \\
\text { Doña Ana County, } \\
\text { NM }\end{array}$ & 0 & 2 & 0 & 0 & 2 \\
\hline $\begin{array}{l}\text { 41EP8, } \\
\text { El Paso County, TX }\end{array}$ & 0 & 1 & 0 & 0 & 1 \\
\hline $\begin{array}{l}\text { 41EP1672, } \\
\text { EI Paso County, TX }\end{array}$ & 0 & 1 & 0 & 0 & 1 \\
\hline Total & 132 & 46 & 36 & 2 & 216 \\
\hline
\end{tabular}

I was part of the excavation crew at the Animas Phase settlement of 76 Draw (LA156980) in Luna County, New Mexico, in 2009 and 2010, which was led by Christine VanPool, Todd VanPool and Gordon Rakita. The site, identified by Brand (1933) and Sayles (1936) as the northern-most Casas Grandes settlement, was excavated specifically to provide insight into the nature of regional interaction among the Salado, Casas Grandes, El Paso phase, and other 13th- and 14th-century people living along what is now the U.S.-Mexican border. The directors conducted three years of excavations in 2009, 2010, and 2013 (Rakita et al. 2011; VanPool et al. 2014). My research provides more information about the degree of interaction among Animas 
Phase sites within the Casas Grandes and Salado areas by using NAA and petrography of Chihuahuan and Salado polychrome pottery from 76 Draw and comparing the results with compositional data from pottery from contemporaneous sites in New Mexico and western Texas.

One hundred and two sherds of various types from 76 Draw were prepared and analyzed by the author at the University of Missouri Research Reactor (MURR) and include 31 plainware, 33 Ramos Polychrome, 36 Gila Polychrome, and one each of Tonto Polychrome and Villa Ahumada Polychrome. In the same county, 103 sherds from Black Mountain are compared in this research; 101 are plainwares and two are Ramos Polychrome. The rest of the 11 Ramos Polychrome sherds analyzed at MURR are from: Simon Ranch in Luna County, New Mexico; LA15062 in Grant County, New Mexico, and LA26788 in Doña Ana County, New Mexico; and 41EP8 and 41EP1672 in El Paso County, Texas. 


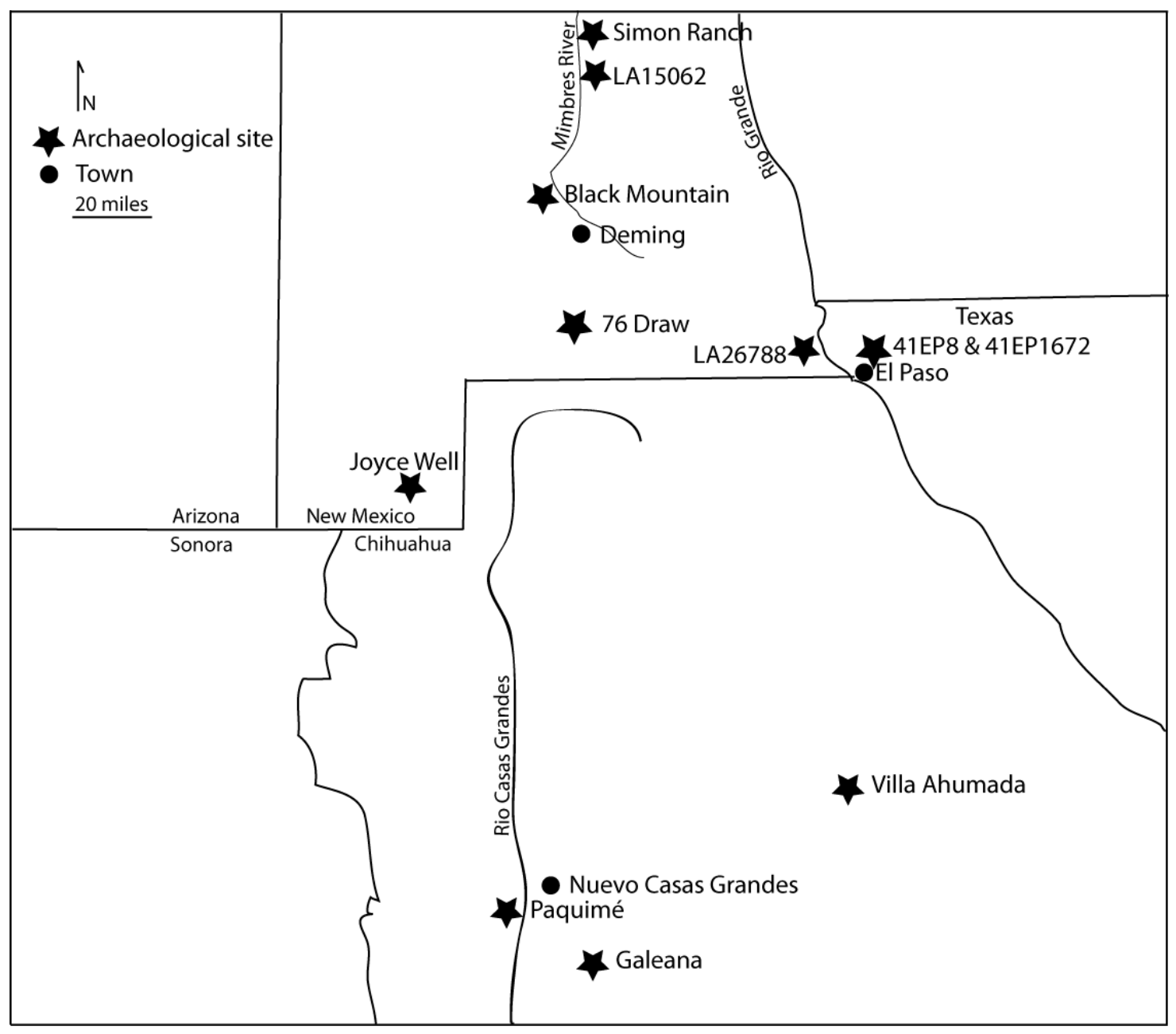

Figure 1.2 Map of study area. Some sites and modern towns are marked for reference. Lab of Anthropology (LA) numbers for named sites are: LA156980 for 76 Draw, LA49 for Black Mountain, and LA11823 for Joyce Well.

In Chapter 4, I will present the details of the analysis, but here I briefly present my results. Gila Polychrome sherds from 76 Draw belong to a single compositional group that also includes the only Tonto Polychrome and Villa Ahumada Polychrome sherds in the analysis. Speakman (2013) and Putsavage (2015) tied other pottery from this production source to the Upper Mimbres Valley. This clay source was used for 
hundreds of years to make many types of pottery, including the entire Mimbres sequence, Alma Plain, Playas series, and Gila Polychrome, and more.

The Ramos Polychrome samples $(n=46)$ make up three compositional groups (R1, $R 2, R 3)$, suggesting the clay came from three locations. Sherds from 76 Draw are in all three Ramos Polychrome groups defined here, and Group R3 matched Triadan et al.'s (2018) Core Group 2, likely from the area around Paquimé, demonstrating that 76 Draw is part of the Casas Grandes interaction sphere. Groups R1 and R2 might have been made at or near 76 Draw. Based on NAA, X-ray fluorescence (XRF), and petrographic analysis performed by other researchers (Britton 2018; Carpenter 2002; Triadan et al. 2018; Woosley and Olinger 1993), as well as the NAA results reported here, the people north of Paquimé acquired Ramos Polychromes made in the Paquimé region but also acquired Ramos Polychrome produced elsewhere, and perhaps made locally.

For this study, plainwares are defined as undecorated pottery, meaning vessels had no paint or designs such as corrugation and incising. The plainware samples came from 76 Draw and Black Mountain in Luna County, New Mexico, and comprise six compositional groups. Three plainware groups contained sherds from both sites (Groups P1, P2, and P3), and three had sherds from Black Mountain only (Groups BMP1, BMP2, BMP3). 76 Draw had plainware pottery from at least three production locations, and at least one of which was likely at or near the site. Plainware pottery also moved across the landscape.

The research presented here demonstrates how a community, 76 Draw, on the border of two culture areas, participated in multiple social networks but in different 
ways. The people of this settlement used the same kind of material-pottery-from different networks with different designs that held religious/political power. They participated in the Casas Grandes religious sphere but were clearly in close contact with, and thus aware of, the culture and religion associated the Salado tradition. Gila Polychrome, manufactured at a single location, was exchanged from the north, but Ramos Polychrome from multiple sources, at least one likely from deep in Chihuahua, was present (see Lieber et al. 2014; Putsavage 2015). Much of the plainwares were local, but some came from other sources, suggesting that the social interaction in this borderland region was fluid, with substantial interaction across cultural boundaries. 


\section{Chapter 2 Background}

As mentioned, there is a considerable area in which the Casas Grandes and Salado regions overlap. 76 Draw is a site on the border of both cultural regions. Reflecting the confusion that can sometimes be created by changing cultural-historical taxonomies, this area is called the Animas Phase area, despite the fact that it is not a distinct phase within a larger cultural-historical sequence as was originally suggested (Gladwin and Gladwin 1934), and is not limited only to the Animas region of the bootheel of New Mexico, where it was originally defined (Rakita et al. 2011). The Animas Phase area includes settlements that are clearly aligned with the Casas Grandes Medio period culture (e.g., Joyce Well [Skibo et al. 2002]), aligned with the Salado people (e.g., Pendleton Ruin [Kidder et al. 1949]), or independent of both cultural traditions (Douglas 1995).

I review below the Medio Period (A.D. 1200-1450) of the Casas Grandes culture, as well as the Salado (A.D. 1275-1450), describe their polychrome pottery types, and then cover the Animas Phase of southwestern New Mexico. I also review 76 Draw and briefly describe the additional polychrome and plainware sherds used as comparative collections that were analyzed by other researchers using NAA at the University of Missouri Research Reactor (MURR), as well as by petrographic analysis.

Casas Grandes Medio Period (A.D. 1200-1450)

Most of what we know about the Medio Period is based on Di Peso's (1974) report on the excavations of Paquimé, in northwest Chihuahua, Mexico, which is also 
the largest site in the region. Paquimé was excavated in 1958-1961 by the Joint Casas Grandes Expedition (JCGE), which was sponsored by the Instituto Nacionál de Antropología e Historia (INAH) and the Amerind Foundation (Di Peso 1974). The site was well known even before the JCGE excavations, being one of the earliest settlements mentioned by European explorers in the Greater Southwest. The earliest remarks on the site come from Baltasar de Obregon (1584 [quoted in Gamboa 2002]), the chronicler of the Ibarra Expedition, who noted that the city had great houses six and seven stories tall with magnificent patios with beautiful stones. He went on to say the houses were whitewashed and beautifully painted, causing them to look like they had just been abandoned. Adolph Bandolier visited Paquimé in the late 1800s (Bandelier 1892), and later others did as well (Amsden 1928; Blackiston 1909; Carey 1931; Kidder 1916; Lumholtz 1902; Sauer and Brand 1931; Sayles 1936). They each commented on the size and beauty of the buildings, but it was clear that natural degradation had changed the settlement's appearance. The murals were gone, walls were collapsing, and the adobe was melting. The site was further damaged by the Parral earthquake in 1928 that collapsed additional walls (Doser and Rodriguez 1993). By the time the JCGE started their excavations in 1958, the buildings had become large mounds of melted adobe. Subsurface preservation of nonperishable materials was quite good, though. Excavations revealed that Paquimé has very thick walls $(60-120 \mathrm{~cm}$ thick), raised (platform) hearths, ballcourts, platform and effigy mounds, macaw and turkey pens, marine shell, pit ovens, exceptionally rich burials indicating a well-developed political hierarchy, a greater number and variety of copper items relative to anywhere else in the 
North American Southwest, and polychrome pottery (Di Peso 1974; Minnis 1988; Rakita 2009; Dean and Ravesloot 1993). Many of the most impressive items (e.g., the copper and ball-court architecture) appear to be derived from West Mexico (Harmon 2006; Vargas 1995). The sites surrounding Paquimé, in the core area of about $30 \mathrm{~km}$ (Whalen and Minnis 1999), also have many of these features, but as one moves away from this area ballcourts, mounds, bird pens, and polychrome pottery become less common (Whalen and Minnis 2001). Beyond 60 km away from Paquimé, in Whalen and Minnis' (1999) outer zone of Paquimé's control, we still find these features, though only occasionally. It appears that Paquimé's economic and religious influence was focused most heavily in the area within a day's walk, and then decreased as one traveled farther from the site. 76 Draw, as well as other settlements such as Joyce Well, Box Canyon, and Clanton Draw in New Mexico, are among the more distant settlements that reflect close affiliation with Paquimé (McCluney 1962; Rakita et al. 2011; Skibo et al. 2002). For example, Joyce Well, Culberson Ruin, and Timberlake Ruin, sites that are in the bootheel of New Mexico, have ballcourts (Harmon 2006), and 76 Draw has architectural construction methods similar to Paquimé's (Rakita et al. 2011; VanPool et al. 2014).

The amount of Mesoamerican influence during the Medio Period has been a debate for 50 years. Charles Di Peso (1974) suggested that "puchtecas" from Mesoamerica came to Paquimé and set up a trading/production outpost at the beginning of the Medio period to gain access to Southwestern goods such as turquoise. Exotic items, such as macaws, copper bells, turquoise, and marine shell were traded. In general, Southwestern archaeologists have rejected Di Peso's Puchteca hypothesis; 
although Paquimé stockpiled resources such as almost four million shells, these resources did not seem to be traded across the region as one would expect at a redistribution center (VanPool et al. 2005). Macaws were found in burials in the areas around the Paquimé core area, and a few sites had stone circles that were evidence of macaw breeding cages (Figure 2.1), but again, macaw production seemed to be for local consumption as opposed to a broadly structured trade system. Ocean shell came from the Gulf of California (Krug 2018), and copper likely came from farther south in West Mexico (Krug et al. 2016; Vargas 1995). None of these patterns are what would be expected of a Mesoamerican trading outpost.

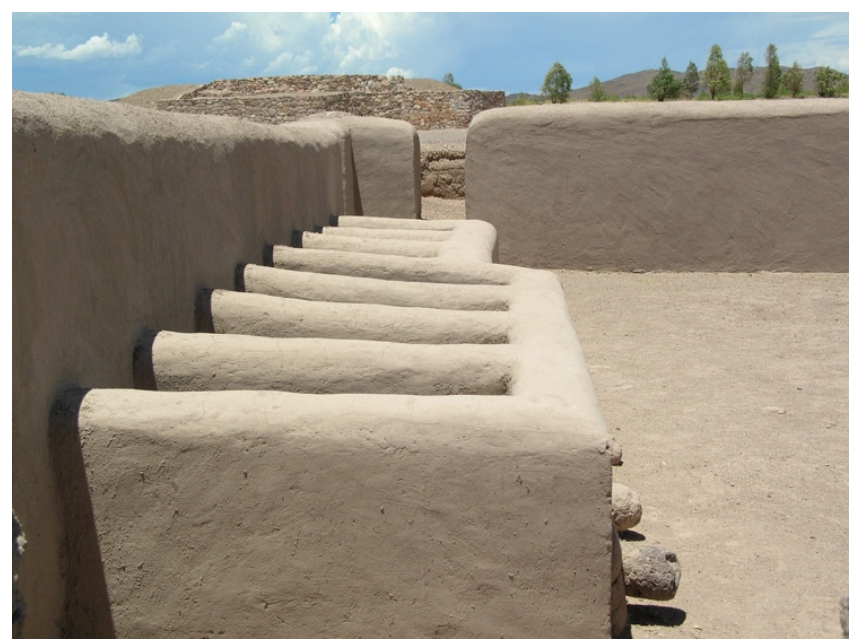

Figure 2.1 Macaw pens with their stone rings and plugs at Paquimé. Photo courtesy of Donna Walters.

A modified version of the trade-center model was advocated by Kelley (1993), who proposed that Paquimé was the focus of trade with the Aztalán tradition and people of West Mexico. The Aztatlán tradition was a trade-based system of prestige in which local elites exchanged goods with each other for the purpose of establishing political authority and reinforcing their status (Kelley 2000; Pierce 2017). Some evidence 
supports this, including apparent population mixing between Casas Grandes and West Mexico. Turner (1999) examined tooth cusps from human remains in Casas Grandes burials and found a similarity with people in West Mexico and some with the Mimbres area. Waller (2017) found similar treatments for the dead in these areas, and Harmon (2006) noted architectural similarities in ballcourt design. Also, trade goods such as the copper bells had Aztatlán designs (Vargas 1995).

Yet not everyone is supportive of a West Mexican origin for the Medio Period culture. Lekson (1999) suggests a Puebloan connection based on the location of Paquimé (due south of Chaco Canyon), above-ground architecture with plazas, sub-floor burials, and other similarities. Whalen and Minnis (2009) suggest that Paquimé and the subsequent Medio Period pattern may simply reflect in situ cultural development without substantial influence from outside cultures.

Despite uncertainty about the "origin" of the Medio period culture, archaeologists do seem to agree on several significant points (Minnis and Whalen 2015; VanPool and VanPool 2012). First, the Medio Period culture reflected West Mexican influence and the use of West Mexican religious concepts. Second, this religious system served as the basis of a regional system that integrated settlements across much of northwestern Mexico and southern New Mexico. Third, Paquimé was the ceremonial center for this system, but had inconsistent influence. Differences in dominant ceramic types and religious architecture likely reflect these differences, with the areas dominated more heavily by Ramos Polychrome reflecting greater levels of religious (and consequently political) integration with Paquimé (Whalen and Minnis 2001), and areas 
with comparatively higher relative frequencies of other Casas Grandes polychromes likely being less integrated (see Carpenter 2002: Figure 7.2). More specifically, Paquimé seems to have been most influential in nearby settlements and settlements that have a majority of Ramos Polychrome vessels in the Animas Phase area, but less dominant (although almost certainly retaining some religious and political influence) in intermediate settlements between these areas.

\section{Chihuahuan Polychrome Pottery}

As illustrated by Carpenter (2002:Figure 7.2), archaeologists have suggested that various Chihuahuan polychromes and other Casas Grandes pottery (e.g., Ramos Black) were made in different regions (Carpenter 2002; Rakita 2009). Types include Ramos, Babícora, and Villa Ahumada Polychromes, and the less common types of Carretas, Corralitos, Huerigos, and Dublan Polychromes, and most were made by the coil and scrape method. The terms inclusions, aplastics, and temper, have specific meanings. Aplastics, or inclusions, are non-plastic particles that occur naturally in clays. Temper is an aplastic that has been added to the clay by the potter. When the term temper is used here, I am referring to aplastics that were intentionally added by the potter.

Charles Di Peso's typology was used for this work based on VanPool et al.'s (2008) ability to replicate it based on his descriptions in volume six (Di Peso et al. 1974; see also Rakita and Raymond 2003). This typology is hierarchical with Ramos Polychrome at the top of the hierarchy. It was based on technical skill as measured by finish (slip/no slip, polish/no polish, smooth/texture), form, and line execution (fine, 
sloppy). Here I concentrated on the technological traits because they were the basis used to classify the sherds in this study.

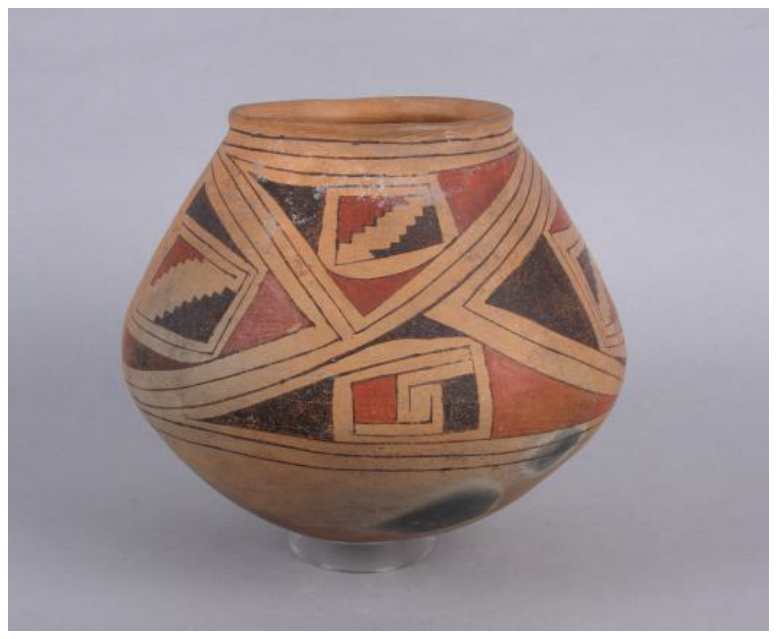

Figure 2.2 Ramos Polychrome jar. Catalogue No. 65.24.22. Photo courtesy of the Maxwell Museum of Anthropology, University of New Mexico. The other side of the jar has the same design repeated.

Ramos Polychrome is buff color, and ranges from white to very pale brown, and was well-polished creating a self-slip. Some have polishing over the red and black paint. The black paint ranges from true black to very dark gray, with dark gray the typical color. The red paint is dusky red to weak red with medium red being the most common. Paint analysis using visual spectroscopy was done by Robert O'Haire of the Arizona Bureau of Mines (1966 [quoted in Rinaldo 1974]). He found that the black paint has major amounts of copper and lead, with intermediate amounts of manganese (O'Haire 1966 [quoted in Rinaldo 1974:257]). Iron is the red paint's major mineral. Ramos Polychrome has a fine-textured paste with fine inclusions that are angular and an opaque white color, which Rinaldo (1974:252) suggested was tuff. Ramos Polychrome also has some clear crystalline particles, and very few red, black, pink, and yellowish grains. The vessels are strong, with a hardness range of 3.5 to 5.5 on the Moh's hardness scale, with 
the typical hardness of 4.0 (Rinaldo 1974:252). Ramos Polychrome has three variants:

(1) standard, which has solid red areas outlined in black; (2) a black-on-white variant;

and (3) Capulín, with red areas that are not outlined in black.

Babícora Polychrome typically is a pale brown color in the standard variant, but can range from pink to white to very pale brown. Some were polished over after the black and red paints. The black paint ranges from gray to very dark gray to black, with very dark gray being typical. The red paint is a weak red to (more commonly) dark red. A few sherds have a black subglaze to glaze. For the Paquimé variant, the black and red paint compositions are like those on Ramos Polychrome and usually have light brown to buff surfaces. Babícora has a fine-textured paste, and inclusions are also opaque white, but often with clear crystalline particles mixed in. Vessels are also well-smoothed with a light polish, but some have a light slip that is lighter in color than the paste. For the standard variant, the paste is light reddish brown to pink or very pale brown, with the last being typical. Hardness is 3.5 to 5.5 , with 4.0 as most common, and vessels are as strong as Villa Ahumada Polychrome (Rinaldo 1974:184).

Villa Ahumada Polychrome has a white to light gray to brown color surface. The paste appears to be much darker than that of Ramos Polychrome because of its carbon streak. "Zoning of the paste was typical. The majority of sherds examined had a gray (7.5YR 5/0), dark gray (7.5YR 4/0) or very dark grey (7.5 YR 3/0) streak which was up to $4.0 \mathrm{~mm}$ thick and constituted most of the core" (Rinaldo 1974:300). This carbon streak is a result of incomplete carbon oxidation during firing, and it did not usually occur in Ramos Polychrome. Villa Ahumada polychrome has angular opaque white particles for 
inclusions, with some clear crystalline, red, yellow, and black inclusions and usually had a fine textured. This paste was covered in a white slip, which was not polished (Fenner 1974:303) and the red and black painted decorations were sometimes polished (Rinaldo 1974:301; Fenner 1974:303). One sherd was analyzed for its black paint minerals and it had iron, barium, and manganese, and only trace amounts of copper and lead ( $\mathrm{O}^{\prime} \mathrm{Haire}$ 1966 as discussed by Rinaldo 1974). Paste colors ranged from light gray to dark gray. The bottoms of vessels were usually not slipped and were brown. Variants of Villa Ahumada Polychrome include standard, Ramos, Capulín, and Memmott. Standard has bands of alternating red and black motifs. Ramos and Capulín variants have painted lines like those for Ramos Polychrome, except that they are over a white slip while Ramos Polychrome does not have a white slip. Memmott had designs painted only in black, with occasionally a few red framing lines. Hardness ranges from 3.0 to 5.5 , with a usual score of 3.5, and they were difficult to fracture (Rinaldo 1974:300).

Carretas Polychrome is typically reddish-yellow or orange in color, but can range from light red to very pale brown. Sometimes the potters polished these vessels. Like the other polychromes, it has opaque white inclusions that are usually angular, along with some clear, red, and black inclusions. Typically, the inclusions are fine grained. The paste is white to reddish yellow to very pale brown to dark brown, with reddish yellow being the most common. The black paint on this type is a subglaze, and occasionally the red is as well. Di Peso et al. (1974) defined two variants: standard and Black-on-orange. Carretas Polychrome hardness ranges from 4.0 to 5.0 is, with 4.5 being typical and is as strong as Heurigos Polychrome (Rinaldo 1974:65; VanPool et al. 2008). 
Corralitos Polychrome can be textured, punched or non-punched. What

differentiates this type from the other types is that the painted areas are often outlined by incising or texturing. Sometimes the design band was polished after incising and painting. The surface is pinkish tan to reddish yellow. Red paint varies from weak red to dark red to reddish brown, and black paint is very dark gray. The inclusions are angular opaque white with some red, tan, and black grains as well, and are typically of medium size. Paste color ranges from light brown to reddish brown to yellowish red, with the last being typical. Hardness is 3.5 to 4.0 , with 4.5 as typical, and the strength of this pottery is like that of Villa Ahumada Polychrome (Rinaldo 1974:208).

Huerigos Polychrome is a reddish-yellow to orange color, with a black sub-glaze paint, though a few have a glaze paint; and red paint. The interior of bowls are heavily slipped. "Analysis of Huerigos Poly and comparison with Carretas Poly revealed that the two types are virtually identical, differ in only minor attributes besides interior slip, and were very closely related" (Rinaldo 1974:243). Paint on three sherds were analyzed and they had the same composition as Ramos Polychrome (O'Haire 1966 [quoted in Rinaldo 1974]). The bowl interiors were slipped in white and lightly polished. The inclusions are like in Villa Ahumada Polychrome: fine opaque white, with clear, red, and black particles. Paste color ranges from gray to reddish gray to reddish yellow, with light reddish brown as most common. The vessels are strong with a hardness of 4.0 to 6.0, with 4.5 being typical. This type has two variants, standard and black-on-orange (Di Peso et al. 1974:243). 
Dublan Polychrome has a white to light gray to light brownish gray surface with red and black painted designs. Like Corralitos Polychrome, this type has texture, but it is corrugated or scored, on the necks of the jars. The vessels could be textured, slipped, and painted. The inclusions are opaque white with clear crystalline particles; many of the inclusions are rounded, but others are angular. There are minor amounts of red, yellow, and black inclusions. Paste color is white to pale brown; pale brown is most common. These vessels are hard and compact, with a typical hardness of 5.0, but range from 3.0 to 6.0 (Rinaldo 1974:221).

Designs on the polychromes are made with red and black paints, and are often dynamic and intricate, especially on Ramos Polychrome, which often demonstrates extremely fine line work, complex motifs, and a greater number of designs (Di Peso et al. 1974:255; Hendrickson 2003). The layout of the designs of Ramos Polychrome typically have a primary band; often it is was bisected into two panels (or into diamonds or X-shapes) in which interlocking designs, such as scrolls and steps were placed. However, zigzag bands were found on significant ollas such as the three large ollas that held postcranial remains at Paquimé. These zigzag bands were also common on snake effigies. Furthermore, the primary band was not always paneled, but rather the band was divided into alternating red and black bands with ticking (VanPool 2003) (see Figure 2.2). Zigzag bands found on some Casas Grandes polychromes divided the vessels into pairs or quadrants. This was different than some of the zigzag bands that Crown (1994:61) recorded on Salado polychromes because the jar was divided into three sections. More thorough coverage of design analysis can be found in works by VanPool 
(2003), Fenner (1974), and Hendrickson 2003), for Casas Grandes polychromes, and Crown (1994) for Salado polychromes.

The designs on Chihuahuan polychrome pottery likely had symbolic meanings (VanPool 2003). The VanPools suggested that duality was on important concept in the Casas Grandes area and was shown on the pottery in the design layouts and with structurally opposed designs being paired like interlocking steps; the double-headed macaw and twined snake designs also demonstrated duality (VanPool 2003; VanPool and VanPool 2002). Macaws, serpents, and humans were the primary icons identified by VanPool, and she suggested that they were the bases of Casas Grandes cosmology (VanPool 2003). There was a shamanistic theme found in a small subset of polychromes. Male and female effigies are portrayed in different activities and with different designs (e.g., men were shown holding pipes and had plumed serpents painted on them, whereas women held bowls and had birds painted on them). These gender roles also indicated duality (VanPool 2003).

The organization of pottery production can have many levels: pottery can be made at the level of independent households by generalized producers, or by specialized households, or in specialized workshops (Sprehn 2003), and the organization can vary throughout a culture area. Specialized production at one or only a few places allows a few people to control a good, either who can have it and/or what it is made of and looks like. Local production of pottery demonstrates that more people are directly participating in the system, and are able to replicate the types and designs with local raw materials. Paquimé has evidence of specialized production of goods, including 
metates, macaws and turkeys, and large Ramos Polychrome jars (Minnis 1988; Sprehn 2006; Topi et al. 2018; VanPool and Leonard 2002). This specialized production demonstrated a level of economic complexity not present elsewhere in the North American Southwest, where households were the typical focus of production, as well as the presence of economic integration and social relationships that extended across hundreds and even thousands of kilometers.

Salado (A.D. 1250-1450)

The Salado regional cult, or the Salado Phenomenon as it is also called, covers the area of central to southeastern Arizona and central to southwestern New Mexico. Salado sites are easily identified by the distinctive locally produced Salado polychrome pottery (Crown 1994; Huntley et al. 2013). Salado was not so much a culture as it was a social movement. Salado towns were built by culturally diverse groups of people that had an inclusive ideology that was depicted on the pottery (Crown 1994; Huntley et al. 2013; VanPool et al. 2006). People from the Kayenta area in Arizona moved south into this area and joined with others living there, as demonstrated by the change in architecture and the appearance of perforated plates for pottery manufacture (Lowell 2007; Lyons and Lindsay 2006). This new pottery tradition provided a means for people to come together to demonstrate their cohesiveness (VanPool et al. 2006), but it did not replace the previously existing cultural differences.

Salado sites were variable in virtually all other aspects of material culture, aside from having locally produced Salado pottery. Some had cobble architecture, whereas 
others exhibited adobe compounds of above-ground room blocks surrounding a plaza (Huntley et al. 2013; Nelson and LeBlanc 1986). Burials varied in form, ranging from cremation to extended or flexed inhumations (Crown 1994; Dean and Woosley 2000). Previously existing pottery traditions continued according to local custom, as did differences in religious architecture such as kivas. Despite these cultural differences, inter-settlement conflict (e.g., warfare) seems to have decreased and interaction seems to have increased with the spread of the Salado tradition. For example, there was increased use of obsidian in the Tonto Basin, and the majority of the obsidian in the Upper Gila region came from the relatively distant $(40 \mathrm{~km})$ Mule Creek source in western New Mexico later in the period (Huntley et al. 2013).

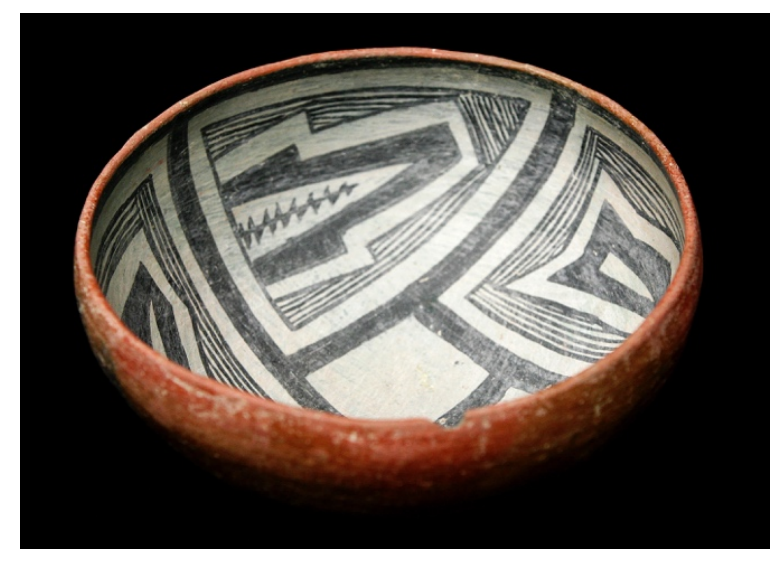

Figure 2.3 Gila Polychrome bowl. MAC 1995-0035. Photo courtesy of the Museum of Anthropology, University of Missouri.

\section{Salado Polychrome Pottery}

Salado polychrome pottery was made from A.D. 1275-1450 and includes several types, with the most common being Pinto, Gila, and Tonto Polychromes. They were made with local raw materials at many locations in Arizona and New Mexico (Crown 
1994; Huntley et al. 2013) such as with local sand aplastics at Gila Pueblo (Huntley et al. 2013). It was the designs, and not the paste, that set the Salado types apart. There were three basic categories of design layouts: structured around a line or band, designs structured around a point or finite design, and asymmetrical designs (Crown 1994:57).

Gila Polychrome, the type with the widest geographic distribution, was made A.D. 1300-1450, and black designs were painted on white slipped bowl interiors and the exterior of the bowls were red slipped (see Figure 2.3). Designs were found in bands of geometric shapes, designs rotated around a point, or the designs were placed in asymmetrical band (Crown 1994), and the elements tended to be broader (e.g., had thicker black line work compared to Ramos Polychrome) (VanPool 2003). Pinto Polychrome was an earlier type (A.D. 1270-1330) that was similar to Gila but without the lifeline (the thick band) around the rim. Tonto Polychrome (A.D. 1350-1450) had the same paints and slip colors as the other two types, but the black-on-white designs were surrounded by red slipped areas making a dynamic interaction of colors (Crown 1994:19).

\section{Casas Grandes Pottery versus Salado Pottery}

Salado Polychromes were made with iron-rich clays, unlike Casas Grandes polychromes. Ramos Polychrome has a light tan paste composition indicating that they were probably not made with iron rich clays or that the pottery used a bleaching agent like lime to lighten the color. Villa Ahumada Polychromes typically had a brown to dark brown paste composition indicating that different clay sources were used for their 
construction than what was used for Ramos Polychromes, and perhaps kaolinite was used as a slip. Carretas and Huerigos Polychromes tended to have brown to orange paste and surfaces (perhaps more iron in the clay). Huerigos Polychrome was slipped with a white clay. Salado polychromes in general had red to brown paste and red slips, indicating iron-rich clays were used for their production.

Casas Grandes polychrome designs on ollas tended to occur in bands that were divided into panels. There were major differences between bowls and jars. Often on Salado polychrome bowls the designs were placed around a main point or sometimes they were placed on the bowl asymmetrically. The exterior of the jars of Casas Grandes polychromes, especially Ramos Polychrome, had complex motifs and likely had special symbolic meaning in the serpents and shamans depicted on them. Both Casas Grandes polychromes and Salado polychromes included bowls, jars, and bird effigies, while Salado polychromes had few human and snake effigies. Salado polychromes had many types of painted geometric shapes, and the vessels also had symbolic meaning (Crown 1994). The vessels also had serpents painted on them, but in opposite colors, i.e. in black as opposed to Casas Grandes' white serpents. Salado serpents had backward pointing horns and Casas Grandes horned serpents typically had forward-pointing horns. These differences probably indicate cultural differences between the two regions (VanPool et al. 2006). 
Animas Phase (A.D. 1200-1450)

The Animas Phase is in Southwestern New Mexico, specifically the bootheel and the area about $30 \mathrm{~km}$ to the east (see Carpenter 2002: Figure 7.2) (Skibo et al. 2002; VanPool et al. 2014). This borderland area is between the Casas Grandes region and the Salado, and the Jornada Mogollon region is to the east and the Hohokam to the west. Some sites in the area are typical Casas Grandes Medio Period sites, such as Joyce Well (Skibo et al. 2002), but others, such as Pendleton Ruin (Kidder et al. 1949), are more consistent with Salado settlements to the north and west. Here, I use Animas Phase to refer to those settlements that have the characteristics of the Medio Period Casas Grandes settlements, and Salado to refer to the other sites more typical of that tradition.

The Animas Phase sites of southern New Mexico are in the outer circle of Whalen and Minnis's (1999) zones of Casas Grandes integration, yet many (but not all) have very thick $(60 \mathrm{~cm}+)$ walls, mounds, roasting ovens, ballcourts, and Chihuahuan polychrome pottery more common in settlements closer to Paquimé. Like Paquimé, most of these sites also have some Salado polychrome pottery.

\section{Draw}

76 Draw is $30 \mathrm{~km}$ south of Deming, New Mexico, and $180 \mathrm{~km}$ north of Paquimé in Chihuahua, Mexico (Figure 1.2). It contains a low mound with exposed and buried adobe walls, two roasting pits, possible plaza areas, and a surface scatter of pottery, stone artifacts, and other archaeological materials. Although outside the Animas area as 
originally defined, Brand (1935) labeled 76 Draw as the most northern Casas Grandes site. VanPool et al. (2014) agree with Brand (1935) that the settlement reflects cultural affiliation with the Casas Grandes culture and indeed suggest it was religiously and politically integrated with Paquimé based on the predominance of Ramos Polychrome, the presence and apparent direct collection of obsidian that is intermediate between the two settlements, and architectural similarities (Lieber et al. 2014; Noneman et al. 2017; Rakita et al. 2011; VanPool et al. 2014).

76 Draw was modified in modern times as a result of a dam built to the west and excavations by avocational archaeologists, but enough remained to learn about the site. Recent excavations uncovered thick walls, a hearth, Chihuahuan polychrome pottery, obsidian from southern sources, and a bird burial (probably macaw) (McCarthy et al. 2014; Rakita et al. 2011; VanPool et al. 2013; VanPool et al. 2014). The pottery assemblage reflected a mixture of Casas Grandes polychromes and pottery associated with the El Paso Phase and Salado cultures; my interest is between the Salado and Casas Grandes wares, though examining the El Paso Phase would be a productive future focus. Ramos Polychrome made up 35.3\% of the decorated assemblage (Lieber et al. 2014), and Casas Grandes decorated pottery (the Chihuahuan polychromes plus Madera Blackon-red and Ramos Black) made up over half (56\%) of the assemblage of diagnostic decorated wares (see Table 2.1). Gila Polychrome made up $21 \%$ of the decorated wares. The Casas Grandes plainwares together (plainwares, corrugated, scored, and incised) made up $27 \%$ of the plainware assemblage (Lieber et al. 2014). Lieber and colleagues also found that $43 \%$ of the plainwares are general Mogollon plainware 
(including corrugated and scored; some of these could be Alma Plain (Christine VanPool, personal communication 2012) and El Paso brownware made up 25\%. This was rounded out by $2.8 \%$ Playas Red and 1.2\% unspecified plainware (Lieber et al. 2014).

Table 2.1 Polychrome Pottery Sherd Counts and Percentages of the Decorated Wares from 76 Draw. Adapted from Lieber et. al 2014. Decorated wares Total: 2,349 sherds. Plainwares Total: 10,903 sherds. Type Descriptions can be found in Crown (1994), Di

Peso et al. (1974), and Stallings (1931).

\begin{tabular}{lcc}
\hline Pottery Type & Count & $\begin{array}{c}\text { \% of Decorated } \\
\text { Assemblage }\end{array}$ \\
\hline Ramos Polychrome & 830 & 35.3 \\
Gila Polychrome & 494 & 21.0 \\
El Paso Polychrome & 346 & 14.7 \\
Madera Black-on-Red & 226 & 9.6 \\
Chupadero Black-on-Red & 102 & 4.3 \\
Ramos Black & 70 & 2.9 \\
Villa Ahumada Polychrome & 64 & 2.7 \\
Carretas Polychrome & 36 & 1.5 \\
Huerigos Polychrome & 17 & 0.7 \\
Tonto Polychrome & 15 & 0.6 \\
St. John's Polychrome & 5 & 0.2 \\
Indeterminate polychrome & 144 & 6.1 \\
\hline \hline
\end{tabular}

\section{Other Settlements Used for Comparisons}

Few settlements in the Animas region with Casas Grandes materials have been excavated and even fewer have had geochemical sourcing studies of pottery such as what I completed for 76 Draw. The only available comparative samples of pottery counts were from Box Canyon, Clanton Draw, Joyce Well, and Pendleton Ruin. Box Canyon and Clanton Draw, in Hidalgo County, New Mexico, have adobe architecture with Chihuahuan polychrome pottery (making up 50\% and $82 \%$ of the painted assemblage, respectively), as well as some Salado polychromes ( $48 \%$ and $10 \%$ respectively). McCluney (1962) suggested both sites were affiliated with the Medio 
Period Animas Phase. Neither site had a ballcourt, but three sites within walking distance do: Joyce Well, Culberson Ruin, and Timberlake Ruin (Harmon 2006). Joyce Well is also in Hidalgo County and was excavated by McCluney in 1963, with additional excavations by Skibo and Walker in 1999. Results of both seasons were reported in Skibo et al. (2002). As with Paquimé, the site had a ballcourt, raised platform hearths, adobe architecture, T-shaped doorways, sub-floor burials, and numerous grinding stones. Ramos Polychrome made up $97 \%$ of the Chihuahuan polychromes on site (whereas it was $88 \%$ of the Chihuahuan polychromes at 76 Draw). Based on his 1963 work, McCluney (2002) suggested that the majority of it was made at Joyce Well-a determination made after viewing the aplastics with a hand lens. Carpenter (2002) had petrographic analysis done on 21 sherds from the site, and much of it could have been made from local raw materials. But again, being on the border of several areas, $60 \%$ of the site's total pottery was El Paso Polychrome and "Jornada Brown" (undifferentiated brown ware found at Joyce Well that may or may not fit with the formal type defined by Jennings (1940) and Mera (1943) and later refined and redefined by Jelinek (1967), Kelley (1984), Wiseman (2014) and others). Sherds that were labeled as "Jornada Brown," Carpenter suggested were actually undecorated sherds of El Paso Polychrome (2002:159) and not Jornada Brown as the type was defined. It is important to be clear when brownwares are described and typed, as Jornada Brown and El Paso Brownwares are different types. The formal type of Jornada Brown can be confused, but I used the type as it was labeled in my analysis section and as Carpenter labeled them in his table, but please keep in mind that he states that the 
“Jornada Brown" sherds were likely the undecorated portion of El Paso Polychrome vessels (2002:159). Carpenter (2002) found that this brownware was likely made at Joyce Well (Carpenter 2002); two El Paso Polychrome sherds and one Ramos Polychrome sherd had the same temper type (Group 3) containing latite in Carpenter's petrographic analysis. Ramos Polychrome was in temper Group 1, the largest group, and this group contained 8 sherds (Carpenter 2002:158). However, there was also a Ramos Polychrome sample in temper Group 2. Tuff found in both Groups 1 and 2, the Park and Gillispe Tuffs, can be found within $4 \mathrm{~km}$ of the site, making associations tenuous at this time.

Pendleton Ruin is on the far west of the New Mexico bootheel. Kidder and the Cosgroves (1949) initially excavated the site, believing it showed a strong cultural affiliation to the Casas Grandes region, but concluded that it was not closely affiliated. Chihuahuan polychromes were $68.5 \%$ of the painted wares and Salado polychromes made up $25 \%$, but they were only $5 \%$ and $1.8 \%$ respectively of the total pottery assemblage. The ruin had adobe construction and plazas, but there were no platform hearths, sub-floor burials, or deeply scooped metates demonstrating that it was not closely integrated with Casas Grandes.

Forty kilometers to the north of 76 Draw, and still in Luna County, New Mexico, is the Black Mountain site. This is the type site of the Black Mountain Phase (A.D. 11501300), but it also has an El Paso Phase (A.D. 1300-1475) component. The site was damaged by mechanical grading, but Putsavage (2015) was able to define three areas with adobe architecture and provided more information about the site based on 
excavation. Two areas of the site had Chihuahuan polychromes ( $n=43$ and 24 sherds in Locus 1 and 2, respectively) and Salado polychromes ( $n=63$ and 8 sherds) (Putsavage 2015:180). There were many more El Paso sherds (polychromes, bichromes, and undifferentiated El Paso, $\mathrm{n}=222$ and 167) in Locus 1 and 2, as well as Playas Red Series (including Playas Red cord marked, incised, and punctate, $n=263$ and 1,287) at Black Mountain (Putsavage 2015:199). Her NAA showed that pottery was being made on site as well as being traded in from the Upper Mimbres and Upper Gila Valleys during occupation. Obsidian was obtained from the southern sources, similar to Casas Grandes sites, in the Black Mountain Phase, but later (1300-1450 A.D.) the closer Mule Creek source was utilized more often (Putsavage 2015:284).

\section{Pottery Production in the Casas Grandes and Salado Regions}

The nature of regional integration during the Medio Period has been debated by archaeologists for over 100 years, starting with Bandelier (1892) and Kidder (1916), then Di Peso's (1974) groundbreaking work (1958-1961), and now more recent scholarly works (VanPool et al. 2005; Whalen and Minnis 2001). Broadly speaking, there are at least five similarities between the Casas Grandes and Salado areas: polychrome pottery with red, black, and white colors; serpents on the pottery; copper bells; platform mounds (Schaafsma and Riley 1999b; VanPool et al. 2006); and shells from possibly the same sources (Krug 2018; Schaafsma and Riley 1999b; VanPool et al. 2006). The most obvious difference between the Animas Phase settlements, which reflected integration with the Casas Grandes culture, is the preponderance of Casas Grandes polychromes 
and Ramos Polychrome specifically. However, these pottery differences corresponded to architectural differences (e.g., thick walls, ball courts, adobe hearths) (Douglas 1995; Skibo et al. 2002; Whalen and Minnis 2009). I would add that the sites usually had other types of pottery (e.g., El Paso Polychrome), further indicating some form of contact and even cultural syncretization between those participating in each culture.

Pottery sourcing studies are an excellent means of evaluating several important issues related to the Animas Phase sites, and 76 Draw in particular. Was Ramos Polychrome pottery made locally, or was it imported from other Medio Period settlements? If it was made locally, then they might have had direct participation in the Medio Period religious system, especially as it was reflected at Paquimé. If it was made elsewhere and brought to Animas Phase sites, then it may be possible to recreate specific trade relationships (and the underlying social relationships). If it was made both locally and at Paquimé, this might support the idea that Paquimé was a pilgrimage site (VanPool and VanPool 2018), with participants making the pottery for use when they were not able to get it from the core area. Was Salado made locally, or was it imported from other Salado settlements? Were 76 Draw people merging Casas Grandes and Salado religious concepts? Identifying imported pottery might allow archaeologists to reconstruct trade and social relationships.

Pottery in the Greater Southwest has been examined using NAA for over 50 years (Glowacki and Neff 2002) providing a large database of samples. Crown (1994) and Huntley et al. (2013) have completed large NAA projects on Salado pottery. Both studies demonstrated that Salado polychrome, including Gila Polychrome, were made 
locally, with local raw materials, throughout the region where they were found, although not every site made Salado polychrome and there was some trading of vessels (Crown 1994; Huntley et al. 2013).

Ramos Polychrome from Paquimé and surrounding sites in Chihuahua were analyzed using NAA and petrography by Triadan et al. $(2005,2018)$. They found that Ramos Polychrome, as well as Villa Ahumada and Babícora Polychromes (both of which are part of the Casas Grandes polychrome tradition), were made with similar highlyprocessed clays and tempers. Based on the 655 sherds from 31 sites that they analyzed with NAA, there were three large compositional groups and eight smaller groups, each of which contained all three polychrome types. The sherds are from Paquimé, four large and very large sites in the core of the Casas Grandes area, and smaller sites in the inner zone as well as the periphery. Triadan et al. (2018) conclude potters were: 1) using three main clay sources as well as others, 2) using similar or identical paste recipes to make each of the three polychromes, and 3) had apparently unrestricted access to the same clay sources. They also defined eight smaller compositional groups; each of which also contained all three types of polychromes and all included some sherds found at Paquimé. Two more small groups contain predominantly Babícora Polychrome, and are from sites around the Babícora Basin and the Santa Maria and Santa Clara rivers, suggesting they may reflect a local clay source or distinctive recipe south of Paquimé (Triadan et al. 2018:158). These two groups were the only ones that Triadan and colleagues found to correlate with a region or area; the other groups had sherds found in many areas across the region and at Paquimé. They concluded that because Paquimé 
used so many polychrome vessels, many people in and around Paquimé made polychromes, though a large portion, from the three large groups, were likely made at or near Paquimé (2018:163).

Triadan et al. (2018) attributed their results from NAA and petrography to the high levels of clay processing using a standard recipe shared among the potters. Petrographic analysis determined that most of the temper was rhyolite, or rhyolitic tuff, and they suggested that Medio Period potters used primary residual clays with crushed rhyolite temper. This highly processed paste takes considerable work to create, considering that many modern Southwestern potters used secondary clays, which required less processing (Crown 1994:32-40; Triadan 1997). When the secondary clays settle, they are sorted by particle size and have lower amounts of nonplastics in them; potters might have desired to use these sorted clays with less aplastics. Primary clays often need sifting to remove nondesireable aplastics, thus adding another step to the process. Medio Period pottery added finely crushed rhyolite to at least one of the eight clay groups (Triadan et al. 2018).

Triadan's et al.'s $(2005,2018)$ work can be augmented by Britton's (2018) recent work on Ramos, Babícora, and White-Paste Babícora Polychromes. Britton examined the aplastics in sherds from the Sayles's 1936 surface collection from across Chihuahua, and defined six temper groups using petrographic analysis. The groups include the same three pottery types, and, if some Babícora Polychromes are considered one of the earliest polychromes (i.e. Design Horizon A designated Whalen and Minnis (2009) (Gladwin and Gladwin 1934; Sayles 1936; Whalen and Minnis 2009:121; Whalen and 
Minnis also suggest that White-Paste Babícora is early too), then the use of tempers was consistent throughout the Medio Period (Di Peso et al. 1974). Britton determined that there was a "cohesive knowledge network" of potters choosing the clays from a narrow range of raw materials (2018:129). Like Triadan, she found them to be primary clays, and she adds that they were from igneous felsic parentage; the potters were choosing specific clays to make these three polychromes. Based on igneous aplastics in the various pastes found during petrographic analysis at Site 204 (a site to the west of Paquimé in the Casas Grandes heartland), there is the possibility of community-based specialization of polychromes at this site, but it is many people accessing many clay sources and not a limited number of potters from a few sites (Britton 2018:166). Like Triadan and colleagues, Britton found that potters from all over the area were making the polychromes and choosing primary clays from igneous sources, and those sources are found throughout the region.

Kathryn Putsavage (2015) used NAA to learn more about the pottery at Black Mountain. She compared her data with Speakman's (2013) data and found many of her sherds were from the same production locations that he defined. She concluded that the pottery from the site was made in the Upper Gila Valley, the Mimbres Valley, and at the site. Black Mountain is a post-Mimbres site, and the potters likely were familiar with the clay sources in that valley.

Maria Sprehn (2003) suggested that Ramos Polychrome pottery was made in one or a few sites, probably in or near Paquimé. She examined vessel size and design execution by looking at whole vessels in museums, and because of the low coefficient of 
variation, she suggested they were made by specialists. Topi et al. (2018) also examined whole vessels using geometric morphometrics and found that Ramos and Babícora Polychromes were standardized in size and shape, and that they were contemporaneous types. They concluded that the low coefficients in variation indicated the pottery was made by specialists.

In addition to Triadan et al. (2005, 2018), other researchers including Cruz Antillon et al. (2004), Whalen and Minnis (2009) and Pitezel (2011) have found that Chihuahuan polychromes were not made in a central location. Also, polychrome ceramics were found in all contexts at sites, and not only with elites or other special groups (Di Peso et al. 1974). Ceramics were found in rooms, plazas, ballcourts, and burials of different social levels, demonstrating that everyone used polychromes at Medio Period sites. The polychromes, especially Ramos, were also used for a wide variety of purposes from cooking jars, small serving bowls, food storage jars, being used as grave goods, to holding post-cranial remains.

Ultimately, sourcing studies have shown great utility in both the Casas Grandes and Salado areas, and NAA and petrographic analysis of the 76 Draw pottery assemblage will provide additional insights into the production and trade of Ramos Polychrome. Thus, the level of integration of sites on the northern periphery of the Casas Grandes world with Paquimé can be determined. 


\section{Chapter 3 Materials and Methods}

Here I focus on the pottery samples from 76 Draw and a comparison dataset from six other sites (Table 1.1). The 102 samples from 76 Draw along with more limited comparative data from nearby sites ( $n=114$ sherds from six sites) tell us more about trade and exchange in the region during the Medio Period. Here I typed the pottery using the classification outlined by Di Peso et al. (1974:183-250) and VanPool et al. (2008), and then determined its geochemical composition using NAA. These data along with the comparative data were used to define compositional groups. I also compiled thin-section data on the pottery's aplastics from 76 Draw and other settlements that other researchers had compiled through petrographic analysis (Britton 2018; Hill 2010;

Triadan et al. 2018). As stated previously, samples from 76 Draw were chosen to reflect both Casas Grandes and Salado pottery. Plainwares were chosen assuming that the majority of them would be locally made, as they are in the Cibola area (Peeples 2011:137-138). They could therefore likely be a control group to allow determination of what compositional groups might reflect local manufacture. All of the sherds were compared together as one dataset for NAA.

\section{Neutron Activation Analysis}

Many geochemical characterization techniques are available today (Glascock 2014; Rice 1987; Sall et al. 2001). The most popular of these for ceramic analysis is instrumental neutron activation analysis (or INAA or just NAA), which has been in use for over 50 years (Glascock and Neff 2003). It is a bulk-chemical technique that 
measures with analytical precision and sensitivity the major, minor, and trace elements in clay and temper. Samples are bombarded by a neutron flux, which causes a small proportion of the atomic nuclei to become radioactive isotopes (see Figure 3.1) with known halflives. While decaying, these elements emit gamma rays with distinct energies that are characteristic of each element (Glascock 1992). The gamma rays are counted with high-purity germanium detectors to find the concentration of each element in the sample.

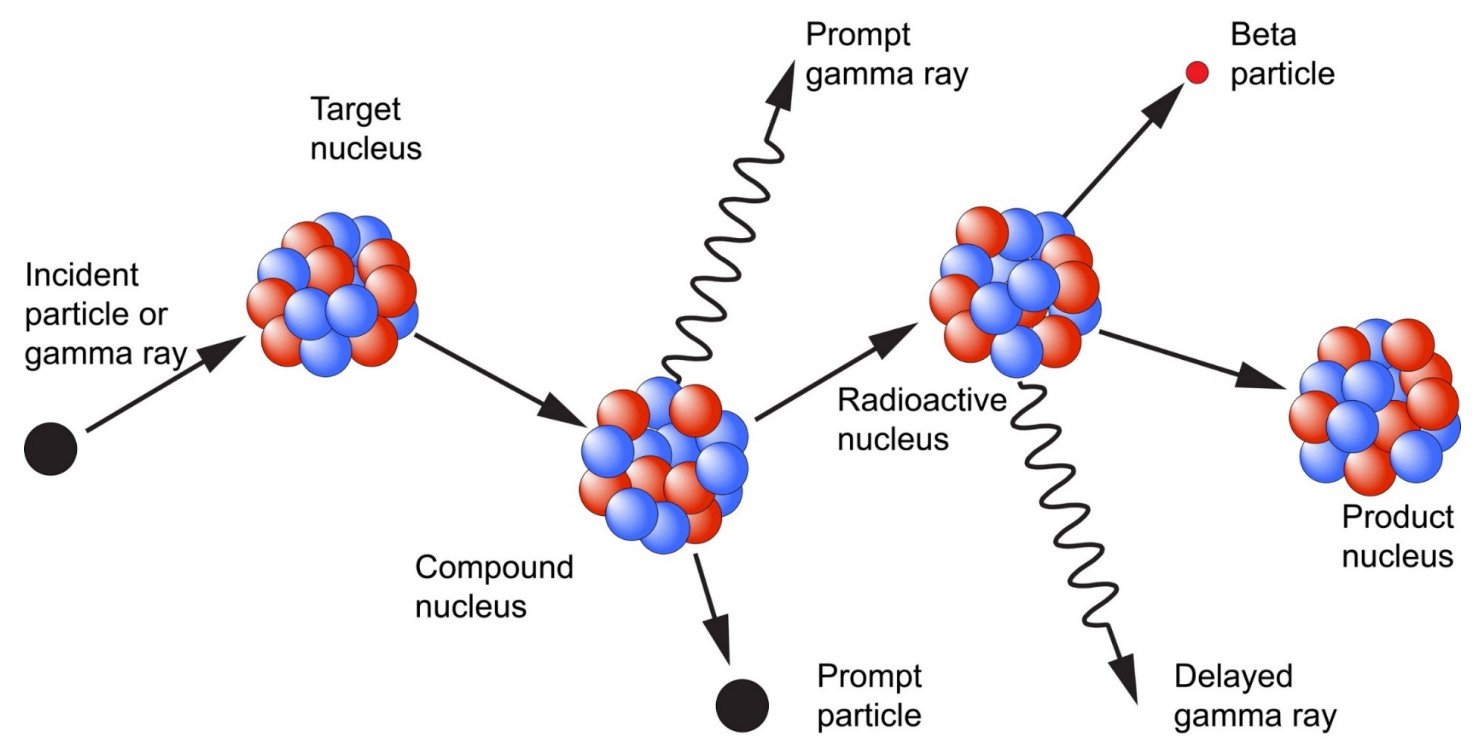

Figure 3.1 Diagram illustrating the process of neutron capture by a target nucleus followed by the emission of gamma rays in neutron activation analysis. Figure courtesy of Michael D. Glascock.

NAA is useful for geochemical characterization because clay and temper sources have different chemical "fingerprints" relative to other available sources. Potters from a community, and even different groups of potters from the same community, will often use locally available resources to create pottery "recipes" that are at least potentially chemically distinct from each other. This situation reflects the provenance postulate, 
which states that sourcing is possible if there is a greater quantitative difference between sources than within sources (Neff and Glowacki 2002; Weigand et al. 1977). For example, some clay sources can be high in calcium, low in nickel, or otherwise have elemental differences relative to other sources. Pattern recognition in different plots allows the sources to be separated into groups. Knowledge of the local geology is needed to understand the available raw materials, and southern New Mexico has sufficiently distinct geology to differentiate clays and temper (Ownby 2014; USGS 2005). A potential complicating factor is temper, which can affect the bulk geochemical composition of pottery, sometimes enough that it may be hard to recognize the signatures of the clay sources. This is not always an issue; some clay sources may have sufficient aplastics that potters do not add temper. In such cases, the bulk composition of ceramics and specific clay sources may match one another. However, when the potter adds temper to change the properties of the clay, the bulk composition may change meaningfully (Neff and Glowacki 2002). Several types of temper have been used in the North American Southwest, including sand, volcanic tuff and other ground rock, and ground sherds (Cordell 1997; Rice 1987; Shepard 1995). Consideration of variation in clay sources across a region, the presence and types of temper added to pottery, the processing of the clay (which might remove naturally occurring aplastics), and the interaction of all of these variables into the final recipe used by the potter is needed when analyzing pottery. Yet it may still be possible to identify the geochemical source of specific pastes associated with local cultural traditions even when specific pottery recipes cannot be tied to specific clay deposits because they are not known or 
processing (e.g., removing aplastics, adding temper) has changed the clays chemical makeup (Speakman 2013). Objects, including pottery, are more frequent closer to their origin, according to the criterion of abundance (Bishop et al. 1992), which in turn suggests absent other evidence of clear trade of those ceramics, the more abundant compositional recipes are more likely locally made. Further, there is a common assumption, which might not always be true, that plainware pottery is less commonly traded than decorated wares (Arnold 1989). Thus, common compositional recipes of plainware pottery are most likely to be locally produced, common recipes of plentiful decorated types are likely locally produced, and less common recipes, especially for decorated wares, are more likely to be acquired by exchange, everything else being equal (Arnold 1989; Neff 2014).

\section{The Samples}

For the current analysis, 31 plainwares, 33 Ramos Polychrome, and 36 Gila Polychrome sherds were analyzed from 76 Draw (see Table 1.1). I also analyzed one Tonto Polychrome sherd and one Villa Ahumada Polychrome sherd. These data were combined with data from additional sherds from other sites nearby in New Mexico and westernmost Texas that were also analyzed at MURR. These additional sherds were comparable to the sherds from 76 Draw because they were the same types and were contemporaneous.

To ensure samples of pottery were not from the same vessel, sherds were chosen out of many provenience designations at 76 Draw, and design and vessel 
thickness were compared to be sure they did not match. Plainwares were chosen to be the proxy for local wares because they tended to be traded less often (Peeples 2011:137-138). 76 Draw is on the border of several culture areas, including the Casas Grandes, Salado, and El Paso, and to not assume that the site was one of the cultures over the others before more evidence was gathered, plainwares of different types were selected (Casas Grandes Plainware n=21; El Paso Brownware n=9; and Ramos Black $n=1)$.

The polychromes chosen represented those that have the widest geographic distribution for their culture area, and they also were the types with the highest percentages of decorated wares at 76 Draw: Ramos and Gila Polychromes (see Table 2.1). These two types are considered the hallmark of their areas and were made throughout the $13^{\text {th }}, 14^{\text {th }}$, and the first half of the $15^{\text {th }}$ centuries. Also, two more polychrome types were sampled with one sherd each: Villa Ahumada and Tonto Polychromes. These two types were also widespread, but not nearly as much as Ramos and Gila Polychromes; they were from the Casas Grandes and Salado areas, respectively.

The comparative samples, plainwares and polychromes, were also analyzed by NAA at MURR (see Table 1.1). The analysts of these samples gave permission for comparison and include: Creel, Laumbach, Putsavage, and Reed. The plainwares came from Black Mountain, also in Luna County, New Mexico and were chosen for comparison because this site is contemporaneous and close to 76 Draw (40 km to the north). 
All of the other Ramos Polychrome sherds analyzed at MURR by 2016 were used for comparison because so few of this type have been analyzed, especially those from sites in the United States. The comparative samples come from 6 sites $(n=13)$ in southern New Mexico and westernmost Texas (see figure 1.2). The probability that these sites were using different resource areas is high because they are all over $18 \mathrm{~km}$ apart; 12 to $18 \mathrm{~km}$ is the threshold that Arnold (1989:58) has set to make it likely that communities would use using separate resources.

Many hundreds of Gila Polychrome samples have already been analyzed (Crown 1994; Huntley et al. 2013) and many compositional groups are already known, so no further samples were analyzed here. The Gila Polychrome sherds from 76 Draw $(n=36)$ were compared with those known groups and were found to be a new, or previously unknown, compositional group (Deborah Huntley, personal communication 2012).

\section{Sample Preparation}

When the samples were prepared for NAA, the exterior was removed, including any paints and/or slip to minimize depositional contamination from sherds. The sherds were washed in deionized water and air-dried. They were then powdered using agate mortar and pestles and placed in glass jars. The powder was dried for 24 hours and was then weighed into high-density polyethylene vials $(150 \mathrm{mg})$ for short irradiations and quartz vials (200 mg) for long irradiations. Standards made from National Institute of Standards and Technology (NIST) reference materials of SRM-1633a Coal Fly Ash and 
SRM-278 Obsidian Rock, as well as Ohio Red Clay, were included for calibration in both irradiations (Glascock 1992).

The short irradiation lasted 5 seconds at a flux of $8 \times 10^{13} \mathrm{n} / \mathrm{cm}^{2} / \mathrm{s}$, and after a 25-minute decay, samples were counted for 12 minutes on a high-purity germanium detector. Short-lived elements (see Table 3.1) detected include aluminum (AI), barium (Ba), calcium (Ca), dysprosium (Dy), potassium (K), manganese (Mn), sodium (Na), titanium (Ti), and vanadium (V) (see table 3.1). Long irradiation of the quartz vials lasted 24 hours at a flux of $5 \times 10^{13} \mathrm{n} / \mathrm{cm}^{2} / \mathrm{s}$. After a decay of seven to eight days the middle count lasted 2,000 seconds for each vial. This mid-count detects arsenic (As), lanthanum (La), lutetium (Lu), neodymium (Nd), samarium (Sm), uranium (U), and ytterbium (Yb). A second decay of four to five weeks for the samples in quartz vials was completed before the long count of three hours, which measures cerium (Ce), cobalt (Co), chromium ( $\mathrm{Cr}$ ), cesium (Cs), europium (Eu), iron (Fe), hafnium (Hf), nickel (Ni), rubidium $(\mathrm{Rb})$, antimony $(\mathrm{Sb})$, scandium $(\mathrm{Sc})$, strontium $(\mathrm{Sr})$, tantalum $(\mathrm{Ta})$, terbium $(\mathrm{Tb})$, thorium (Th), zinc (Zn), and zirconium (Zr). 
Table 3.1 Elements Counted in Neutron Activation Analysis at MURR.

\begin{tabular}{llclc}
\hline \hline & Element & Abbreviation & Element & Abbreviation \\
\hline Short Count & Aluminum & $\mathrm{Al}$ & Manganese & $\mathrm{Mn}$ \\
& Barium & $\mathrm{Ba}$ & Sodium & $\mathrm{Na}$ \\
& Calcium & $\mathrm{Ca}$ & Titanium & $\mathrm{Ti}$ \\
& Dysprosium & $\mathrm{Dy}$ & Vanadium & $\mathrm{V}$ \\
& Potassium & $\mathrm{K}$ & & \\
Mid Count & Arsenic & $\mathrm{As}$ & Samarian & $\mathrm{Sm}$ \\
& Lanthanum & $\mathrm{La}$ & Uranium & $\mathrm{U}$ \\
& Lutetium & $\mathrm{Lu}$ & Ytterbium & $\mathrm{Yb}$ \\
& Neodymium & $\mathrm{Nd}$ & & \\
& & & & $\mathrm{Sb}$ \\
Long Count & Cerium & $\mathrm{Ce}$ & Antimony & $\mathrm{Sc}$ \\
& Cobalt & $\mathrm{Co}$ & Scandium & $\mathrm{Sr}$ \\
& Chromium & $\mathrm{Cr}$ & Strontium & $\mathrm{Ta}$ \\
& Cesium & $\mathrm{Cs}$ & Tantalum & $\mathrm{Tb}$ \\
& Europium & $\mathrm{Eu}$ & Terbium & $\mathrm{Th}$ \\
& Iron & $\mathrm{Fe}$ & Thorium & $\mathrm{Zn}$ \\
& Hafnium & $\mathrm{Hf}$ & Zinc & $\mathrm{Zr}$ \\
& Nickel & $\mathrm{Ni}$ & Zirconium & \\
\hline \hline
\end{tabular}

Multivariate Analysis

A full discussion of the multivariate statistical protocol for determining sources using NAA data produced at MURR is provided by Glascock (1992). Briefly, the NAA data take the form of a list of the amount of each element, usually in parts per million, for each sample submitted. Some elements may not be in a particular sample or the amounts are below detection limits, and often the researcher chooses to leave that element out of the analysis. In this analysis, nickel was not used because it was missing for several of the 76 Draw samples, which is not unusual in the Southwest (Speakman 2013). Zirconium was also not used because of some missing values in the comparison data. Ultimately, 31 elements were used. The data were transformed to log 
concentrations to compensate for the difference in scale between major $(>0.1 \%)$, minor (> 100 parts per million $<0.1 \%$ ), and trace $(<100$ parts per million) elements (Glascock 1992; Neff 2002; Speakman 2013). This process transformed the concentrations for each element into a more normally distributed distribution.

Cluster analysis (CA) was then used to identify preliminary groups. Shown in a dendrogram, cluster analysis attempts to link samples based on similar concentrations of the 31 elements. This tree (Appendix A) was then tested with other techniques to define and refine group memberships. Principal components analysis (PCA) was then used. Coefficients were examined to identify "correlated variables and possible geochemical (or cultural) explanations for the structures in the dataset" (Glascock 1992:18). Biplots of PCA allowed both samples and elemental vectors to be shown at the same time (Figure 3.2). 


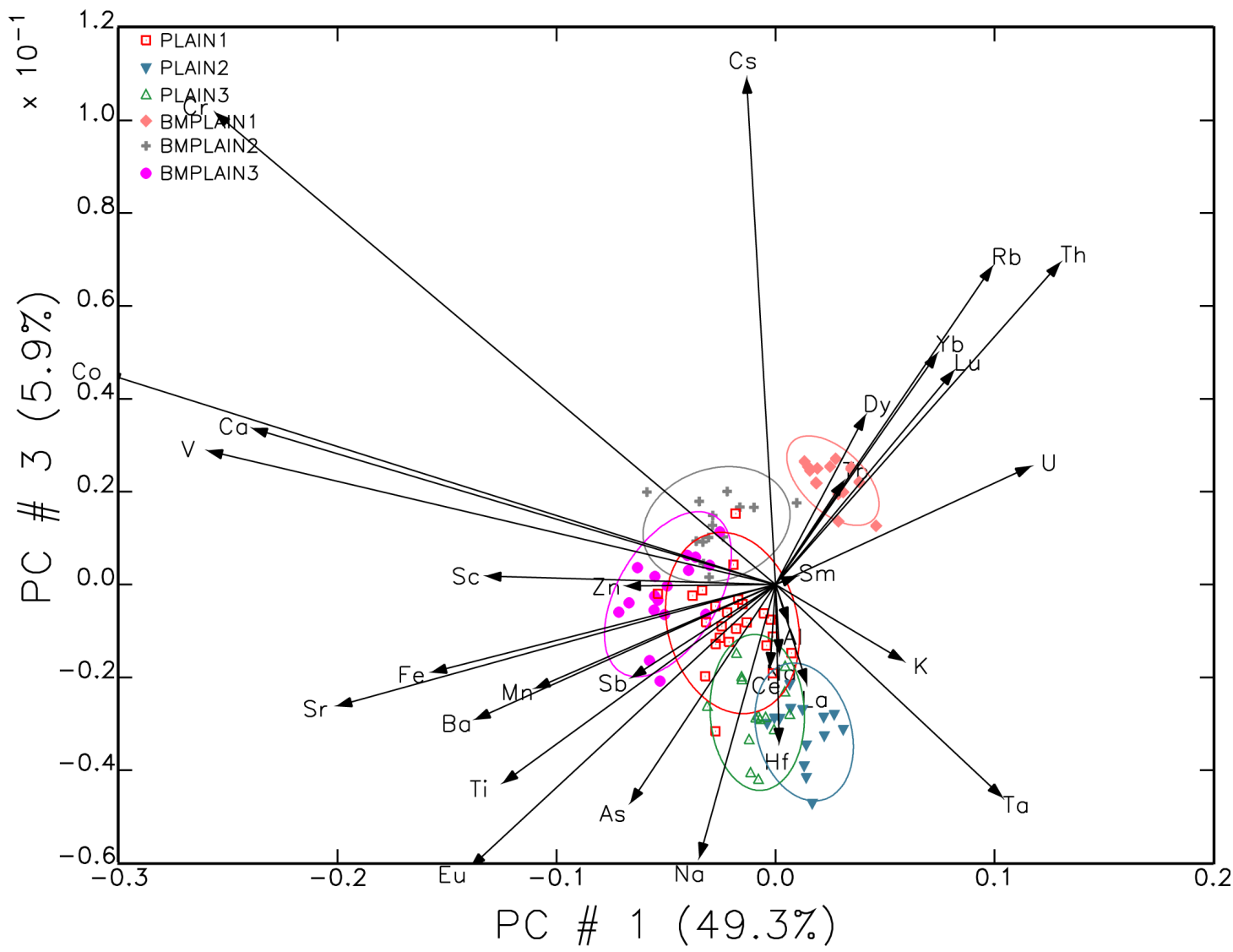

Figure 3.2 Principal components 1 vs. 3 with vectors. Samarium (Sm) has a short vector showing that it is not driving the variation here. Cobalt (Co) and Chromium ( $\mathrm{Cr}$ ) have long vectors, as does Cesium (Cs), demonstrating that there is considerable variation in these elements among the samples and therefore are likely useful for differentiating clay sources. The length of the vector is equal to its eigenvalue.

The first principal component (PC) summarizes the largest amount of variation in the data, and subsequent PCs summarize decreasing amounts of the remaining variation, (i.e., the second component summarizes the second largest amount of variation, the third component summarizes the third largest amount, and so on). All of the variation will necessarily be explained by the same number of PCs as elements considered, because of the underlying mathematical relationships, but typically nearly all of the variation is explained in a handful of PCs, if in fact the data are patterned. 
Often in ceramic analysis, $70 \%$ of the variation in a dataset can be summarized in the first three principal components (Glascock 1992). Here, the first three PCs summarized $77 \%$ of the variation. By plotting the PCs against each other, we could see the samples that were the same, i.e., have the same amount of each element, group together on the plot. The results of the PC allowed the identification of groups, which ideally corresponded to distinct compositional recipes. These recipes relate to specific communities with spatially distinct clay and potentially temper sources. Many production locations have been identified in the Southwest by NAA. In this study, the samples may group in one or more areas of the PCA plots demonstrating differences in the pastes (see Figure 3.3 for 10 groups). 


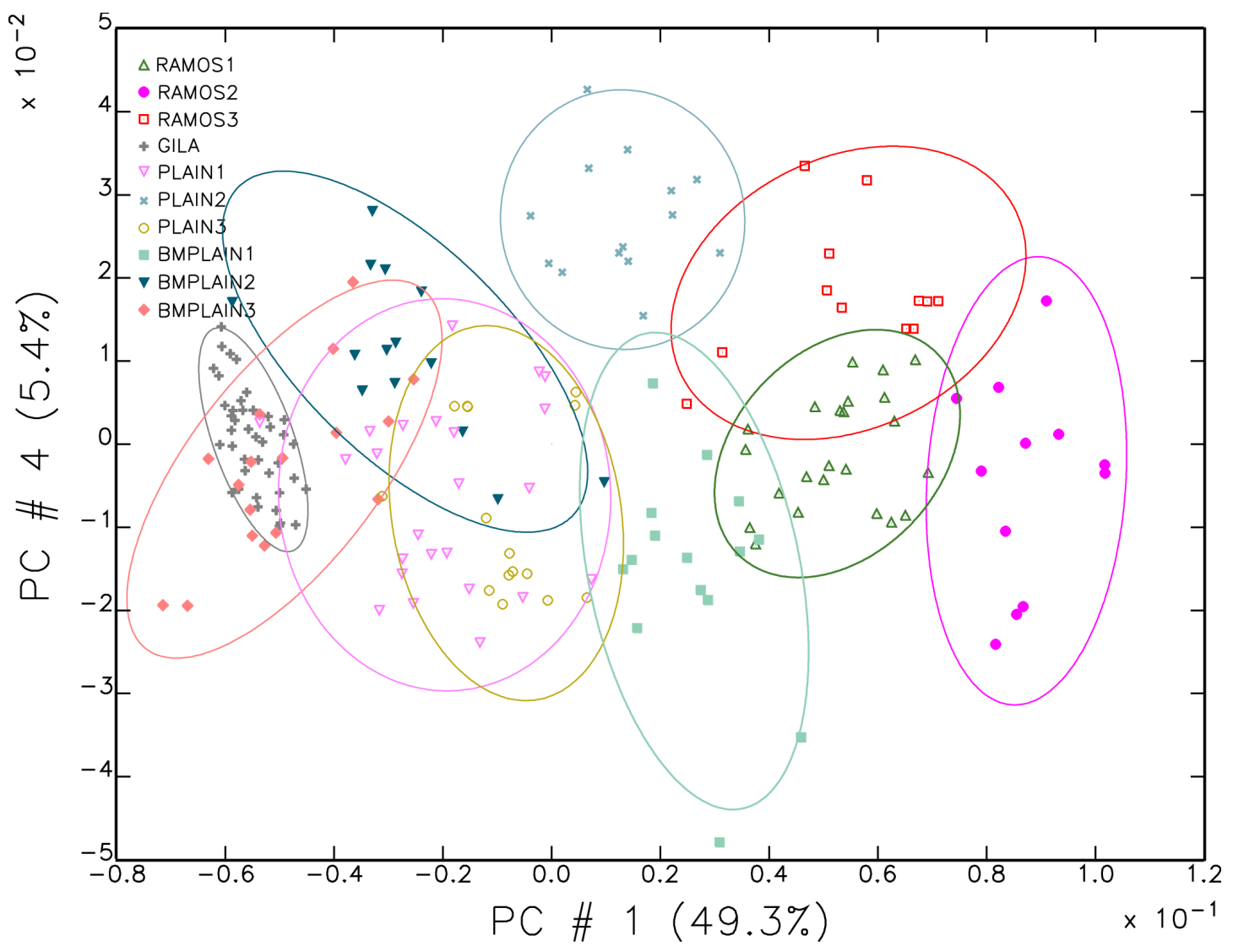

Figure 3.3 Principal components 1 vs 4 of all groups. This combination spreads the groups across the plot most evenly for viewing all the groups at one time. Note that while there is considerable overlap among some of the groups in this figure (e.g., BMPLAIN3 and Gila), these same groups may be distinct when comparing other PCs.

Groups were shown in scatterplots, with $90 \%$ confidence ellipses, which may overlap with one another. Samples were placed in groups based on pattern recognition from viewing the CA and PCA. These groups are further analyzed using many scatterplots of element pairs to ensure they reflected shared variation and reasonable grouping of samples (Figure 3.4). These plots also allowed for pattern recognition, and groups were assigned based on them. After looking at many scatterplots, if a particular sample was consistently associated with a particular group, then it likely was part of that underlying group. Plots were again reviewed with groups shown with confidence 
ellipses to see if they were consistent among many elemental plots. Once groups were assigned, then group membership probabilities were tested to see if the groups were valid (i.e., there is more variation among the groups than within the groups).

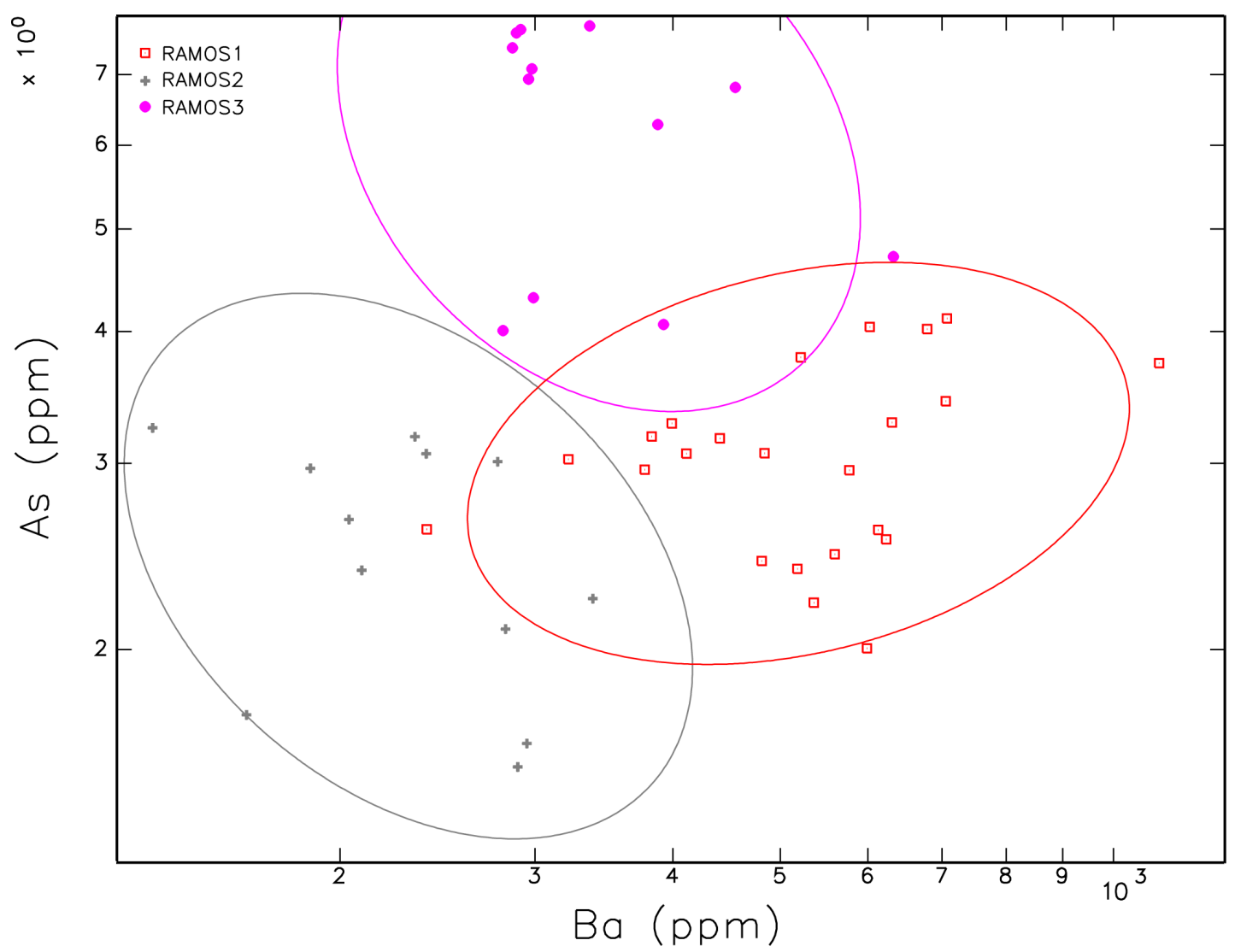

Figure 3.4 Scatterplot comparing barium and arsenic compositions of the three Ramos Polychrome groups. Groups R1 and R2 have about the same amount of arsenic, but R1 has more barium.

Mahalanobis distance shows separation between groups or between a sample and a group(s), by showing the distance between the sample and a group centroid, i.e., the statistical center of the group/sample, which in turn tests the probability of a sample belonging to a group (Glascock 1992). Mahalanobis distance takes variances and covariances into account in the multivariate group. The distances can be converted to 
probabilities of group membership for samples (Speakman 2013). Of course, probabilities fluctuate whether the sample is already assumed to be part of the group, which in turn moves the group's centroid as the group "stretches" to include the location of the sample in elemental concentration space (Speakman 2013:67), but this stretching can be avoided by excluding each sample from the group before calculating the probability of group membership (Harbottle 1976). The center of a group is used to calculate the probability of the sample being a part of that group. Thus, groups can be differentiated from each other visually with scatterplots and statistically in multiple dimensions (Speakman 2013).

I also combined all of the samples from 76 Draw and the other sites into a single database as opposed to doing separate analyses of Ramos Polychrome, Gila Polychrome, and so on. This was done for both practical and analytic reasons. First, I was trying to determine if some or all of the pottery from the various types reflected the same underlying recipe (and therefore the same source or potter). Second, Mahalanobis distance requires that there be more samples in a group than the number of elements analyzed. A good rule of thumb is that probabilities have greater accuracy if the number of components is greater than 2.5 times the number of samples. This analysis includes 31 elements, but most groups do not have 31 members, making the statistical analysis problematic. Combining the samples ( $n=216$ in this analysis) increased sample size and thereby increased the strength of the analysis. So instead of analyzing each type from each settlement separately, this analysis was based on all of the samples (see Appendix B for Mahalanobis distance probabilities). The results of this 
analysis are the ten compositional groups (Figure 3.3), which are discussed in the next chapter.

\section{Petrographic analysis}

Petrographic analysis, or petrography, is a technique from geology and has been applied to pottery for decades (Hill 2010; Kidder and Shepard 1936). This technique visually examines mineral inclusions within the paste. Like clay, aplastics may be distinct to specific locations. Further, different ceramic recipes are often distinct as different types, amounts, and size of temper/aplastics were used and they were analyzed because they can help define the texture and fabric of the paste. NAA interpretations are stronger with petrographic supplementation (Cecil and Neff 2006).

To conduct petrographic analysis, samples are impregnated with epoxy to hold them together and thin sections of the sherds are cut and ground. Once thin enough to be translucent, polarized light is passed through the sample and the crystalline structures of the minerals, and the color and texture of the paste are examined (Hill 2010). Petrographic microscopes are a special type of microscope. They have a polarized light below the stage that lets in light in one direction. A second polarized light can move through the microscope tube, and transmits light at right angles that enter the specimen (Shepard 1995:139). The specimen can be turned on the stage allowing the light to pass through. Training in optical crystallography is needed to identify the minerals based on their shape, color, and symmetry. The types of minerals in each sample are noted; occasionally percentages of each mineral are calculated and 
recorded. The shapes of the inclusions are also recorded; windblown sand is angular, and so is volcanic tuff that has been ground. The types and shapes of the minerals can indicate where minerals are found and collected, as well as the processing steps potters use to make vessels. Mineral inclusions in archaeological specimen are widely varied, and knowledge of the local geology is required to tie thin sections to specific geographic locations. Temper is aplastics that were added to a clay by the potter, as opposed to naturally occurring aplastics.

As with geochemical sourcing, though, it may be possible to identify different groups based on their similarity, even if the exact location is not known, i.e., one can often identify distinct recipes, even if one doesn't know exactly where the aplastics originated.

\section{Chapter Summary}

This chapter explains and describes the materials and methods used. Several complementary analyses were applied to identify the presence and number of distinct ceramic production recipes that may be reflected in the analyzed sherds from 76 Draw and the other settlements. NAA was used to identify geochemical similarities in bulk analysis whereas thin sections were used to evaluate similarities and differences in temper/aplastics and other technological choices. NAA allowed grouping of similar compositions by their "fingerprints" by finding the percentages, in parts per million, of the major, minor, and trace elements in the samples, and multivariate analysis tested the statistical strength of those groups. Petrographic analysis identified individual 
minerals in the samples and that information was used to identify aplastic groups in pottery. The next chapter provides the results of the NAA and petrographic analysis. 


\section{Chapter 4 NAA and Petrographic Analysis and Results}

\section{NAA Compositional Results}

Compositional data from the 76 Draw ceramic sample were evaluated along with compositional data for ceramics from nearby sites (Table 4.1) and 10 compositional groups were defined. Preliminary compositional groups were made using the results of a cluster analysis (Appendix A), and these groups were evaluated and refined as follows:

- Principal components were calculated; the first eight PCs explain $91.34 \%$ of the variation in the dataset (Figure 4.1). Bolded elements in Table 4.2 are the elements driving the variation in each principal component.

- $\quad$ Principal components scatterplots and elemental plots were examined to identify those elements that maximize intergroup distinctions and minimized intragroup variation.

- $\quad$ Once groups were formed, the typological designation of sherds assigned to that group were assessed to see if there was any congruence between composition-and therefore paste recipe-and ceramic type.

- As a final test of compositional group robustness, the probability of group membership for each specimen was calculated based on its Mahalanobis distance (MD) to the compositional group centroid. Because of the relatively small size of some of these groups, I used the first eight principal components-accounting for $91 \%$ of the total chemical variation-to calculate Mahalanobis distances (Appendix B). 
Table 4.1 Sites and Pottery Types Used in this Research.

\begin{tabular}{|c|c|c|}
\hline Site & Researcher & Samples \\
\hline 76 Draw (LA156980), & Candace Sall & 33 Ramos Polychrome \\
\hline \multirow[t]{4}{*}{ Luna County, NM } & & 36 Gila Polychrome \\
\hline & & 31 plainware \\
\hline & & 1 Tonto Polychrome \\
\hline & & 1 Villa Ahumada Polychrome \\
\hline Black Mountain (LA49), & Kathryn Putsavage & 2 Ramos Polychrome \\
\hline Luna County, NM & & 101 plainware \\
\hline Simon Ranch, Luna County, NM & Darrell Creel & 3 Ramos Polychrome \\
\hline LA15062, Grant County, NM & Darrell Creel & 4 Ramos Polychrome \\
\hline LA26788, Doña Ana County, NM & Karl Laumbach & 2 Ramos Polychrome \\
\hline 41EP8, El Paso County, TX & Lori Reed & 1 Ramos Polychrome \\
\hline 41EP1672, El Paso County, TX & Lori Reed & 1 Ramos Polychrome \\
\hline
\end{tabular}

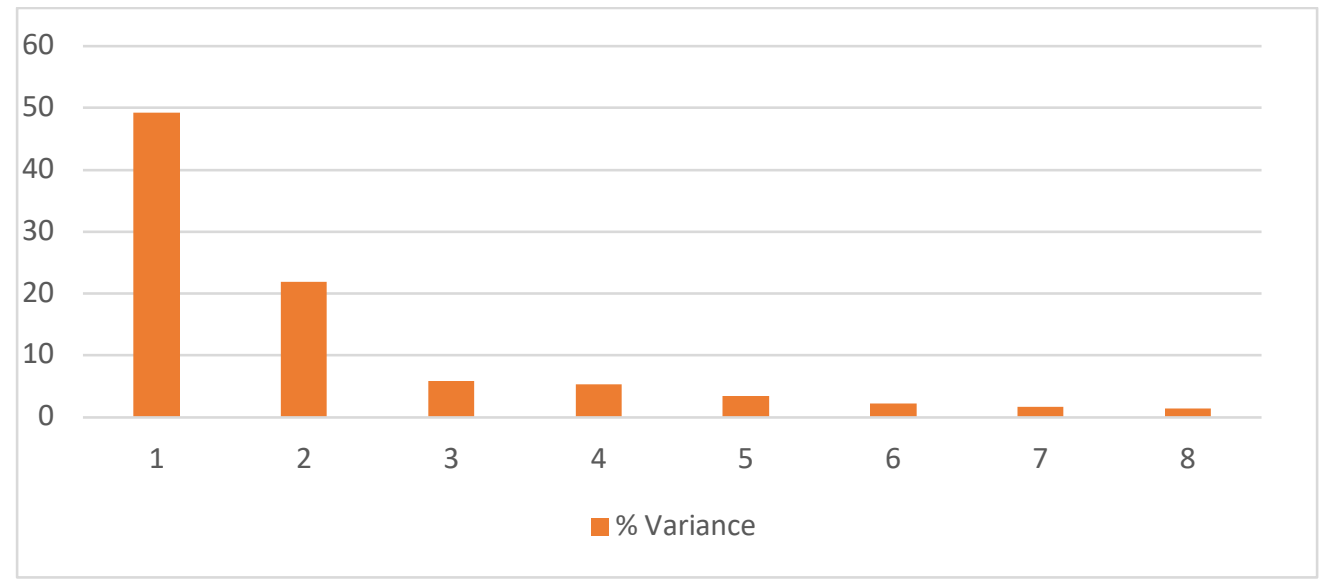

Figure 4.1. Percent of variance explained by each PC calculated for the entire ceramic dataset. 
Table 4.2 The First Row Lists the Percentage of Variance Explained by each PC with the First Eight PCs Explaining 91.3\%. Rows with Element Names Contain the Loading Factors or Coefficients for Transforming from Elements to PCs. The Final Row Contains the Eigenvalues.

\begin{tabular}{|c|c|c|c|c|c|c|c|c|}
\hline Variable & PC1 & PC2 & PC3 & PC4 & PC5 & PC6 & PC7 & PC8 \\
\hline & 49.303 & 21.980 & 5.868 & 5.367 & 3.448 & 2.232 & 1.689 & 1.452 \\
\hline $\mathrm{Na}$ & -0.048 & 0.057 & -0.237 & -0.049 & 0.106 & -0.050 & -0.164 & -0.180 \\
\hline Al & 0.008 & 0.043 & -0.032 & -0.005 & -0.090 & -0.096 & 0.022 & 0.003 \\
\hline K & 0.081 & 0.047 & -0.066 & 0.017 & 0.076 & 0.029 & -0.081 & -0.100 \\
\hline $\mathrm{Ca}$ & -0.333 & -0.187 & 0.136 & -0.278 & 0.166 & 0.637 & -0.086 & 0.136 \\
\hline Sc & -0.184 & 0.152 & 0.007 & 0.109 & 0.024 & -0.130 & 0.105 & 0.059 \\
\hline $\mathrm{Ti}$ & -0.173 & 0.105 & -0.173 & 0.096 & -0.056 & -0.202 & 0.023 & -0.023 \\
\hline V & -0.361 & 0.086 & 0.116 & 0.038 & -0.186 & 0.043 & 0.346 & -0.003 \\
\hline $\mathrm{Cr}$ & -0.357 & 0.074 & 0.410 & 0.224 & -0.013 & -0.145 & -0.018 & -0.249 \\
\hline $\mathrm{Mn}$ & -0.153 & -0.018 & -0.090 & 0.117 & 0.542 & -0.082 & -0.132 & -0.289 \\
\hline $\mathrm{Fe}$ & -0.218 & 0.145 & -0.076 & 0.070 & 0.053 & -0.060 & 0.189 & -0.050 \\
\hline Co & -0.427 & 0.053 & 0.184 & -0.026 & 0.106 & -0.191 & 0.039 & -0.108 \\
\hline $\mathrm{Zn}$ & -0.095 & 0.150 & -0.001 & 0.092 & 0.261 & 0.217 & 0.005 & -0.010 \\
\hline As & -0.092 & 0.137 & -0.189 & 0.417 & -0.389 & 0.520 & 0.097 & -0.142 \\
\hline $\mathrm{Rb}$ & 0.138 & 0.047 & 0.276 & -0.016 & -0.001 & 0.066 & -0.038 & -0.118 \\
\hline $\mathrm{Sr}$ & -0.279 & -0.126 & -0.106 & -0.331 & -0.143 & 0.094 & -0.512 & -0.275 \\
\hline $\mathrm{Sb}$ & -0.091 & 0.098 & -0.081 & 0.360 & -0.205 & 0.044 & -0.397 & 0.067 \\
\hline Cs & -0.018 & 0.091 & 0.440 & 0.239 & -0.079 & -0.104 & -0.467 & 0.431 \\
\hline $\mathrm{Ba}$ & -0.191 & 0.101 & -0.117 & -0.384 & -0.426 & -0.171 & -0.006 & -0.084 \\
\hline La & 0.020 & 0.294 & -0.086 & -0.149 & -0.009 & 0.028 & -0.034 & 0.168 \\
\hline $\mathrm{Ce}$ & -0.003 & 0.265 & -0.071 & -0.126 & 0.049 & 0.005 & -0.094 & 0.112 \\
\hline $\mathrm{Nd}$ & 0.003 & 0.309 & -0.060 & -0.129 & 0.054 & 0.078 & -0.042 & 0.173 \\
\hline Sm & 0.013 & 0.298 & 0.007 & -0.119 & 0.084 & 0.079 & -0.013 & 0.124 \\
\hline $\mathrm{Eu}$ & -0.194 & 0.312 & -0.246 & -0.079 & 0.036 & -0.102 & -0.037 & 0.289 \\
\hline $\mathrm{Tb}$ & 0.043 & 0.276 & 0.090 & -0.084 & 0.124 & 0.086 & 0.019 & 0.020 \\
\hline Dy & 0.057 & 0.254 & 0.147 & -0.101 & 0.097 & 0.100 & 0.082 & -0.024 \\
\hline $\mathrm{Yb}$ & 0.103 & 0.203 & 0.201 & -0.051 & 0.080 & 0.104 & 0.081 & -0.155 \\
\hline Lu & 0.113 & 0.209 & 0.186 & -0.069 & 0.035 & 0.075 & 0.053 & -0.172 \\
\hline $\mathrm{Hf}$ & 0.002 & 0.188 & -0.137 & 0.040 & 0.019 & -0.069 & -0.020 & -0.187 \\
\hline Ta & 0.144 & 0.219 & -0.185 & 0.248 & 0.062 & 0.119 & -0.140 & -0.252 \\
\hline Th & 0.181 & 0.159 & 0.280 & -0.165 & -0.273 & 0.031 & 0.068 & -0.261 \\
\hline$U$ & 0.162 & 0.162 & 0.103 & -0.107 & -0.073 & -0.073 & -0.265 & -0.279 \\
\hline Eigenvalues: & 0.513 & 0.229 & 0.061 & 0.056 & 0.036 & 0.023 & 0.018 & 0.015 \\
\hline
\end{tabular}


Below I describe and compare the geochemical groups and comment on the typological designations of sherds assigned to the groups. The groups tend to contain a mix of sherds assigned to different types, but often one particular type dominates the assemblage (e.g., Group G discussed below contains Salado Polychrome, a Chihuahuan Polychrome, and plainwares but is dominated [ $90 \%$ of the group] by the Salado Polychrome; Table 4.2). In total, I identify 3 groups dominated by Ramos Polychrome, 1 group dominated by Salado Polychrome, and 6 groups of plainware ceramics. 
Table 4.3 Sherds Counts by Site for each Geochemical Group.

\begin{tabular}{|c|c|c|c|c|c|c|c|c|c|c|c|}
\hline & R1 & R2 & R3 & Gila & P1 & P2 & P3 & BMP1 & BMP2 & BMP3 & TOTAL \\
\hline \multicolumn{12}{|l|}{76 Draw } \\
\hline $\begin{array}{l}\text { Ramos } \\
\text { Polychrome }\end{array}$ & 12 & 7 & 8 & & & & & & & & 27 \\
\hline $\begin{array}{l}\text { Gila } \\
\text { Polychrome }\end{array}$ & & & & 36 & & & & & & & 36 \\
\hline $\begin{array}{l}\text { Tonto } \\
\text { Polychrome }\end{array}$ & & & & 1 & & & & & & & 1 \\
\hline $\begin{array}{l}\text { Villa } \\
\text { Ahumada } \\
\text { Polychrome }\end{array}$ & & & & 1 & & & & & & & 1 \\
\hline $\begin{array}{l}\text { Plainware } \\
\text { Black } \\
\text { Mountain }\end{array}$ & 4 & 2 & 2 & & 2 & 4 & 9 & & & & 23 \\
\hline $\begin{array}{l}\text { Ramos } \\
\text { Polychrome }\end{array}$ & 1 & 1 & & & & & & & & & 2 \\
\hline $\begin{array}{l}\text { Plainware } \\
\text { Simon } \\
\text { Ranch }\end{array}$ & 3 & 1 & 1 & 3 & 20 & 10 & 6 & 15 & 14 & 17 & 90 \\
\hline $\begin{array}{l}\text { Ramos } \\
\text { Polychrome }\end{array}$ & 1 & & & & 1 & & & & & & 2 \\
\hline LA15062 & & & & & & & & & & & \\
\hline $\begin{array}{l}\text { Ramos } \\
\text { Polychrome }\end{array}$ & & & & & & & & & & & 0 \\
\hline LA26788 & & & & & & & & & & & \\
\hline $\begin{array}{l}\text { Ramos } \\
\text { Polychrome }\end{array}$ & 1 & & 1 & & & & & & & & 2 \\
\hline 41EP8 & & & & & & & & & & & \\
\hline $\begin{array}{l}\text { Ramos } \\
\text { Polychrome }\end{array}$ & 1 & & & & & & & & & & 1 \\
\hline 41EP1672 & & & & & & & & & & & \\
\hline $\begin{array}{l}\text { Ramos } \\
\text { Polychrome }\end{array}$ & & 1 & & & & & & & & & 1 \\
\hline TOTAL & 23 & 12 & 12 & 41 & 23 & 14 & 15 & 15 & 14 & 17 & 186 \\
\hline
\end{tabular}


The Ramos Polychrome sherds are distributed unevenly in three compositional groups (Figure 4.2). Primary distinctions between Groups R1 and R2 are that R1 specimens tend to be enriched in barium relative to those in R2. Both Groups R1 and R2 are depleted in arsenic relative to Group R3 (Figure 4.3). There are plainware sherds in all three groups. It is likely that these are samples from the unpainted sections of Ramos Polychrome vessels, but they could be plainwares that are made of the same paste recipe.

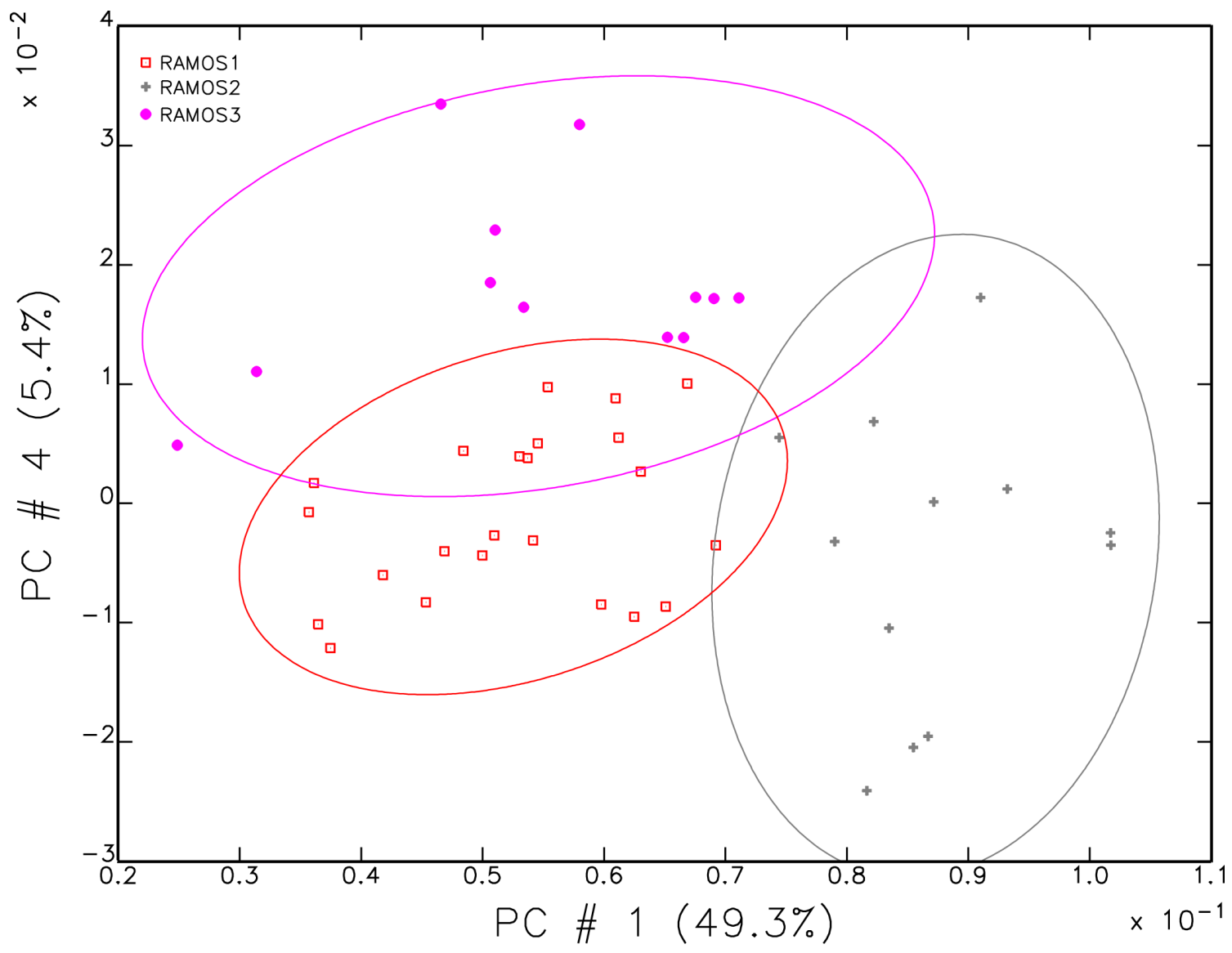

Figure 4.2 Principal components scatterplot of three Ramos Polychrome groups. The variation in principal component 1 is driven by calcium, vanadium, chromium and cobalt. Principal Component 4 is driven by variation in strontium and barium. 
Group R1. This group comprises 23 specimens (16 Ramos Polychrome and 7 plainwares) from five sites-one each from Simon Ranch, LA26788, and 41EP8, as well as 16 sherds from 76 Draw and 4 from Black Mountain (Figure 4.3). Group R2 had the least amount of barium when compared to R1 and R3; R3 samples have the most arsenic of the three groups. Seven specimens were typed as plainwares -3 from Black Mountain and 4 from 76 Draw. Based on the criterion of abundance, this group's locus of production was likely at or near 76 Draw. This group also did not match any of Triadan et al.'s (2018:156-157) published Ramos core sources (see Appendix D), supporting the proposition that it was made at a source (on the northern Casas Grandes frontier) not reflected in the Casas Grandes heartland. 


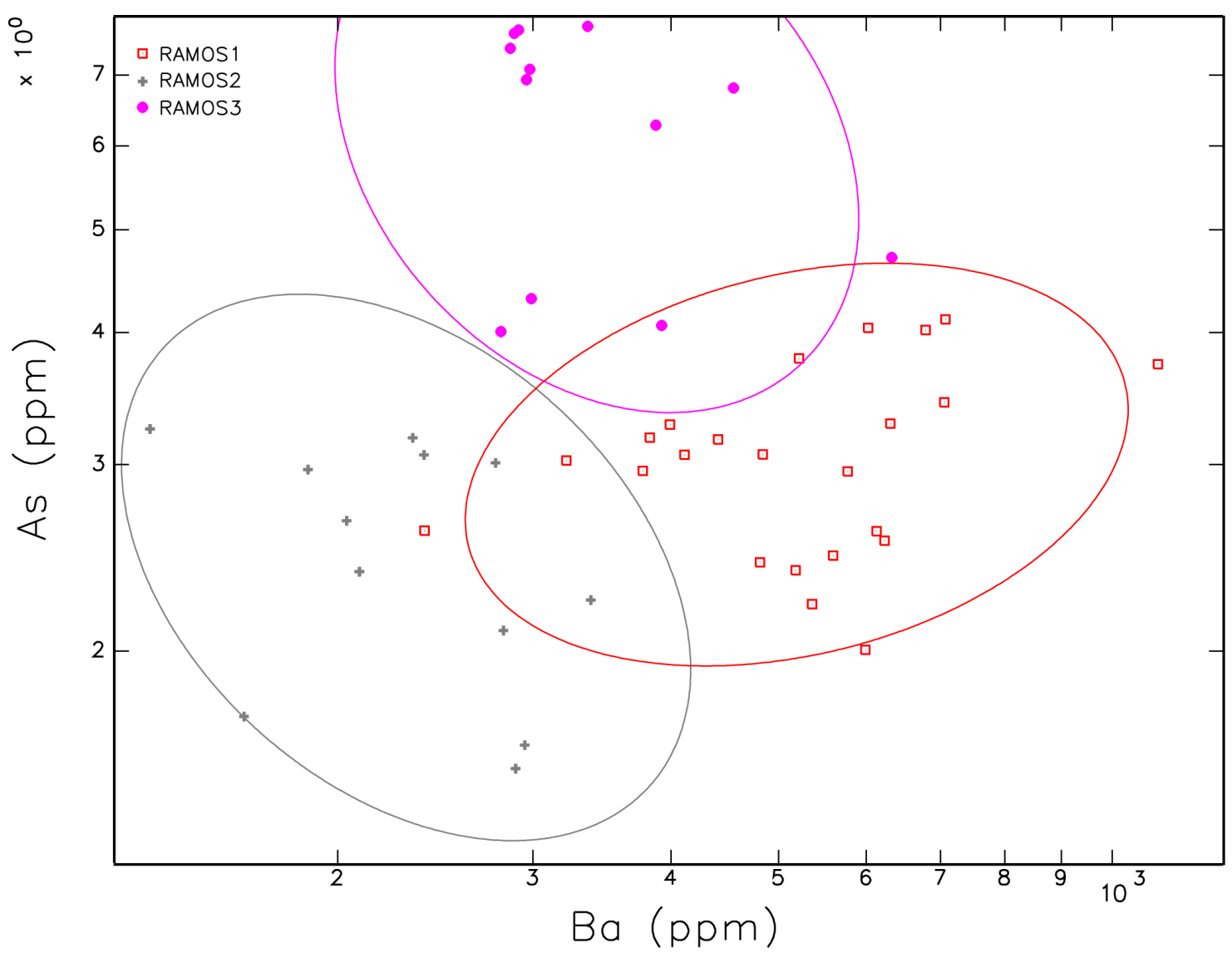

Figure 4.3 Scatterplot comparing barium and arsenic compositions of the three Ramos Polychrome groups. Concentrations are in parts per million and ellipses represent a $90 \%$ confidence interval.

Group R2. This group is made up of 12 specimens (9 Ramos Polychrome and 3 plainware) derived from three sites - nine from 76 Draw, one from 41EP1672, and two from Black Mountain. Putsavage (2015:Appendix C) assigned these same two Black Mountain sherds to her Group G2a, which also included 24 Chihuahuan polychrome sherds ( $75 \%$ of her group), one Salado polychrome sherd ( $3 \%$ of the group), and plainwares (16\% of the group). The Chihuahuan polychrome sherds in Putsavage's G2a included Ramos, Babícora, Villa Ahumada, Carretas, and Dublan. Putsavage (2015) proposed that the clay source from which this geochemical group derives was located in 
the Lower Mimbres Valley, and that this was a source of Chihuahuan polychromes. This source had a comparable abundance to R1 at 76 Draw, which supports the proposition it was locally made. It also did not match any of Triadan et al.'s (2018:156-157) core group sources (see Appendix D). As with R1, additional sampling from other localities will be necessary to narrow down the specific location of production in the lower Mimbres Valley.

Group R3. Twelve sherds make up Group R3 (9 Ramos Polychrome and 3 plainware sherds). Ten are from 76 Draw (2 plainware and 8 Ramos Polychrome), one Ramos sherd was from LA26788, and one plainware sherd was from Black Mountain. This single Black Mountain sherd was assigned by Putsavage $(2015: 209)$ to her Group G2b, which had a similar pottery-type make-up as her Group G2a-75\% Chihuahuan polychromes in both groups ( $G 2 b$ has 19 sherds, consisting of the same types as G2a: Ramos, Babícora, Villa Ahumada, Carretas, and Dublan; the Ramos sherd in Putsavage's G2b however, was outside the group ellipses in this analysis and was not assigned to a group.) Putsavage suggests that G2b was made in the Lower Mimbres Valley, or even in Mexico. Given the strong representation of polychrome sherds in these groups, it may be that the specimens (from both 76 Draw and Black Mountain) classified as plainware could in fact be sherds from undecorated portions of Chihuahuan polychrome vessels. Comparing group R3 to the published elemental scatterplots from Triadan et al. (2018:156-157) indicates it would fit inside their Core Group 2 (see Appendix D). They determined that the sherds from Core Group $2(n=122)$ were present at Paquimé and 
large sites nearby, as well as sites on the periphery, and that the production location was likely at or near Paquimé. If this conclusion is true, it suggests that Ramos Polychrome (and other Chihuahuan polychromes) from Paquimé was brought to 76 Draw, Black Mountain, and LA26788.

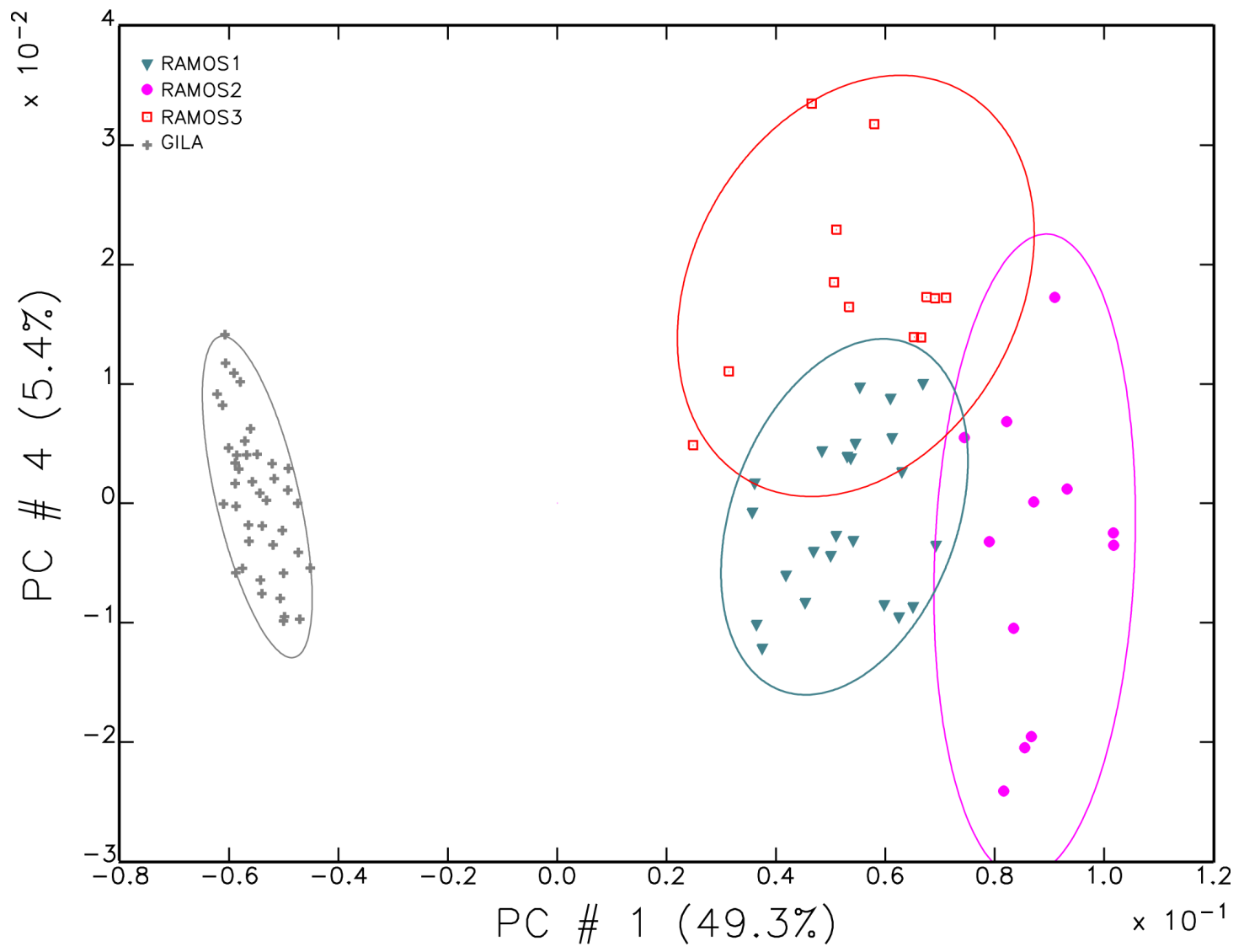

Figure 4.4 Principal components scatterplot of G, R1, R2, and R3 compositional groups of Gila and Ramos Polychromes. The variation in Principal Component 1 is driven by calcium, vanadium, chromium and cobalt. Principal Component 4 is driven by variation in strontium and barium.

Group G (Gila: Salado wares). This well-defined compositional group consists of 41 sherds from two sites (Figure 4.4). A total of 38 polychrome specimens from 76 Draw 
make up the vast majority of sherds in this group. Thirty-six were Gila Polychrome, one was a Tonto Polychrome, and the last was a Villa Ahumada Polychrome. The remaining specimens assigned to the group were three plainware sherds from Black Mountain. These sherds from Black Mountain assigned to Group G were assigned to compositional Group M49a by Putsavage, and this group was originally defined by Speakman (2013; see also Putsavage 2015:209). Speakman (2013) constructed this original group out of 133 sherds and eight clay specimens from 37 sites. Taliaferro's (2014) study found that 20 Playas Red sherds from Old Town matched this group as well. Putsavage (2015) assigned an additional 77 specimens from Black Mountain to Group M49a, including 31 Salado polychromes, 15 Playas Red, 17 plainwares, 8 corrugated wares, 3 Chihuahuan wares (1 Chihuahua Red-on-Brown, 1 Ramos Black, and 1 Madera Black-on-Red), and 1 El Paso Polychrome (Putsavage 2015).

Based on the sherds assigned to M49a by past researchers, the group includes the entire Mimbres sequence of pottery types, plus Alma Plain, Salado polychromes, a couple of Chihuahuan wares (1 Ramos Black and 1 Madera Red-on-Black, making up $2.5 \%$ of the sherds in this group from Putsavage's sample), and other pottery types (Speakman 2013: Appendix E; Putsavage 2015: Appendix C). Speakman suggests that this group's production location could be in the Upper Mimbres Valley, but its broad distribution and high frequency across many sites including NAN Ranch and Old Town suggest that it may be subdivided in the future into multiple groups. Still, all of the Gila Polychrome, as well as the single Tonto Polychrome sherd and single Villa Ahumada Polychrome sherd analyzed from 76 Draw, are assignable to this compositional group, 
which suggests that the vessels were not locally made at 76 Draw, but rather represent imported vessels made in the Upper Mimbres Valley.

Plainwares. The plainwares separate into six distinctive compositional groups (Figure 4.5). Three groups contain sherds from both 76 Draw and Black Mountain, and three contained only sherds from Black Mountain.

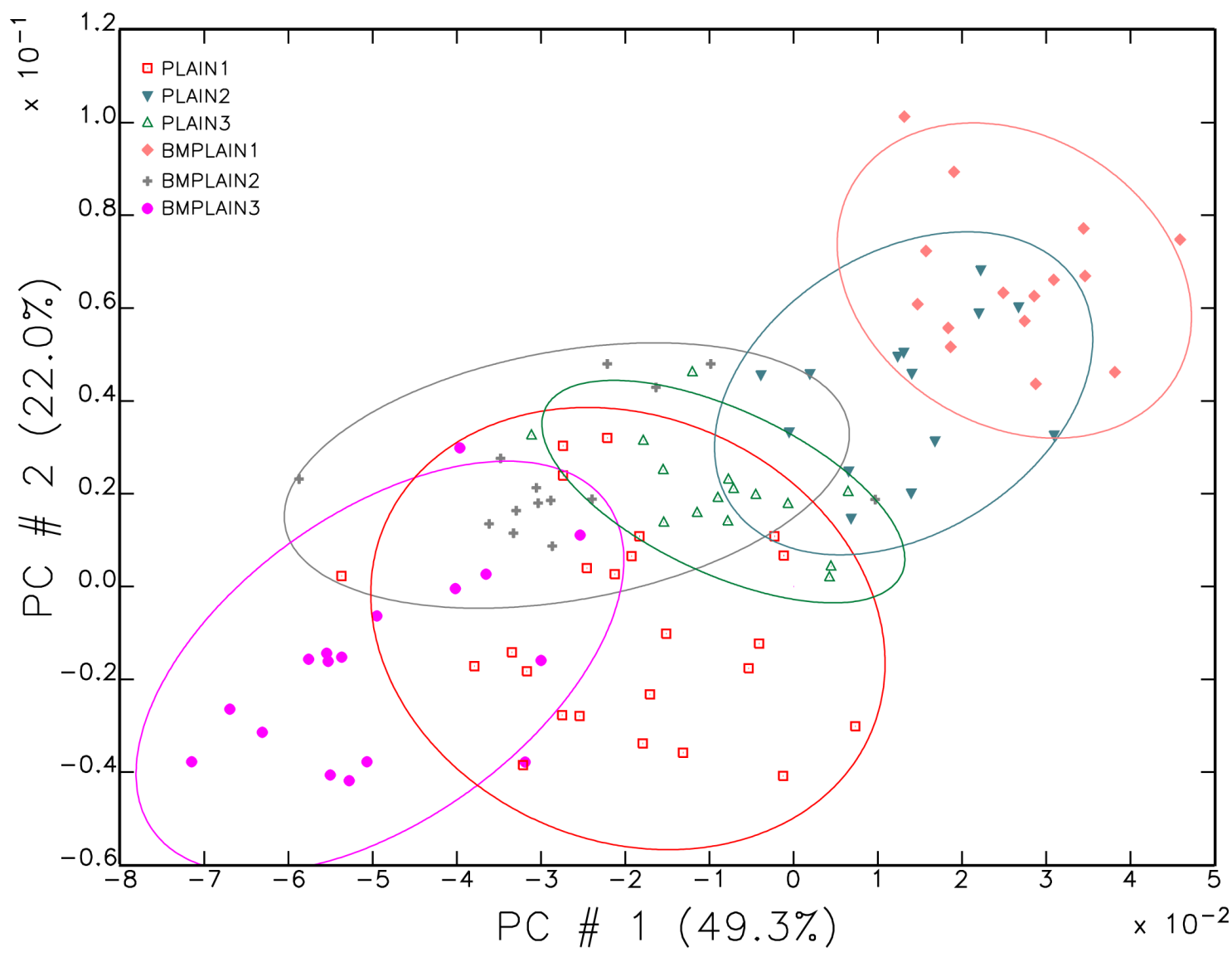

Figure 4.5 Scatterplot of all plainware groups. The variation in Principal Component 1 is driven by calcium, vanadium, chromium and cobalt. Principal Component 2 is driven by variation in neodymium and europium. Groups P1, P2, and P3 contain samples from 76 Draw and Black Mountain. Groups BMP1, BMP2, and BMP3 contain samples from Black Mountain. 
Group P1. Vanadium and calcium separated the Groups P1, P2, and P3 in Figure 4.6, and P2 contained the least amount of both elements when compared to the other plainware groups. Group P1 was made up of 24 plainware specimens including 20 sherds from Black Mountain, 1 sherd from Simon Ranch, and 2 sherds from 76 Draw (both are Casas Grandes Plainware) (Figure 4.7). The sherds from Black Mountain assigned to P1 included nine that were not assigned to any group by Putsavage, and 11 samples that she assigned to three different groups that she affiliated to the Upper Gila and Mimbres Valleys.

The criterion of abundance would suggest that the most-likely locus of production of Group P1 was in the vicinity of Black Mountain, north of 76 Draw, but Putsavage assigned many sherds in this group to the area north of Black Mountain. At the moment there are insufficient data to state where these vessels were produced. Sampling of clays and more sherds at 76 Draw-and from the region between the site, Black Mountain, and the Gila and Mimbres Valleys-would help to narrow down the production location. 


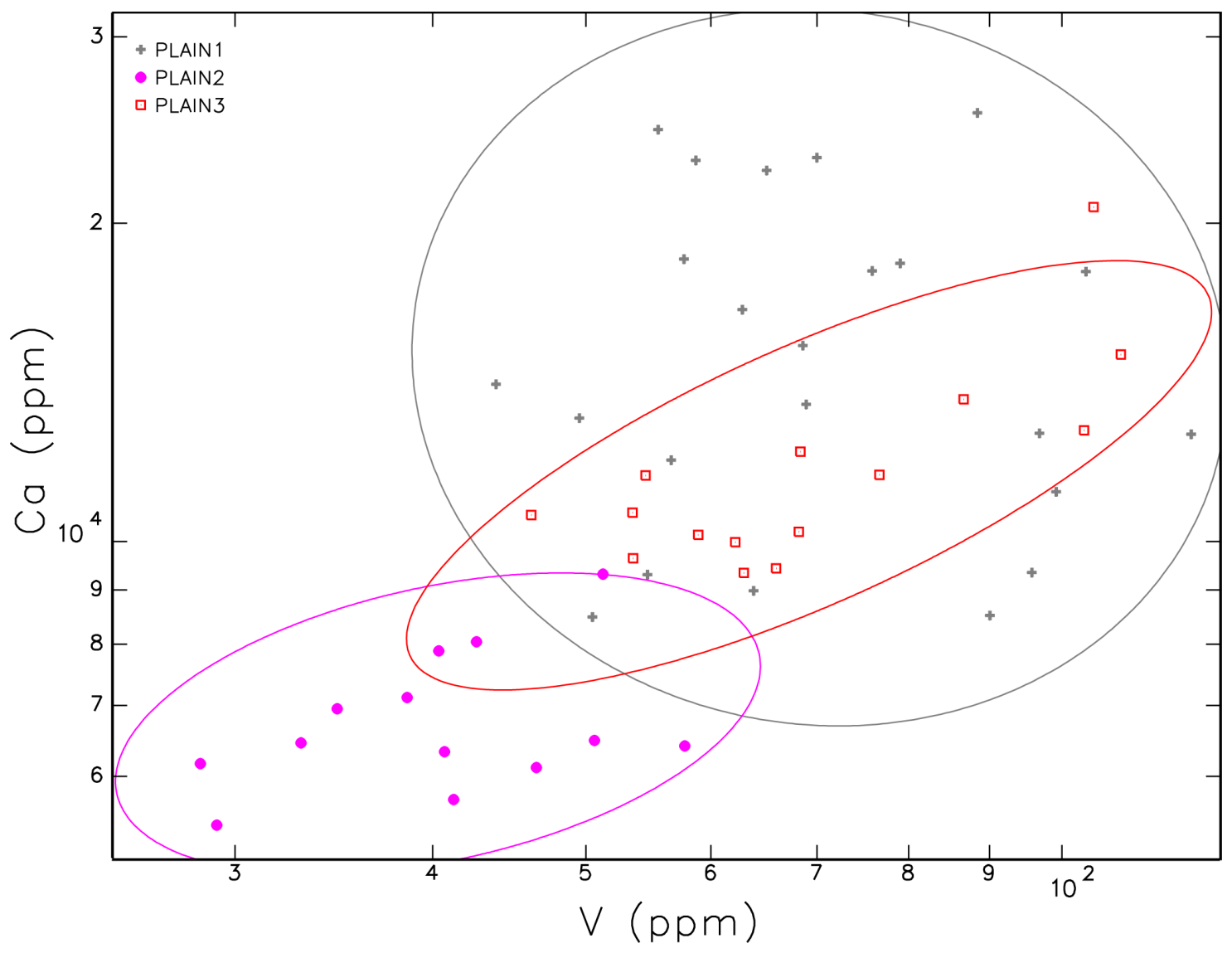

Figure 4.6 Scatterplot of vanadium and calcium with plainware groups 1-3. Group P2 contains the least amount of calcium when compared to groups P1 and P3. Ellipses represent a $90 \%$ confidence interval. 


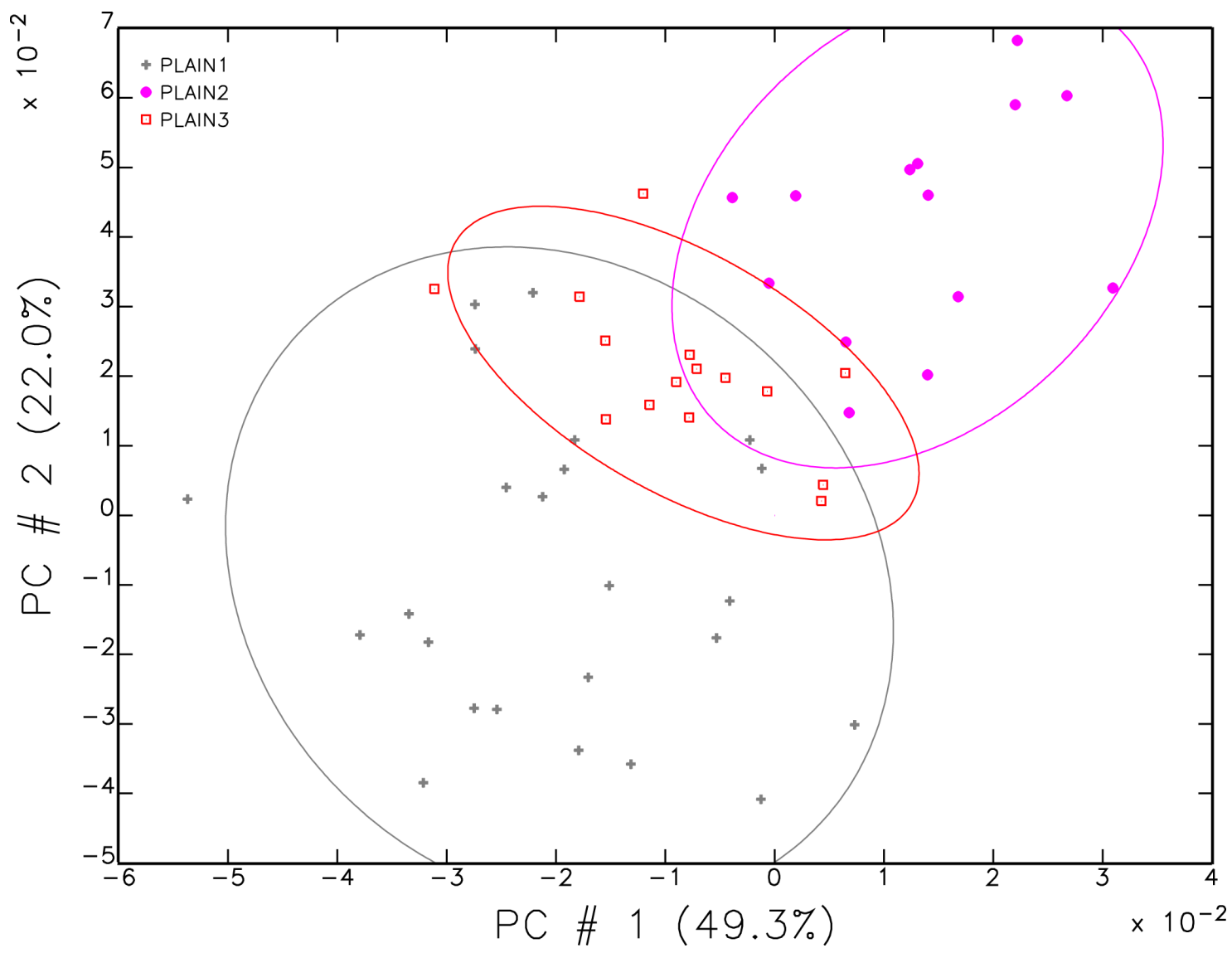

Figure 4.7 Principal components scatterplot of plainware groups 1-3. The variation in Principal Component 1 is driven by calcium, vanadium, chromium and cobalt. Principal Component 2 is driven by variation in neodymium and europium.

Group P2. Fourteen plainware sherds made up this group. Four sherds, all El Paso Brownware, were recovered at 76 Draw. The remaining 10 were from Black Mountain and were assigned by Putsavage (2015) to her PR2 group. PR2 contains a large proportion of Black Mountain phase types such as Playas Red and El Paso Polychrome, and Putsavage suggested that these vessels were likely made in the Upper/Middle Mimbres Valley. With her conclusions about the locus of production, it would appear that at least some plainware vessels from this area were being transported to 76 Draw. 
Group P3. This compositional group contained 9 plainware sherds from 76 Draw (8 are Casas Grandes Plainware and 1 El Paso Brownware) and 6 from Black Mountain. Two of the Black Mountain sherds were assigned by Putsavage (2015) to her Group PR2 that may be from the Upper/Middle Mimbres Valley. The other four were not assigned by her to any group. Here, Group P3 contained the most plainware specimens from 76 Draw, but not by a large number. There are insufficient data at this time to narrow the production location from the Mimbres Valley, though Creel et al. (2002) and Taliaferro (2014) suggested it may be at or near Old Town.

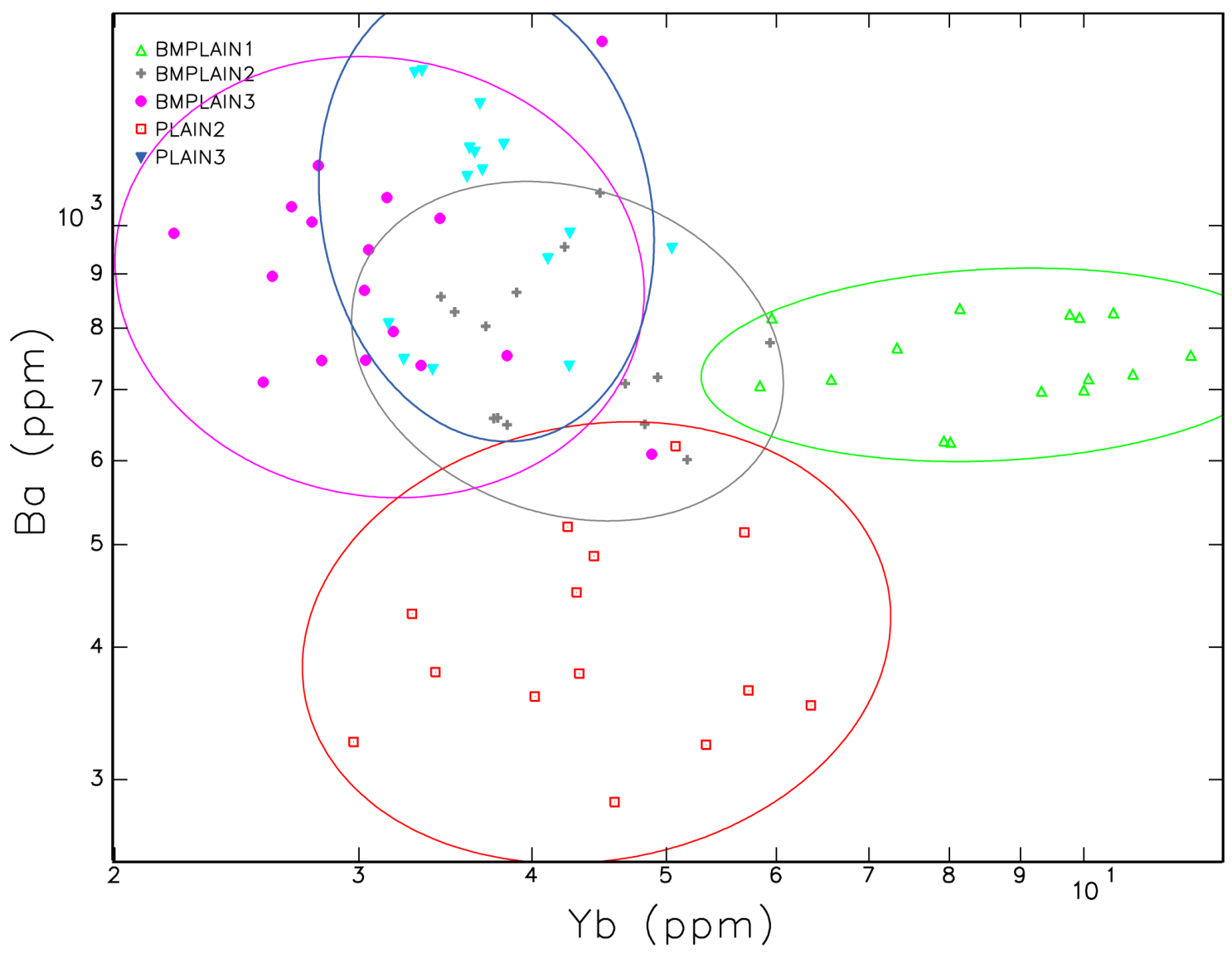

Figure 4.8 Scatterplot of ytterbium and barium with groups BMP1-3 and P2-3. Group $\mathrm{P} 2$ has the least amount of barium when compared to the other groups. BMP1 has more ytterbium than the other groups. 


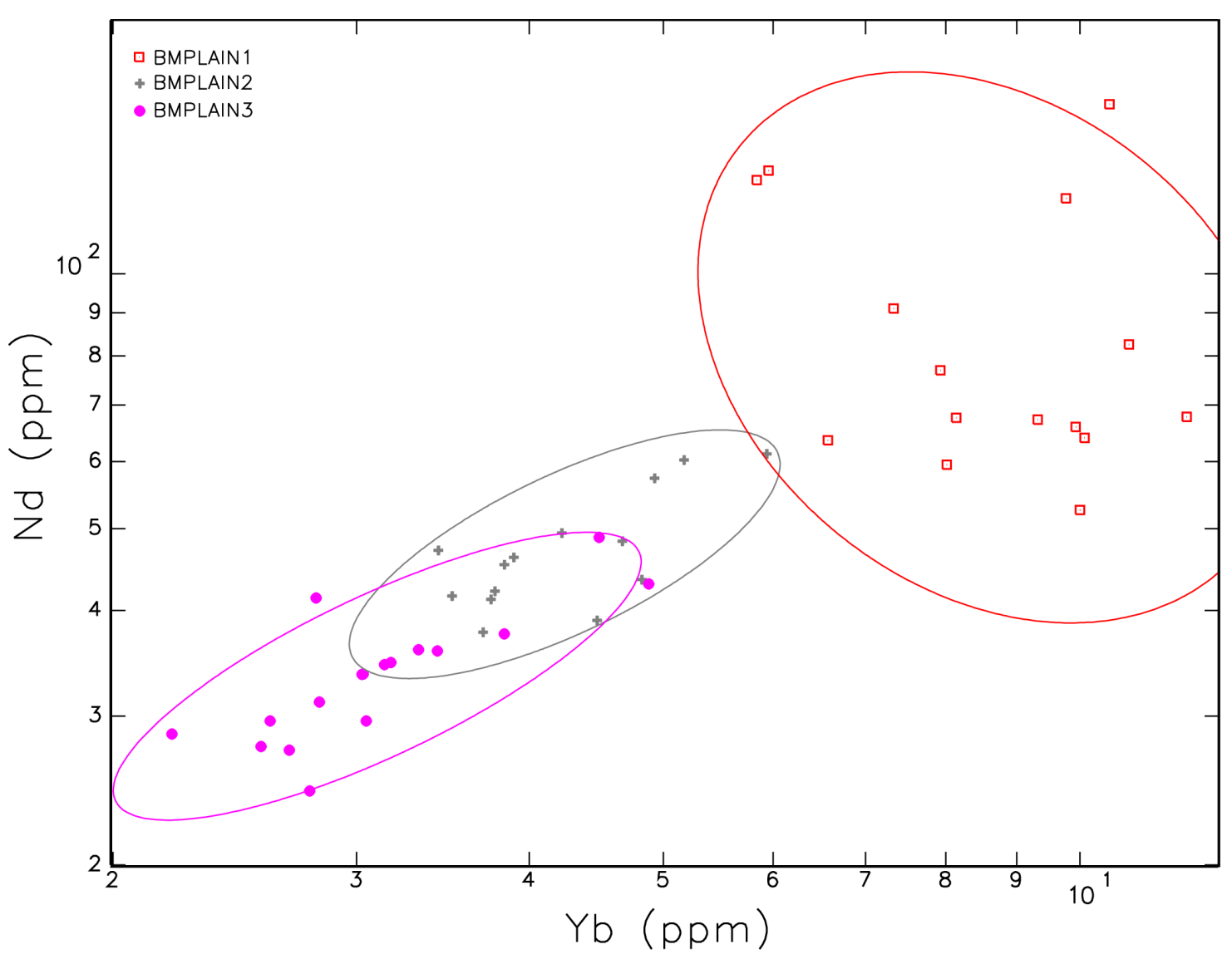

Figure 4.9 Scatterplot of ytterbium and neodymium with groups BMP1-3. The most ytterbium is found in BMP1, and BMP3 has the least amount of neodymium.

When I compared the 76 Draw samples to the Black Mountain samples, I found there were three groups (BMP1-3) defined in the dataset containing only sherds from Black Mountain (Figure 4.8 and alone in 4.9). Neither she nor I differentiated the plainware types before completing NAA, and that could be part of what is causing the differences; there may have been more plainware types at Black Mountain, or the site had pottery from at least three locations that were not present at 76 Draw. 
Group BMP1. This group of 15 plainware sherds, all of which were collected from Black Mountain, corresponded to Putsavage's G3 group. Eighty-seven percent of the sherds assigned to Group G3 were plainwares, and 13\% were Playas Red. Putsavage suggested that these vessels, the plainwares, and the Playas Red, may have been made at or near Black Mountain (Putsavage 2018:210).

Group BMP2. These 14 specimens from Black Mountain came from two of Putsavage's groups, M5a and PR1. Eight additional specimen that she was unable to assign to a specific compositional group were also in this group. It is a tight compositional group as seen in Figure 4.10, but others have separated it (Creel et al. 2002; Taliaferro 2014) and their analysis suggested production locations in the Upper Gila Valley (M5a) and the Middle Mimbres Valley (PR1). BMP2 needs more investigation.

Group BMP3. Seventeen plainware sherds from Black Mountain make up this compositional group. Putsavage did not previously assign six of these to a compositional group but placed 11 sherds in Speakman's Group M49a. Here, these sherds were seen as distinct from Salado sherds assigned to Group G, which also had specimens in Group M49a (Putsavage 2015:209). These may be what Speakman was referring to when he stated that this M49a group might be split in the future into an Upper Mimbres group and a Middle/Lower Mimbres Valley group. Groups G and BMP3 might represent the split, but there is insufficient evidence here to securely support that possibility. 
Ten geochemical compositional groups were identified within the analyzed sample from seven sites. Three distinct geochemical groups were represented among the Ramos Polychrome, one group for Gila Polychrome, and six for plainware pottery. The polychrome types tended to be distinct from one another, suggesting that the vessels were made using different recipes, presumably at different places and/or by different artisans. There was more overlap among the polychromes and plainwares. This could reflect that some of the plainwares were being made using similar technological recipes at the same place and/or by the same artisans, or that some of the plainwares were actually plain sherds from the undecorated parts of polychrome vessels.

\section{Chemical Group Definitions}

- Group R1: This group had the most barium of the R groups, and the same amount of arsenic as R2.

- Group R2: This group had the least amount of barium of the R groups. It had the same amount of arsenic as R1, but less than R3.

- $\quad$ Group R3: This group had an intermediate amount of barium when compared to $\mathrm{R} 1$ and $\mathrm{R} 2$, and it had the most arsenic of the R groups.

- $\quad$ Group G: This group had more calcium than the other samples from 76 Draw.

- $\quad$ Group P1: This group had the most calcium of the P groups, and a wide range of vanadium.

- Group P2: This group had the least calcium, vanadium, and barium of the plainwares. 
- $\quad$ Group P3: This group had more calcium than P2, and the same range of vanadium as $\mathrm{P} 1$.

- $\quad$ Group BMP1: This group had the most ytterbium and neodymium of the BMP groups. It had about the same amount of barium as BMP2 \& BMP3.

- Group BMP2: This group had an intermediate amount of ytterbium and neodymium of the BMP groups. It had about the same amount of barium as BMP1 \& BMP3.

- $\quad$ Group BMP3: This group had the least ytterbium and neodymium of the BMP groups. It had about the same amount of barium as BMP1 \& BMP2, though its range is a bit wider.

Of the total 216 specimens that were analyzed, 30 (13.8\%) were not assigned to any compositional group. This unassigned rate was comparable to Triadan's (1997) earlier analysis of White Mountain Red Wares in Arizona at $18.6 \%$.

\section{Petrographic Analysis}

Petrographic analysis of the aplastics in ten sherds that were also analyzed by neutron activation was completed by David Hill (2010) to supplement the NAA. The sampling strategy I chose for the petrographic analysis at 76 Draw was to balance the number of polychrome and plainware sherds. The four Ramos Polychrome sherds all contained quartz and sanidine. Three of them also contained rhyolitic tuff, a felsic igneous rock made up of volcanic ash. The sample without tuff is in NAA Group R2, and 
the other three are in Groups R1 and R3 (Table 4.4). Three Gila Polychrome sherds all contained quartz, basalt, and tuff, although one sherd had a much lower volume of aplastics than the others. All of the Gila Polychrome sherds were in NAA Group G. The plainwares had different tempers. The two Casas Grandes Plainware sherds had quartz, sanidine, and tuff, but one had a more-glassy groundmass and the other's tuff was more vesicular (Hill 2010:6). The more-glassy inclusions occurred in NAA Group P3. The more vesicular sherd was in R3 with Ramos Polychrome sherds and could be a plain section of a polychrome vessel, or the plainware was made with the same clay as the polychromes. The last sherd for petrographic analysis was an El Paso Brownware sherd. It had quartz, feldspar, biotite and granite, and was in NAA Group P2 that included sherds with medium-sized tempers with brick-red paste or black unoxidized cores. 
Table 4.4 Petrographic Analysis of Minerals (adapted from Hill 2010) and NAA Group for each Sherd.

\begin{tabular}{|c|c|c|c|c|}
\hline ANID & Type & Temper & $\begin{array}{l}\text { Temper } \\
\text { group }\end{array}$ & $\begin{array}{l}\text { NAA } \\
\text { group }\end{array}$ \\
\hline CAS036 & Ramos Polychrome & $\begin{array}{l}\text { Quartz and sanidine, with a trace of } \\
\text { biotite. Rhyolitic tuff. }\end{array}$ & 1 & R3 \\
\hline CAS060 & Ramos Polychrome & $\begin{array}{l}\text { Quartz and sanidine, with a trace of } \\
\text { biotite. Rhyolitic tuff. }\end{array}$ & 1 & $\mathrm{R} 1$ \\
\hline CAS064 & Ramos Polychrome & $\begin{array}{l}\text { Quartz and sanidine, with a trace of } \\
\text { biotite. Rhyolitic tuff. }\end{array}$ & 1 & R1 \\
\hline CAS056 & Ramos Polychrome & Pumice, quartz, and sanidine. & 2 & $\mathrm{R} 2$ \\
\hline CAS069 & Gila Polychrome & Quartz, basalt, tuff. & 3 & G \\
\hline CAS090 & Gila Polychrome & Quartz, basalt, tuff. & 3 & G \\
\hline CAS091 & Gila Polychrome & $\begin{array}{l}\text { Quartz, basalt, tuff, but less than } \\
\text { the other Gilas: only } 15 \% \text { mineral } \\
\text { grains \& tuff. }\end{array}$ & 3 & G \\
\hline CASO04 & $\begin{array}{l}\text { Casas Grandes } \\
\text { Plainware }\end{array}$ & $\begin{array}{l}\text { Quartz and sanidine, tuff, plus very } \\
\text { fine glassy temper added. }\end{array}$ & 4 & P3 \\
\hline CASO26 & $\begin{array}{l}\text { Casas Grandes } \\
\text { Plainware }\end{array}$ & $\begin{array}{l}\text { Quartz and sanidine, tuff, with } \\
\text { fewer inclusions and is more } \\
\text { vesicular than the other CG } \\
\text { plainware sherd. }\end{array}$ & 5 & R3 \\
\hline CAS031 & El Paso Brownware & $\begin{array}{l}\text { Quartz, feldspar, biotite, and } \\
\text { granite. }\end{array}$ & 6 & P2 \\
\hline
\end{tabular}

The aplastics described in Ramos Polychrome sherds from 76 Draw can be compared with sherds of this type from another Animas Phase site, Joyce Well (Carpenter 2002), as well as Casas Grandes sites in Mexico (Britton 2018; Triadan et al. 2018). Carpenter's petrographic analysis of 21 sherds (14 Ramos Polychrome, 4 "Jornada Brownware" (that he later states are likely unpainted sherds from El Paso Polychrome vessels (2002:159)), and 3 El Paso Polychrome) found that all of the sherds had crushed or decomposed igneous temper. These sorted into seven temper groups. Five of the groups had latite or conglomerate sources for the temper, and are distinct from the analyzed sherds from 76 Draw. Groups 1 and 2 consisted of welded tuff, 
similar to samples from 76 Draw, and made up $62 \%$ of the samples analyzed from Joyce Well. In his study, Group 1 was solely Ramos Polychrome, and Group 2 contained all three types.

Triadan et al. (2018) completed petrographic analysis on 52 sherds and 22 clay samples in addition to their NAA analysis. Their sample included Ramos, Babícora, and Villa Ahumada Polychromes. They established that similar pastes were found over a wide area and that the clay used for the pottery appeared to have been collected from primary clay sources. Many traditional potters prefer secondary clay sources as they are finer and better sorted, have fewer nonplastic inclusions, and as a result are easier to work with (Triadan 1997:32-40) Triadan et al. (2018) and Rinaldo (1974) suggest that the primary clays were processed to remove inclusions, at which point crushed rhyolitic tuff was added. However, Triadan et al. (2018:160) cite one instance of a crushed quartz fragment. Again, three of the four Ramos Polychrome sherds (from NAA Groups R1 and R3) from 76 Draw had similar aplastics: rhyolitic tuff. The remaining sherd did not have the volcanic tuff and was part of NAA Group R2.

Britton (2018) examined 185 polychrome sherds using petrography from the Sayles Collection as well as sherds from Sites 204, 291, and 355 in Chihuahua. Three types were studied: Ramos, Babícora, and White-Paste Babícora Polychromes. Like the other studies summarized above, she found that igneous sources were preferred, and she narrowed it down to specifically felsic igneous sources. The clays were from a narrow range of raw materials and demonstrate a regional "cohesive knowledge network" of the potters (Britton 2018:129). She states that the potter's preference was 
for primary clays from igneous sources, and that these clays already had the appropriate aplastics in them. In her analysis, and contrary to Triadan et al.'s (2018) suggestion, she concluded that potters were not significantly modifying the clays by adding tempering materials or mixing clays. She made this argument based on the uniformity of the chemical and physical weathering of the various aplastics in the paste (Britton 2018:105). Britton reminded us that weathering may smooth some fragments, and human rock crushing makes angular fragments, but an introduction of recent sediments into a clay may also explain angular shapes (2018:100). She defined six aplastics groups in her sample, all of which had felsic igneous aplastics that reflected six distinct sources. Babícora Polychrome was in all six groups, Ramos was present in five of the groups (Britton's Groups 1-5), and White-Paste Babícora sherds were in Groups 1 through 4. The 76 Draw Ramos Polychromes in my NAA Groups R1 and R3 fit the general structure of the groups Britton (2018) discussed, whereas Group R2 did not.

To summarize, the Ramos Polychrome sherds from 76 Draw that were analyzed using petrographic analysis were similar to those from Joyce Well as well as sherds from sites in Mexico in that they had igneous aplastics. Britton (2018) and Triadan et al. (2018) both concluded that potters preferred primary clays for Chihuahuan polychromes that had rhyolitic aplastics in them, and Britton supported her claim that the potters did not add temper because the majority of sherds have weathered tuff that were already in the primary clays. Similar aplastics were reflected in Ramos sherds from 76 Draw (Hill 2010), even though one of the sources defined here (R2) did not appear in Britton's (2018) and Triadan et al.'s (2018) groupings. The majority of the groups contained 
igneous aplastics, and this consistency further bolsters Britton's (2018) suggestion there was a wide-spread pottery making tradition shared throughout the Casas Grandes region, even though some pottery (e.g., Group R2) did not contain the rhyolitic aplastics.

Interpreting NAA and Petrography Results

I organized the following discussion by ceramic type.

Ramos. The three Ramos Polychrome NAA groups (R1, R2, R3) I defined herein demonstrated that vessels of this type were being made in more than one location. Two of these geochemical sources (Groups R1 and R2) were probably in southern New Mexico, or northern Mexico, perhaps even in the 76 Draw area (R1). Group R3 perhaps reflected a source from the Casas Grandes heartland around Paquimé. Woosley and Olinger (1993) previously reported multiple production locations after using XRF on sherds from Chihuahua, Arizona, and the Culberson site in New Mexico. Triadan et al. (2018) and Britton (2018) recently suggested multiple production locations using NAA on sherds from Chihuahua. Bottom line, the NAA and petrographic analysis demonstrated once again that some Ramos Polychrome in the Greater Southwest moved considerable distances. If R1 and R2 were produced in southern New Mexico, then at least one vessel from 41EP8 and one from 41EP1672 were found many kilometers away in El Paso County, Texas. Ten sherds from 76 Draw were in the R3 group, along with one each from Black Mountain and LA26788, and this group was likely made near Paquimé. If so, this Ramos Polychrome was transported over 140 km or more to get to 76 Draw. 
More Chihuahuan polychrome vessel types should be analyzed from southern New Mexico to see if they were also made with any of the three geochemical sources identified with Ramos Polychrome. Triadan et al. (2018) found that the three most abundant Chihuahuan polychromes-Ramos, Babícora, and Villa Ahumada-were likely created at multiple production locations in the Casas Grandes region, and Britton (2018) found the same trend with Ramos, Babícora, and White-Paste Babícora Polychromes from Chihuahua. Likewise, Groups R2 and R3 defined in my analysis correspond to Putsavage's Groups G2a and G2b at Black Mountain, which included multiple Chihuahuan polychrome types such as Ramos, Babícora, Villa Ahumada, Carretas, and Dublan.

The petrographic analysis of Ramos Polychrome sherds from 76 Draw revealed two different tempers. NAA Groups R1 and R3 both had quartz, sanidine, biotite and rhyolitic tuff aplastics, whereas the sherd from Group R2 included pumice, quartz, and sanidine but no tuff. These three groups were distinct and were supported by both NAA and petrography data. Triadan found the polychromes at Paquimé and surrounding areas contained rhyolitic aplastics, like two of the groups found at 76 Draw. Three groups of Ramos Polychrome corresponded to three production sources, and were found at 76 Draw. Pottery from in or near the largest Casas Grandes site, Paquimé, traveled to 76 Draw. This indicates that the people of 76 Draw were part of the Casas Grandes interaction sphere and that they participated in the exchange of vessels with Casas Grandes designs as well as made their own. 
Gila. The single Gila (Salado) Polychrome NAA group, Group G, included all of the Gila Polychrome sherds from 76 Draw, as well as some plainware sherds, a Tonto Polychrome, and a Villa Ahumada Polychrome. This group also matched a large compositional group that was identified within the Mimbres Valley. This previously identified compositional group had pottery from 38 sites in the Mimbres Valley (Putsavage 2015:214; Speakman 2013). People at 76 Draw exchanged with members of this Salado polychrome-making site(s), which also supplied pottery to at least 38 other sites in the region. Analysis of more samples from the Mimbres Valley and surrounding area might help determine a more precise production location. Petrographic analysis of three Gila Polychrome sherds determined that they all contained quartz, basalt, and tuff, and all of these were available in the general area.

Gila Polychrome was made in many places across the Salado area, but only one of these sources was reflected at 76 Draw. It was also found at Black Mountain, and it could have been made in the Mimbres Valley. The majority of the sites in Crown's (1994:32) sample had Gila Polychrome from only one site, demonstrating that it was not unusual for a site to have Salado polychrome vessels from only one production location.

Plainware. Over half of the sherds (132 of the 216 samples) examined in this study were plainwares, and the NAA groups showed that plainwares were moving across the landscape. Plainwares have no paint, no slip, nor texturing (i.e. corrugation, scoring, incising). 
The two sites with plainwares analyzed here, 76 Draw and Black Mountain, are on the border of culture areas, and the plainwares were not differentiated prior to NAA. Group P1 contains samples from three sites in Luna County, and those sherds from 76 Draw were Casas Grandes Plainware. A few of the Black Mountain sherds in this group were thought to be from production locations in the Upper Gila and Upper Mimbres Valleys (Putsavage 2015). Future work to include more samples from more sites will help narrow down this area. Vessels represented in Group P2 likely were made in the Upper/Middle Mimbres Valley and the sherds from 76 Draw in this group were El Paso Brownware. The majority of the sherds in Group P3 are from 76 Draw-8 Casas Grandes Plainware and 1 El Paso Brownware-but the numbers were insufficient to confidently say where the vessels were made.

Three plainware groups-BMP1-3-contained sherds only from Black Mountain. BMP1, the same as Putsavage's G3 group, was found only at Black Mountain, and vessels represented in it might have been made in the Lower Mimbres Valley, at or near the site. Fourteen sherds in the BMP2 group came from a mix of ceramic types (Putsavage 2015:Appendix C), which included several samples that were unassigned in previous studies; these groups may be subgroups from a larger group. BMP3 was a combination of unassigned sherds and group M49a from Putsavage's work. This M49a group's production was likely in the Mimbres Valley (Speakman 2013).

The plainware samples sent for petrographic analysis were typed. Petrography of the Casas Grandes Plainware sherds $(n=2)$ from 76 Draw showed them to contain 
quartz, sanidine, and tuff, similar to Ramos Polychrome. The single El Paso Brownware from 76 Draw had quartz, feldspar, biotite, and granite aplastics.

\section{Chapter Summary}

Chemical compositional analysis of samples from southern New Mexico and western Texas demonstrated differences in the same pottery types across the region. Neutron activation analysis defined three Ramos Polychrome groups; two may be made in Southern New Mexico (R1 and R2) and one in Chihuahua at or near Paquimé (R3). A single compositional group of Gila Polychrome from 76 Draw was made to the north in the Upper Mimbres Valley. The plainwares made up six geochemical groups from the region. Two groups may be from at or near 76 Draw (P1 and/or P3, both having the majority of the samples being Casas Grandes Plainware), but more investigation is needed. Group P2 may be from the Upper/Middle Mimbres Valley, and the sherds from 76 Draw in this group were El Paso Brownware. One group may be made at Black Mountain (BMP1 here; Putsavage defined it as group G3). BMP2 had insufficient information to narrow down a location, but BMP3 may be from the Mimbres Valley.

Petrographic analysis demonstrated similarity in many of the sherds from 76

Draw. The Ramos Polychrome sherds $(n=4)$ all contained quartz and sanidine, but three of them also had rhyolitic tuff while the last one contained pumice. The Gila Polychrome sherds all included quartz, basalt, and tuff aplastics, and all these sherds were in NAA Group G. The plainwares submitted for petrography were typed-two Casas Grandes Plainware and one El Paso Brownware. The Casas Grandes Plainware 
sherds had quartz, sanidine, and tuff; one had fewer inclusions and was more vesicular, and the other one had a fine glassy temper in addition to the other minerals. These are similar to the Ramos Polychromes, and in fact, the one with fine glassy temper is in NAA Group R3 that is a majority Ramos Polychrome group from the Paquimé area. The El Paso Brownware sherd had different aplastics-quartz, feldspar, biotite and granite; it is included in NAA Group P2 that came from the Upper/Middle Mimbres Valley.

Ten compositional groups were defined using NAA and six mineral groups were found using petrography. The following chapter places these results into their broader regional and anthropological context. 


\section{Chapter 5 Discussion}

The focus of this research has been to evaluate whether Ramos Polychrome (a Chihuahuan polychrome) and Gila Polychrome (a Salado polychrome) were made locally at 76 Draw, New Mexico, and whether any nonlocal pottery of these types was associated with known sources or geochemical groups. The answer to the first question will help clarify the nature of social interaction and cultural integration in the borderland area between the Medio Period Casas Grandes and Salado cultures. The answer to the second question will help clarify social relationships across the Casas Grandes and Animas regions of southern New Mexico and northern Chihuahua.

The Ramos Polychrome sherds used here were from seven sites in southern New Mexico and southwestern Texas. The NAA identified three Ramos Polychrome compositional groups that encompassed 47 samples from six sites (Figure 5.1). The sites are in Luna and Doña Ana counties New Mexico, and El Paso County, Texas. There are several unassigned samples, including the two Ramos Polychrome sherds from LA15062. The three groups represent three clay compositions and thus probably reflect three production locations. Groups R1 and/or R2 were likely made at or near 76 Draw.

Petrography defined two different aplastics in Ramos Polychrome at 76 Draw (Hill 2010): one with quartz, sanidine, biotite and rhyolitic tuff (NAA Groups R1 and R3) and one sherd with pumice, quartz, and sanidine (no tuff; NAA Group R2). Triadan et al. (2018) and Britton (2018) used petrographic analysis on several of their samples from Mexico, finding that rhyolitic tuff, a felsic igneous rock, was the common aplastic. 76 Draw Ramos Polychrome also has this type of aplastic. The clays used in these vessels 
was likely from the smectite family, which includes montmorillonite and bentonite. These clays by definition were produced from weathering volcanic materials such volcanic ash.

Although I do not have Triadan et al.'s (2018:156-157) data, I was able to compare my Ramos Polychrome NAA results with those from south of the border using the four scatterplots in their article. My Group R3 fit within their Core Group 2 (plots: Fe \& Eu; La \& Cr; La \& Fe; La \& Hf; see Appendix D). Triadan et al.'s Core Group 2 included sherds found at Paquimé and four large sites nearby, as well from sites at the periphery of the ceramic distribution zone (Triadan et al. 2018:148). Triadan et al.'s Core Group 2 also contained all three types of polychromes they tested: Ramos, Villa Ahumada, and Babícora. Thus, Ramos Polychrome did not have a special paste recipe in comparison to the other Chihuahuan polychromes, at least at this production location. The match of R3 within Core Group 2 suggested the pottery trade network circulated $150 \mathrm{~km}$ north to 76 Draw from Paquimé. Triadan and colleagues (2018) remind us to keep in mind that samples from sites represent where pottery was consumed, and not necessarily where they were produced. Nonetheless, this pottery circulated over a large area. I have not tied any compositional group to a physical clay source, but some interpretations can be made based on the geochemical and petrographic groups.

Ramos Polychrome was found over a large area of the international four corners, and the religious iconography on some of the pottery demonstrated the extent of the religious system. Paquimé was the center of this integrated area, and many people may have visited it during pilgrimages (Fish and Fish 1999; VanPool and VanPool 2018). The 
presence of this religiously significant pottery type that may have been carried over a distance of $150 \mathrm{~km}$ suggests the people of 76 Draw were a part of the Casas Grandes religious system.

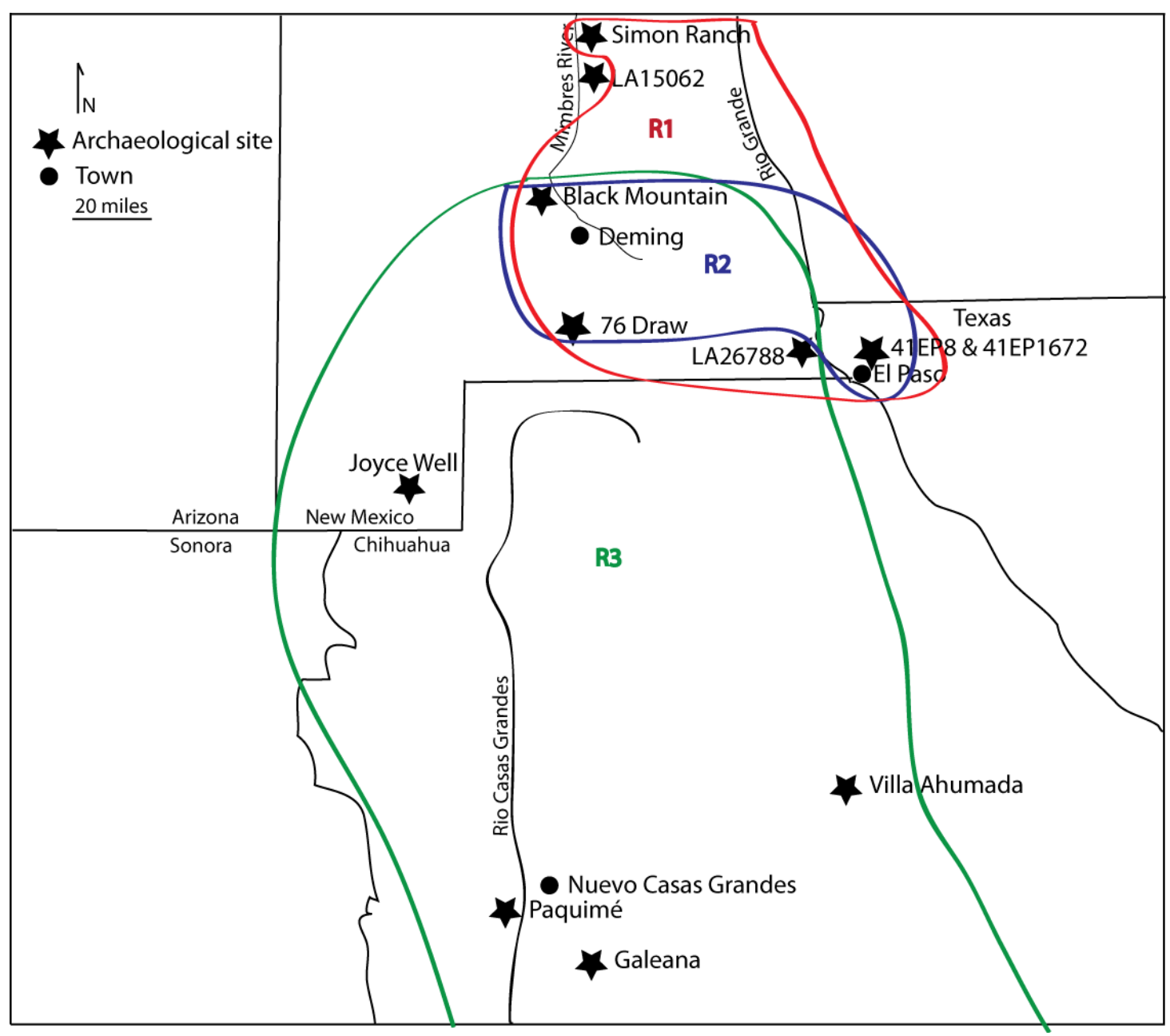

Figure 5.1 Ramos Polychrome group distribution areas.

The Gila Polychrome pottery samples form a single, tight compositional group that includes every Gila sherd sampled from 76 Draw (Figure 5.2 ). This was only a sample of the Gila Polychrome sherds at 76 Draw, but the fact that all 36 of them are in this group indicated that they came from one primary source. Three Black Mountain 
plainware sherds were also in this group. This pottery $(n=3)$ falls into Speakman's M49a group, vessels in which might have been made in the Upper Mimbres Valley, although there may have been a second production location in the Lower Mimbres (Putsavage 2015; Speakman 2013). Putsavage had other types of pottery from Black Mountain match this M49a group, including other Salado polychromes, Playas Red, 2 Chihuahuan types (Ramos Black and Madera Black-on-Red), 1 El Paso Polychrome, and corrugated, for a total of 77 sherds. Speakman (2013) also found that the entire Mimbres sequence of pottery was made from this source, though we do not know the exact location of the clay source. This source was used for over 300 years, demonstrating continued knowledge of it. Black Mountain is $40 \mathrm{~km}$ north of 76 Draw, and it seems likely that any Gila Polychrome pottery from 76 Draw came from the upper Mimbres Valley and could have come through Black Mountain or a nearby settlement. 


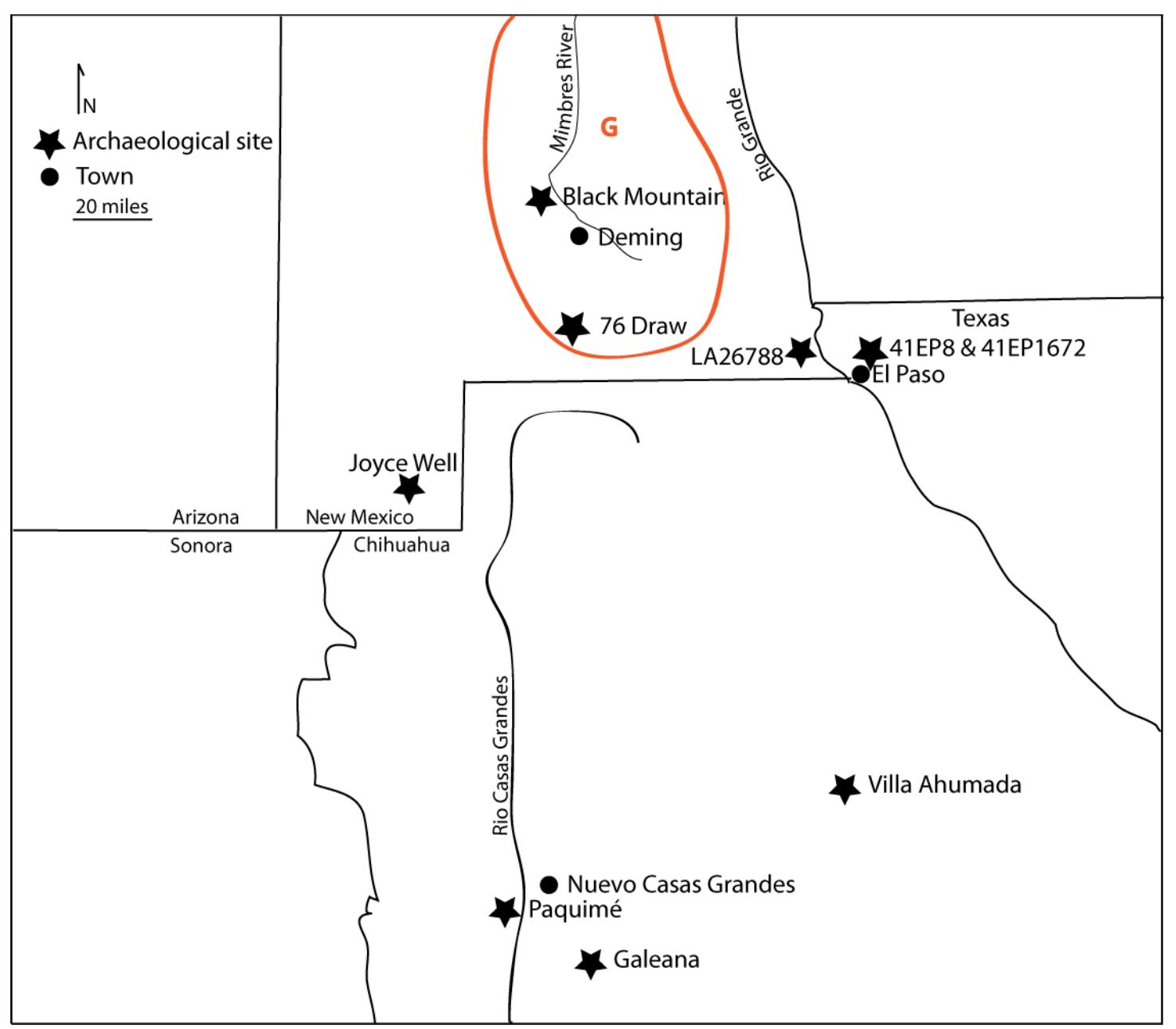

Figure 5.2 Group G (Gila Polychrome) distribution area.

Plainwares were included in my analysis to help determine locally produced pottery based on the assumption that undecorated pottery were not as commonly traded as decorated pottery. Peeples found that the undecorated wares in the Cibola world did not move as much as decorated wares (2011:137-138). However, plainwares were indeed moving; sherds from three different compositional groups may reflect different production areas as represented in the 31 plainware sherd samples analyzed from 76 Draw. Group P1 represents 20 sherds from Black Mountain, one from Simon Ranch (also in Luna County), and two from 76 Draw. However, with only two sherds 
from 76 Draw in this group, it seems unlikely that they were produced locally. The other plainware groups were P2, which includes plainware sherds from 76 Draw (all El Paso Brownware) and 10 from Black Mountain, and P3, which contains 9 sherds from 76 Draw (8 Casas Grandes Plainware and 1 El Paso Brownware) and 6 from Black Mountain. Based on the criterion of abundance, if there was a local plainware group from 76 Draw, it would be P3, but the numbers are too low for sufficient determination. There were also three other plainware groups that only contained sherds from Black Mountain. BMP1 (Putsavage's Group G3) may have been made at Black Mountain. Another group, BMP2, was a broad category of Upper and Middle Mimbres Valley specimen (Putsavage 2015:214) defined by Speakman (2013), M49a. Here, I have defined two groups (Groups G and BMP2) that contained sherds previously grouped in M49a by Putsavage, and this might help split M49a into two subgroups, as Speakman proposed.

\section{Conclusions}

My analysis indicated the presence of three distinct clay sources, possibly corresponding to three different geographic sources and/or groups of potters manufacturing the Ramos Polychrome found at 76 Draw, and indeed across the adjoining region of southern New Mexico. Based on the volcanic tuff aplastics and the correspondence to one of Triadan et al.'s (2018) identified sources, one of these groups might reflect pottery manufactured at or close to Paquimé. Based on this dataset, Ramos Polychrome from Groups R1 and/or R2 may be made at or near 76 Draw, though it is a small sample and needs more data. In contrast, $100 \%$ of the Gila Polychrome 
correspond to a single source, which is likely to the north in the Mimbres Valley. This clay source was also used for many types of pottery over hundreds of years demonstrating continued knowledge. Plainwares manufactured elsewhere were also being brought into 76 Draw. In fact, I cannot ascertain for certain if any of the plainware groups were locally made, although I suspect P3 (the most abundant group at 76 Draw) may have been.

Returning to the two questions at the beginning of the chapter, I have found that there may be local production of Ramos at 76 Draw, but not of Gila. The potential local production at 76 Draw of the symbolically charged Ramos Polychrome might reflect a close cultural affiliation with the Medio Period religious system-a proposition further strengthened by the presence of Ramos Polychrome that may have been brought in from the Paquimé heartland. Krug (2018) suggested that a system of pilgrimage may help explain the concentration of shell at Paquimé, and VanPool and VanPool (2018) suggested that Ramos Polychrome may be a religiously significant token distributed by the Paquimé elites across the region. Mixed with the evidence for the collection of obsidian while traveling to Paquimé or at least settlements to the south (VanPool et al. 2013), I suggest that the Medio Period religious system was central to the lives of those living at 76 Draw (and at other Animas Phase settlements such as Joyce Well [Skibo et al. 2002]), with at least periodic travel (perhaps as part of pilgrimages) to the Paquimé heartland, but also the local production of religiously significant pottery. In contrast, the Gila Polychrome and plainware pottery corresponding to the Mimbres Valley M49a compositional group demonstrated the people at 76 Draw had significant relationships 
with others within the region, including their neighbors to the north. Given the amount of pottery movement, relationships appear to have been friendly based also on no significant defensive works, and may have been especially close with those living at or near Black Mountain, about $40 \mathrm{~km}$ to the north. Black Mountain would be a natural location to funnel the Gila Polychrome and plainware pottery from the north to 76 Draw. Further, there are similarities between the sites; Black Mountain has adobe architecture, many types of pottery including the polychromes, and is using the southern obsidian sources.

This research demonstrates that 76 Draw was part of the exchange network of Ramos Polychrome that included Paquimé, though we know the location of the consumption of the pottery, and not the physical clay sources. This pottery type moved all over (Britton 2018; Carpenter 2002; Triadan et al. 2018; Woosley and Olinger 1993) and was part of a social network that included the Animas Phase and Medio Period sites. Though 76 Draw was considered by some to be in the outer zone of the Casas Grandes interaction sphere and thus only peripherally involved (Whalen and Minnis 1999), it was fully integrated in the religious system based on the iconography on the Ramos Polychrome, architecture, and obsidian sources.

76 Draw is on the border of the Casas Grandes and Salado regions, as well as the Jornada Mogollon. Though it has a high percentage of polychrome sherds on the site from the Casas Grandes and Salado areas (35\% and $21 \%$ of the painted wares respectively), it was likely a part of the Casas Grandes interaction sphere as reflected by its architecture (wall with drop key construction), the collection and use of obsidian, and 
the exchange of pottery. Yet, like Paquimé, the site also possesses Salado polychrome pottery, demonstrating that its inhabitants interacted with people following culturally distinct traditions. This interaction included the exchange of substantial numbers of pottery vessels, likely manufactured in the Upper Mimbres region, and obsidian from the Antelope Creek and Sierra Fresnal sources (VanPool et al. 2013). The borderlands between the Salado and Medio Period Casas Grandes people thus appear to have been a flexible zone in which distinct cultural traditions were maintained but exchange of even religiously symbolic items such as Ramos Polychrome was common.

\section{Future Work}

There is much to do in the future. To begin with, I would like to complete NAA and petrographic analysis of two additional Chihuahuan polychrome types, Babícora and Villa Ahumada. 76 Draw did not have as many sherds of these two types, but by adding them as well as other Chihuahuan polychromes north of the border, we will get a better picture of their production location and/or how many different clay sources may have been used. I would also like to compare these data along with a more robust NAA sample from sites north of the border, including Joyce Well, Culberson, and Timberlake, to data and groups from Mexico. Doing so will allow us to learn more about how much pottery is traveling north of the border and where it is going.

Compositional and petrographic analysis of Salado polychromes south of the border will also provide useful insights. Salado polychromes were found deep into northern Chihuahua. If most or even all of this corresponds to only the Mimbres Valley 
M49a group, then it seems likely that much of it was being funneled through 76 Draw and nearby sites. However, if other Salado polychromes were being made locally in Chihuahua and/or correspond to different sources, especially sources in Arizona or the western most edge of New Mexico, then there were likely multiple points of contact among the Salado and Casas Grandes people, and perhaps cultural intermingling. I would like to analyze the paint on the Salado and Casas Grandes polychromes. We found that paint recipes (minerals) corresponded with Salado polychrome types (Sall et al. 2005), and I would like to see if they may also correspond to the NAA groups defined here as well.

Finally, additional survey is needed to see how many more Animas Phase and Black Mountain Phase sites can be identified in New Mexico and to collect a large sample of Chihuahuan and Salado polychromes for comparison. With more site data we might be able decipher if Black Mountain and Animas Phases were the same or different (Carpenter 2002; Putsavage 2015) or if they have the same features but were just located in different geographic areas. El Paso Polychrome was also found at many of the sites in Southern New Mexico and throughout Chihuahua. Adding samples of this type, as well as Jornada Mogollon types, would provide more information about interaction to the eastern side of the state. More site information and NAA data will allow us to see regional variation and degree of interaction more clearly. 


\section{Appendix A}

Cluster Analysis of dataset (216 samples).

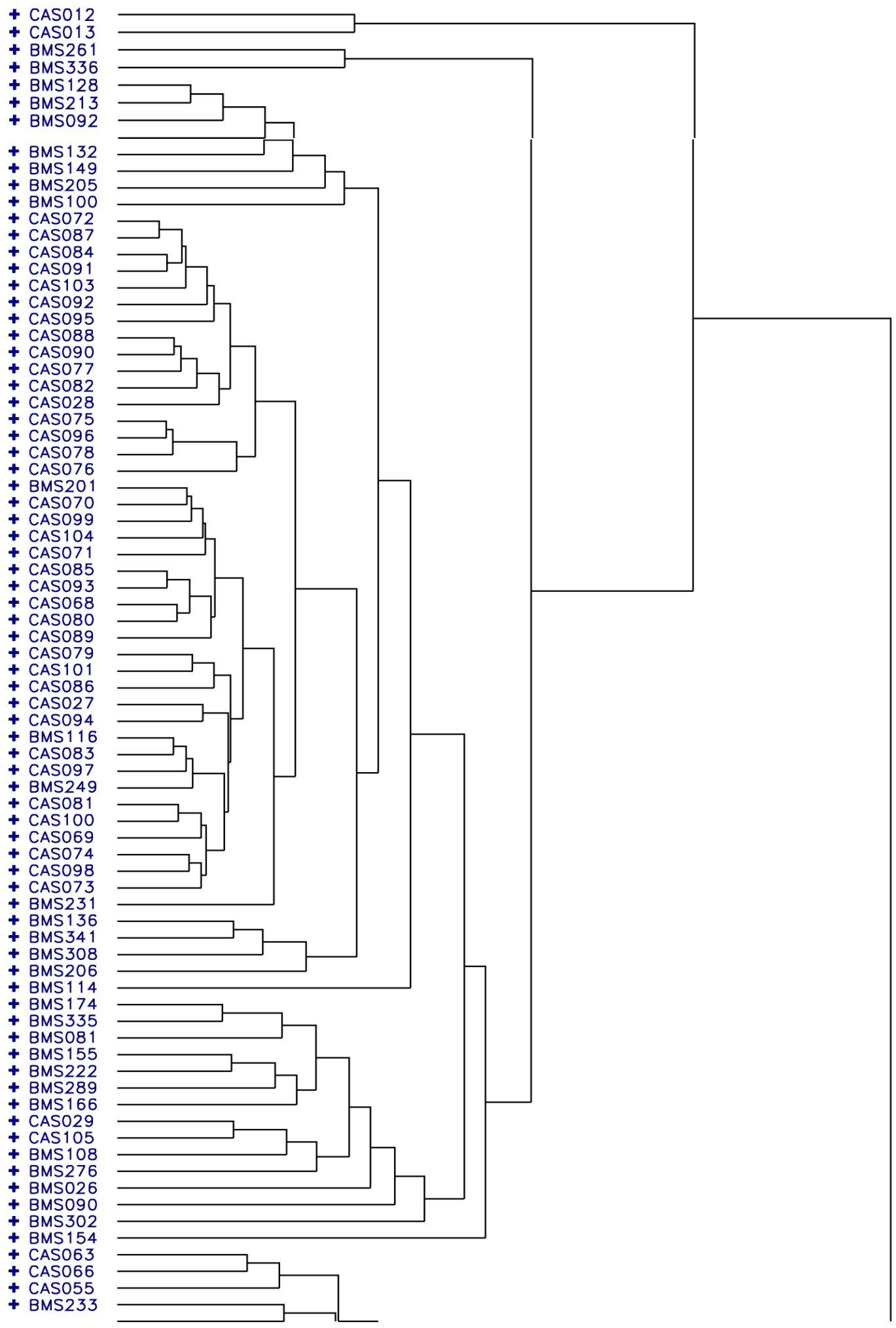




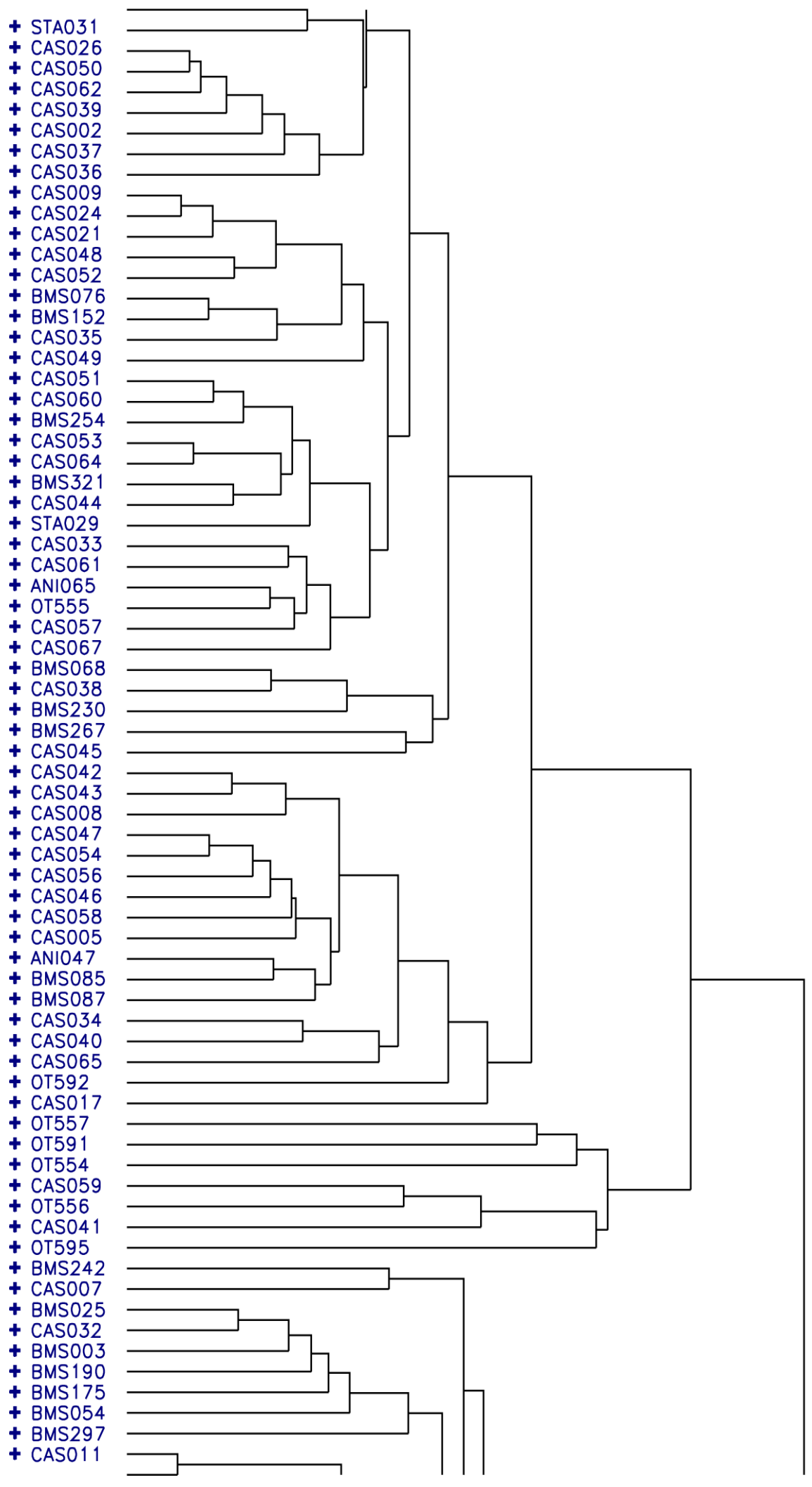




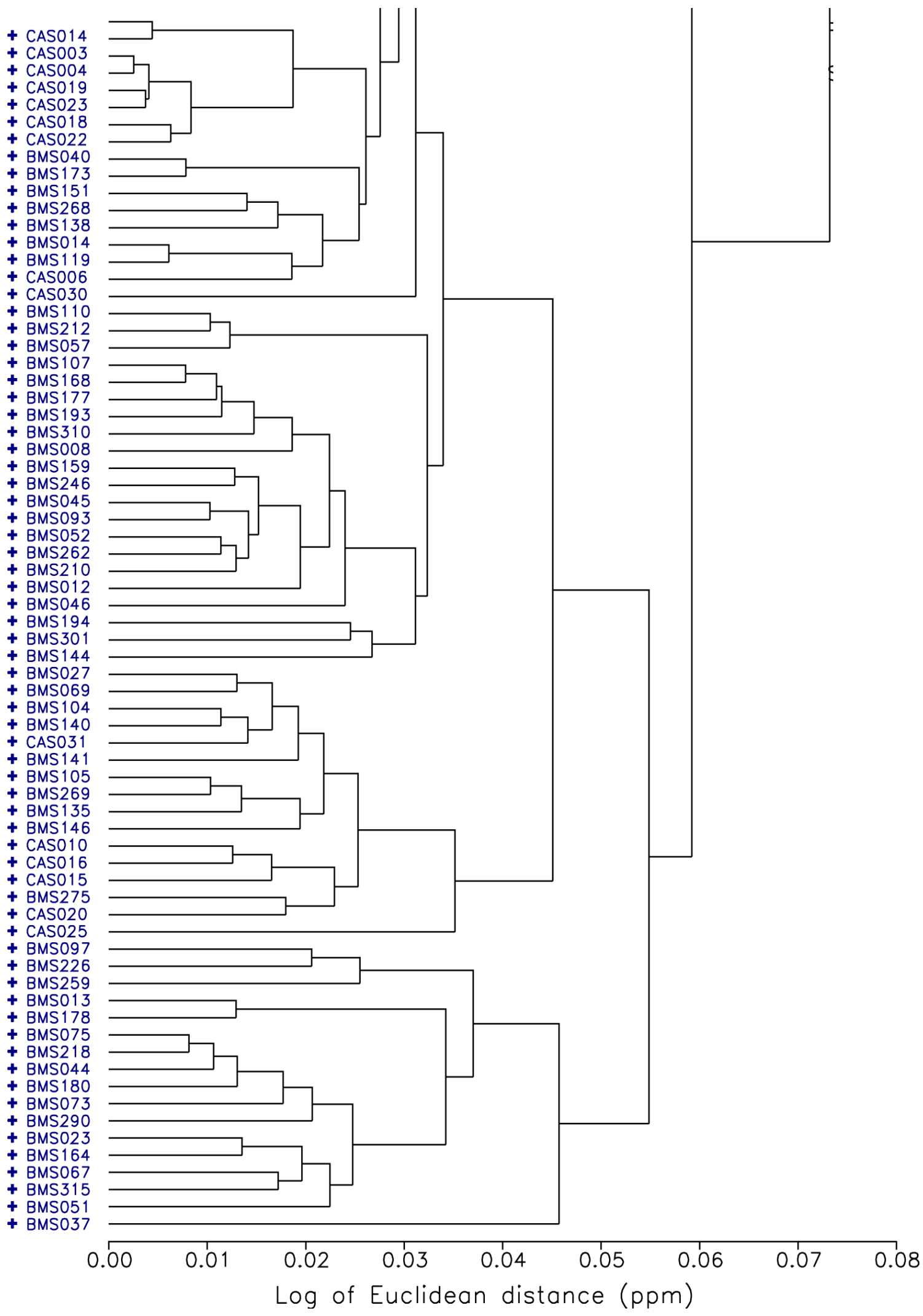


Appendix B

Mahalanobis Distances for NAA groups using the first eight principal components.

\begin{tabular}{|c|c|c|c|c|c|}
\hline ANID & Gila & Ramos2 & Ramos3 & Ramos1 & Best Group \\
\hline --------- & -------- & -------- & -------- & -------- & ---------- \\
\hline BMS116 & 73.318 & 4.559 & 5.389 & 0 & Gila \\
\hline BMS201 & 58.859 & 4.517 & 6.831 & 0 & Gila \\
\hline BMS249 & 55.833 & 4.413 & 6.855 & 0 & Gila \\
\hline CASO27 & 34.335 & 5.716 & 4.256 & 0 & Gila \\
\hline CASO28 & 61.888 & 4.738 & 3.836 & 0 & Gila \\
\hline CAS068 & 66.793 & 5.07 & 7.415 & 0 & Gila \\
\hline CAS069 & 75.101 & 5.058 & 3.928 & 0 & Gila \\
\hline CASO70 & 93.277 & 4.997 & 6.809 & 0 & Gila \\
\hline CAS071 & 60.337 & 5.731 & 5.76 & 0 & Gila \\
\hline CASO72 & 97.236 & 4.939 & 4.25 & 0 & Gila \\
\hline CAS073 & 72.459 & 5.115 & 4.185 & 0 & Gila \\
\hline CASO74 & 80.638 & 5.031 & 5.935 & 0 & Gila \\
\hline CAS075 & 66.319 & 3.746 & 6.642 & 0 & Gila \\
\hline CAS076 & 15.951 & 3.456 & 3.852 & 0 & Gila \\
\hline CASO77 & 76.779 & 4.251 & 5.389 & 0 & Gila \\
\hline CAS078 & 71.816 & 3.695 & 7.32 & 0 & Gila \\
\hline CAS079 & 73.89 & 4.687 & 4.597 & 0 & Gila \\
\hline CASO80 & 47.493 & 4.745 & 7.742 & 0 & Gila \\
\hline CAS081 & 63.553 & 5.424 & 5.376 & 0 & Gila \\
\hline CAS082 & 61.264 & 4.62 & 6.113 & 0 & Gila \\
\hline CAS083 & 85.809 & 4.949 & 4.165 & 0 & Gila \\
\hline CASO84 & 50.711 & 4.359 & 5.88 & 0 & Gila \\
\hline CAS085 & 97.44 & 4.489 & 5.913 & 0 & Gila \\
\hline CAS086 & 36.61 & 6.038 & 6.127 & 0 & Gila \\
\hline CAS087 & 98.746 & 5.171 & 4.843 & 0 & Gila \\
\hline CAS088 & 76.058 & 4.136 & 5.519 & 0 & Gila \\
\hline CAS089 & 47.895 & 5.826 & 5.136 & 0 & Gila \\
\hline CAS090 & 58.855 & 4.109 & 4.285 & 0 & Gila \\
\hline CAS091 & 99.254 & 4.6 & 5.271 & 0 & Gila \\
\hline CASO92 & 40.153 & 4.93 & 3.436 & 0 & Gila \\
\hline CASO93 & 97.389 & 4.725 & 6.716 & 0 & Gila \\
\hline CAS094 & 51.587 & 5.411 & 5.554 & 0 & Gila \\
\hline CAS095 & 30.177 & 4.098 & 4.227 & 0 & Gila \\
\hline CAS096 & 76.886 & 3.765 & 7.723 & 0 & Gila \\
\hline CAS097 & 80.109 & 4.396 & 4.281 & 0 & Gila \\
\hline CAS098 & 97.901 & 4.05 & 5.172 & 0 & Gila \\
\hline
\end{tabular}




\begin{tabular}{|c|c|c|c|c|c|}
\hline CASO99 & 88.385 & 4.984 & 4.863 & 0 & Gila \\
\hline CAS100 & 87.025 & 4.614 & 5.43 & 0 & Gila \\
\hline CAS101 & 59.817 & 4.718 & 7.939 & 0 & Gila \\
\hline CAS103 & 74.962 & 4.52 & 4.11 & 0 & Gila \\
\hline CAS104 & 33.473 & 4.96 & 6.064 & 0 & Gila \\
\hline --------- & -------- & -------- & -------- & -------- & --------- \\
\hline ANID & Gila & Ramos2 & Ramos3 & Ramos1 & Best Group \\
\hline --------- & -------- & -------- & -------- & -------- & --------- \\
\hline ANI065 & 0 & 19.986 & 22.198 & 61.028 & Ramos1 \\
\hline BMS076 & 0 & 15.457 & 18.625 & 94.714 & Ramos1 \\
\hline BMS152 & 0 & 17.303 & 25.889 & 87.293 & Ramos1 \\
\hline BMS254 & 0 & 18.376 & 21.214 & 97.872 & Ramos1 \\
\hline BMS321 & 0 & 18.763 & 66.177 & 71.814 & Ramos1 \\
\hline CASO09 & 0 & 5.832 & 21.218 & 93.213 & Ramos1 \\
\hline CAS021 & 0 & 4.236 & 17.355 & 85.08 & Ramos1 \\
\hline CASO24 & 0 & 6.642 & 24.252 & 94.465 & Ramos1 \\
\hline CASO33 & 0 & 12.46 & 25.062 & 58.7 & Ramos1 \\
\hline CAS035 & 0 & 9.093 & 28.386 & 84.864 & Ramos1 \\
\hline CASO44 & 0 & 24.055 & 68.459 & 88.885 & Ramos1 \\
\hline CASO48 & 0 & 9.654 & 12.695 & 86.109 & Ramos1 \\
\hline CASO49 & 0 & 9.765 & 35.873 & 71.299 & Ramos1 \\
\hline CAS051 & 0 & 12.652 & 33.902 & 91.566 & Ramos1 \\
\hline CAS052 & 0 & 7.796 & 46.546 & 88.43 & Ramos1 \\
\hline CASO53 & 0 & 28.053 & 50.525 & 91.659 & Ramos1 \\
\hline CAS057 & 0 & 23.137 & 5.483 & 75.868 & Ramos1 \\
\hline CASO60 & 0 & 15.454 & 36.887 & 97.664 & Ramos1 \\
\hline CAS061 & 0 & 38.395 & 20.71 & 70.585 & Ramos1 \\
\hline CASO64 & 0 & 25.276 & 48.489 & 90.792 & Ramos1 \\
\hline CAS067 & 0 & 9.18 & 27.008 & 54.47 & Ramos1 \\
\hline OT555 & 0 & 23.329 & 9.527 & 69.476 & Ramos1 \\
\hline STA029 & 0 & 10.921 & 20.525 & 81.277 & Ramos1 \\
\hline --------- & -------- & -------- & -------- & |------- & ---------- \\
\hline BMS087 & 0 & 98.363 & 5.766 & 0.286 & Ramos2 \\
\hline CASO05 & 0 & 98.18 & 65.696 & 3.167 & Ramos2 \\
\hline CASO08 & 0 & 98.081 & 11.61 & 0.097 & Ramos2 \\
\hline CASO42 & 0 & 98.095 & 8.867 & 0.013 & Ramos2 \\
\hline CASO43 & 0 & 98.048 & 21.829 & 0.033 & Ramos2 \\
\hline CASO46 & 0 & 98.008 & 15.597 & 3.991 & Ramos2 \\
\hline CASO47 & 0 & 98.86 & 41.474 & 1.942 & Ramos2 \\
\hline
\end{tabular}




\begin{tabular}{|l|l|l|l|l|l|}
\hline CAS054 & 0 & 99.837 & 33.549 & 0.801 & Ramos2 \\
\hline CAS056 & 0 & 98.472 & 42.236 & 0.172 & Ramos2 \\
\hline CAS058 & 0 & 98.304 & 39.996 & 0.206 & Ramos2 \\
\hline
\end{tabular}

\begin{tabular}{|l|r|r|r|r|l|}
\hline ANID & Gila & \multicolumn{1}{|c|}{ Ramos2 } & \multicolumn{1}{c|}{ Ramos3 } & Ramos1 & Best Group \\
\hline-------- & ------- & ------- & ------- & ------- & --------- \\
\hline BMS233 & 0 & 18.867 & 98.074 & 1.015 & Ramos3 \\
\hline CAS002 & 0 & 39.042 & 98.009 & 14.242 & Ramos3 \\
\hline CAS026 & 0 & 27.445 & 99.611 & 6.351 & Ramos3 \\
\hline CAS036 & 0 & 6.678 & 98.103 & 5.592 & Ramos3 \\
\hline CAS037 & 0 & 16.884 & 97.978 & 12.478 & Ramos3 \\
\hline CAS039 & 0 & 31.473 & 98.13 & 1.937 & Ramos3 \\
\hline CAS050 & 0 & 19.767 & 99.001 & 5.901 & Ramos3 \\
\hline CAS055 & 0 & 20.344 & 98.157 & 14.288 & Ramos3 \\
\hline CAS062 & 0 & 20.01 & 98.088 & 2.752 & Ramos3 \\
\hline CAS063 & 0 & 12.581 & 99.115 & 4.056 & Ramos3 \\
\hline CAS066 & 0 & 16.941 & 98.36 & 0.4 & Ramos3 \\
\hline STA031 & 0 & 14.282 & 97.985 & 14.326 & Ramos3 \\
\hline-------- & -------- & ------- & ------ & ------ & --------- \\
\hline
\end{tabular}

\begin{tabular}{|c|c|c|c|c|c|c|c|}
\hline ANID & BMplain2 & BMPlain3 & Plain1 & Plain2 & Plain3 & BMplain1 & $\begin{array}{l}\text { Best } \\
\text { Group }\end{array}$ \\
\hline --------- & -------- & -------- & -------- & -------- & -------- & ------- & ------- \\
\hline BMS014 & 4.551 & 29.116 & 97.239 & 2.9. & 5.68 & 6.251 & Plain1 \\
\hline BMS026 & 1.042 & 24.726 & 78.415 & 2.9 & 1.121 & 1.055 & Plain1 \\
\hline BMS081 & 1.67 & 63.557 & 95.825 & 1.7. & 6.258 & 2.471 & Plain1 \\
\hline BMS090 & 11.392 & 18.861 & 82.783 & 2.0 & 0.367 & 0.917 & Plain1 \\
\hline BMS119 & 3.572 & 25.098 & 95.362 & 3. & 17.528 & 4.622 & Plain1 \\
\hline BMS132 & 26.733 & 40.083 & 75.827 & 7.0 & 3.723 & 3.353 & Plain1 \\
\hline BMS138 & 4.754 & 33.13 & 98.729 & 6.0 & 21.972 & 2.553 & Plain1 \\
\hline BMS144 & 19.982 & 3.572 & 72.467 & 1.3. & 0.324 & 3.194 & Plain1 \\
\hline BMS151 & 6.23 & 3.962 & 94.106 & 5.3 & 4.906 & 3.328 & Plain1 \\
\hline BMS155 & 3.264 & 52.31 & 97.333 & 4.6. & 6.617 & 2.89 & Plain1 \\
\hline BMS166 & 5.002 & 15.259 & 84.518 & 2.5 & 0.874 & 1.221 & Plain1 \\
\hline BMS174 & 1.659 & 10.355 & 93.069 & 1.2 & 6.8 & 1.609 & Plain1 \\
\hline BMS175 & 3.166 & 1.005 & 69.608 & 10.7 & 19.269 & 0.792 & Plain1 \\
\hline BMS222 & 3.393 & 58.973 & 96.635 & 3.5 & 7.793 & 1.508 & Plain1 \\
\hline BMS231 & 17.181 & 66.702 & 91.98 & 3.2. & 5.675 & 2.036 & Plain1 \\
\hline BMS242 & 22.893 & 4.539 & 78.817 & 1.2. & 0.394 & 0.814 & Plain1 \\
\hline BMS268 & 31.501 & 4.742 & 95.952 & 2.5 & 1.886 & 5.573 & Plain1 \\
\hline BMS276 & 1.619 & 39.292 & 77.307 & 2.4 & 0.819 & 2.591 & Plain1 \\
\hline BMS289 & 4.121 & 35.106 & 97.935 & 3.6 & 4.328 & 2.994 & Plain1 \\
\hline
\end{tabular}




\begin{tabular}{|c|c|c|c|c|c|c|c|}
\hline BMS297 & 16.608 & 1.588 & 74.398 & 1.6 & 1.172 & 1.587 & Plain1 \\
\hline CASO06 & 1.99 & 18.508 & 87.833 & 2.1 & 3.25 & 2.133 & Plain1 \\
\hline CASO29 & 5.076 & 59.679 & 97.352 & 5.4 & 0.583 & 1.684 & Plain1 \\
\hline CAS105 & 5.696 & 43.692 & 93.391 & 6.8 & 0.566 & 1.648 & Plain1 \\
\hline OT557 & 2.67 & 5.187 & 71.776 & 3.9 & 0.176 & 0.739 & Plain1 \\
\hline ANID & BMplain2 & BMPlain3 & Plain1 & Plain2 & Plain3 & BMplain1 & $\begin{array}{l}\text { Best } \\
\text { Group }\end{array}$ \\
\hline - & -------- & -------- & -------- & -------- & -------- & ------- & -------- \\
\hline BMS027 & 9.491 & 0.043 & 0.003 & 99.4 & 0.29 & 0.788 & Plain2 \\
\hline BMS069 & 11.965 & 0.038 & 0.001 & 99.4 & 0.156 & 0.778 & Plain2 \\
\hline BMS104 & 4.157 & 0.017 & 0 & 99.0 & 0.102 & 0.602 & Plain2 \\
\hline BMS105 & 2.987 & 0.011 & 0 & 99. & 0.097 & 0.59 & Plain2 \\
\hline BMS135 & 2.169 & 0.009 & 0 & 99. & 0.1 & 0.511 & Plain2 \\
\hline BMS140 & 5.8 & 0.023 & 0.003 & 99.1. & 0.144 & 0.797 & Plain2 \\
\hline BMS141 & 5.38 & 0.02 & 0 & 99.0 & 0.068 & 0.427 & Plain2 \\
\hline BMS146 & 3.445 & 0.007 & 0 & 99.2 & 0.04 & 0.424 & Plain2 \\
\hline BMS269 & 2.37 & 0.009 & 0 & 99.0 & 0.073 & 0.521 & Plain2 \\
\hline BMS275 & 7.101 & 0.011 & 0 & 99.1 & 0.045 & 0.277 & Plain2 \\
\hline CAS010 & 5.876 & 0.028 & 0.001 & 99 & 0.131 & 0.686 & Plain2 \\
\hline CAS016 & 13.551 & 0.062 & 0.01 & 99. & 0.13 & 0.67 & Plain2 \\
\hline CASO20 & 5.183 & 0.007 & 0 & 99.0 & 0.04 & 0.333 & Plain2 \\
\hline CAS031 & 5.975 & 0.034 & 0 & 99.0 & 0.128 & 0.686 & Plain2 \\
\hline --------- & -------- & -------- & -------- & -------- & -------- & -------- & -------- \\
\hline ANID & BMplain2 & BMPlain3 & Plain1 & Plain2 & Plain3 & BMplain1 & $\begin{array}{l}\text { Best } \\
\text { Group }\end{array}$ \\
\hline -------- & -------- & -------- & -------- & -------- & -------- & -------- & -------- \\
\hline BMSO03 & 21.973 & 0.434 & 5.854 & 5.1 & 97.714 & 0.941 & Plain3 \\
\hline BMSO25 & 25.017 & 0.841 & 48.1 & 6.8 & 97.679 & 1.318 & Plain3 \\
\hline BMSO40 & 8.939 & 1.655 & 6.276 & 2.1 & 99.583 & 1.827 & Plain3 \\
\hline BMS054 & 7.482 & 0.203 & 0.631 & 6. & 97.685 & 0.868 & Plain3 \\
\hline BMS173 & 4.768 & 1.134 & 0.489 & 1.4 & 99.017 & 1.132 & Plain3 \\
\hline BMS190 & 18.649 & 0.278 & 30.533 & 3.2 & 97.803 & 1.302 & Plain3 \\
\hline CASO03 & 1.044 & 4.754 & 40.857 & 1.9 & 99.84 & 1.319 & Plain3 \\
\hline CASO04 & 1.193 & 4.342 & 41.386 & 2.3 & 99.106 & 1.384 & Plain3 \\
\hline CAS011 & 1.394 & 0.225 & 1.733 & 1.4 & 98.48 & 0.343 & Plain3 \\
\hline CASO14 & 1.205 & 0.271 & 0.784 & 1.2 & 98.802 & 0.334 & Plain3 \\
\hline CAS018 & 1.175 & 3.02 & 40.995 & 1.5. & 98.325 & 0.869 & Plain3 \\
\hline CAS019 & 1.062 & 3.651 & 41.245 & 2.4 & 98.279 & 1.222 & Plain3 \\
\hline CASO22 & 1.462 & 2.852 & 53.541 & 1. & 97.989 & 1.017 & Plain3 \\
\hline CASO23 & 1.158 & 4.619 & 40.57 & 2.1 & 98.278 & 1.298 & Plain3 \\
\hline CASO32 & 28.768 & 2.091 & 33.306 & 12.3 & 97.863 & 2.302 & Plain3 \\
\hline
\end{tabular}




\begin{tabular}{|c|c|c|c|c|c|c|c|}
\hline ANID & BMplain2 & BMPlain3 & Plain1 & Plain2 & Plain3 & BMplain1 & $\begin{array}{l}\text { Best } \\
\text { Group }\end{array}$ \\
\hline - ------- & --- & -------- & -------- & -------- & -------- & -------- & -------- \\
\hline BMS013 & 5.906 & 0.352 & 0.006 & 1.7 & 0.245 & 99.413 & BMplain1 \\
\hline BMSO23 & 10.131 & 0.365 & 0.526 & 0.9 & 0.14 & 97.762 & BMplain1 \\
\hline BMSO44 & 21.79 & 0.409 & 0.002 & 4.1. & 0.324 & 98.696 & BMplain1 \\
\hline BMS051 & 5.946 & 1.564 & 0.102 & 1.8. & 0.362 & 98.516 & BMplain1 \\
\hline BMS067 & 20.574 & 2.727 & 0.018 & 1.5 & 0.147 & 98.153 & BMplain1 \\
\hline BMS073 & 20.549 & 1.4 & 0.004 & 4.0. & 1.137 & 98.139 & BMplain1 \\
\hline BMS075 & 19.431 & 1.201 & 0.047 & 4.5 & 0.352 & 99.353 & BMplain1 \\
\hline BMS097 & 20.717 & 0.061 & 0.025 & 0. & 0.056 & 97.732 & BMplain1 \\
\hline BMS164 & 14.733 & 0.531 & 0.087 & 2.2 & 0.328 & 97.821 & BMplain1 \\
\hline BMS178 & 4.49 & 0.145 & 0.002 & 2.1 & 0.127 & 98.912 & BMplain1 \\
\hline BMS180 & 7.177 & 0.368 & 0.004 & 4.0 & 0.361 & 98.783 & BMplain1 \\
\hline BMS218 & 16.801 & 0.74 & 0.005 & 4.7 & 0.369 & 99.62 & BMplain1 \\
\hline BMS259 & 1.82 & 0.062 & 0.008 & 0.9 & 0.19 & & BMplain1 \\
\hline BMS290 & 2.109 & 2.471 & 0.003 & 3.0 & 0.392 & 97.833 & BMplain1 \\
\hline BMS315 & 13.123 & 4.43 & 0.037 & 4.1 & 0.356 & 98.13 & BMplain1 \\
\hline --------- & -------- & -------- & -------- & -------- & -------- & -------- & ---------- \\
\hline ANID & BMplain2 & BMPlain3 & Plain1 & Plain2 & Plain3 & BMplain1 & $\begin{array}{l}\text { Best } \\
\text { Group }\end{array}$ \\
\hline - & -------- & -------- & -------- & -------- & -------- & -------- & ---------- \\
\hline BMS012 & 99.104 & 6.215 & 6.556 & 1.525 & 0.103 & 2.941 & BMplain2 \\
\hline BMSO45 & 98.999 & 84.704 & 56.542 & 3.59 & 0.538 & 6.182 & BMplain2 \\
\hline BMS052 & 99.012 & 88.085 & 66.821 & 3.13 & 0.919 & 6.27 & BMplain2 \\
\hline BMS057 & 99.172 & 13.063 & 0.046 & 4.325 & 0.231 & 3.868 & BMplain2 \\
\hline BMS107 & 99.152 & 62.525 & 23.08 & 5.75 & 0.416 & 14.512 & BMplain2 \\
\hline BMS110 & 99.005 & 8.021 & 0.343 & 6.824 & 0.716 & 3.708 & BMplain2 \\
\hline BMS159 & 99.295 & 10.938 & 33.907 & 1.76 & 0.417 & 5.216 & BMplain2 \\
\hline BMS168 & 99.005 & 9.36 & 29.707 & 10.211 & 1.125 & 9.087 & BMplain2 \\
\hline BMS177 & 99.047 & 28.264 & 51.121 & 4.497 & 0.624 & 7.537 & BMplain2 \\
\hline BMS193 & 99.664 & 60.725 & 4.742 & 4.186 & 0.275 & 12.642 & BMplain2 \\
\hline BMS210 & 99.087 & 42.844 & 24.053 & 5.357 & 1.842 & 5.306 & BMplain2 \\
\hline BMS212 & 99.59 & 6.662 & 0.077 & 3.956 & 0.587 & 3.875 & BMplain2 \\
\hline BMS246 & 99.583 & 7.92 & 4.96 & 2.004 & 0.254 & 6.995 & BMplain2 \\
\hline BMS301 & 99.164 & 17.725 & 3.472 & 1.526 & 0.543 & 16.838 & BMplain2 \\
\hline
\end{tabular}




\begin{tabular}{|l|l|l|l|l|l|l|l|}
\hline ANID & BMplain2 & BMPlain3 & Plain1 & Plain2 & Plain3 & BMplain1 & $\begin{array}{l}\text { Best } \\
\text { Group }\end{array}$ \\
\hline-------- & ------- & ------- & ------- & ------- & ------- & ------- & --------- \\
\hline BMS008 & 29.269 & 94.12 & 8.464 & 2.763 & 0.229 & 4.049 & BMPlain3 \\
\hline BMS092 & 2.779 & 95.599 & 73.214 & 9.635 & 3.496 & 2.638 & BMPlain3 \\
\hline BMS093 & 62.404 & 95.212 & 80.913 & 3.437 & 1.15 & 4.363 & BMPlain3 \\
\hline BMS100 & 1.924 & 95.519 & 29.802 & 36.92 & 2.207 & 1.431 & BMPlain3 \\
\hline BMS108 & 9.244 & 98.777 & 87.437 & 8.98 & 2.226 & 3.548 & BMPlain3 \\
\hline BMS114 & 3.54 & 94.139 & 20.929 & 2.438 & 0.819 & 1.785 & BMPlain3 \\
\hline BMS128 & 5.602 & 99.377 & 78.601 & 11.922 & 10.933 & 2.572 & BMPlain3 \\
\hline BMS136 & 8.285 & 98.73 & 12.919 & 1.759 & 2.425 & 1.443 & BMPlain3 \\
\hline BMS149 & 2.875 & 99.157 & 1.627 & 9.523 & 6.201 & 2.135 & BMPlain3 \\
\hline BMS205 & 2.308 & 98.062 & 0.729 & 3.064 & 3.276 & 1.738 & BMPlain3 \\
\hline BMS206 & 6.376 & 94.68 & 6.8 & 1.849 & 1.224 & 2.342 & BMPlain3 \\
\hline BMS213 & 4.796 & 99.243 & 75.49 & 10.606 & 3.145 & 2.085 & BMPlain3 \\
\hline BMS262 & 44.125 & 96.234 & 83.613 & 4.344 & 4.154 & 7.529 & BMPlain3 \\
\hline BMS302 & 1.775 & 94.812 & 13.835 & 11.571 & 0.07 & 0.376 & BMPlain3 \\
\hline BMS308 & 4.473 & 97.18 & 11.295 & 0.884 & 1.208 & 1.677 & BMPlain3 \\
\hline BMS310 & 10.706 & 94.815 & 21.845 & 3.548 & 0.892 & 6.768 & BMPlain3 \\
\hline BMS341 & 5.261 & 93.12 & 9.344 & 1.466 & 1.791 & 1.591 & BMPlain3 \\
\hline-------- & ------- & ------- & ------- & ------- & ------- & ------- & --------- \\
\hline
\end{tabular}


Appendix C

Analysis Identification numbers with provenience designation and NAA group

\begin{tabular}{|c|c|c|c|}
\hline ANID & $\begin{array}{l}\text { Provenience } \\
\text { Designation }\end{array}$ & Type & NAA group \\
\hline CASO02 & 17 & Casas Grandes Plainware & R3 \\
\hline CASO03 & 20 & Casas Grandes Plainware & P3 \\
\hline CASO04 & 20 & Casas Grandes Plainware & P3 \\
\hline CASO05 & 22 & Casas Grandes Plainware & $\mathrm{R} 2$ \\
\hline CASO06 & 23 & Casas Grandes Plainware & P1 \\
\hline CASO07 & 23 & El Paso Brownware & unassigned \\
\hline CAS008 & 26 & Casas Grandes Plainware & $\mathrm{R} 1$ \\
\hline CASO09 & 26 & Casas Grandes Plainware & R1 \\
\hline CAS010 & 26 & Casas Grandes Plainware & $\mathrm{P} 2$ \\
\hline CAS011 & 48 & Casas Grandes Plainware & P3 \\
\hline CAS012 & 48 & El Paso Brownware & unassigned \\
\hline CAS013 & 48 & El Paso Brownware & unassigned \\
\hline CAS014 & 48 & Casas Grandes Plainware & P3 \\
\hline CAS015 & 48 & El Paso Brownware & unassigned \\
\hline CAS016 & 54 & El Paso Brownware & $\mathrm{P} 2$ \\
\hline CAS017 & 54 & Casas Grandes Plainware & unassigned \\
\hline CAS018 & 55 & Casas Grandes Plainware & P3 \\
\hline CAS019 & 55 & Casas Grandes Plainware & P3 \\
\hline CASO20 & 56 & El Paso Brownware & P2 \\
\hline CAS021 & 62 & Casas Grandes Plainware & R1 \\
\hline CAS022 & 62 & Casas Grandes Plainware & P3 \\
\hline CAS023 & 62 & Casas Grandes Plainware & P3 \\
\hline CAS024 & 62 & Casas Grandes Plainware & R1 \\
\hline CASO25 & 73 & El Paso Brownware & unassigned \\
\hline CASO26 & 82 & Casas Grandes Plainware & R3 \\
\hline CASO27 & 93 & Gila Polychrome & Gila \\
\hline CASO28 & 93 & Gila Polychrome & Gila \\
\hline CAS029 & 93 & Casas Grandes Plainware & P1 \\
\hline CASO30 & 108 & Ramos Black & unassigned \\
\hline CAS031 & 129 & El Paso Brownware & unassigned \\
\hline CAS032 & 133 & El Paso Brownware & P3 \\
\hline CAS033 & 1020 & Casas Grandes Plainware & R1 \\
\hline CAS034 & 1022 & Casas Grandes Plainware & unassigned \\
\hline CAS035 & 17 & Ramos Polychrome & $\mathrm{R} 1$ \\
\hline CAS036 & 20 & Ramos Polychrome & R3 \\
\hline CAS037 & 20 & Ramos Polychrome & R3 \\
\hline CAS038 & 23 & Ramos Polychrome & unassigned \\
\hline
\end{tabular}




\begin{tabular}{|c|c|c|c|}
\hline CAS039 & 23 & Ramos Polychrome & R3 \\
\hline CASO40 & 26 & Ramos Polychrome & unassigned \\
\hline CAS041 & 26 & Ramos Polychrome & unassigned \\
\hline CASO42 & 26 & Ramos Polychrome & $\mathrm{R} 2$ \\
\hline CASO43 & 28 & Ramos Polychrome & $\mathrm{R} 2$ \\
\hline CASO44 & 28 & Ramos Polychrome & $\mathrm{R} 1$ \\
\hline CASO45 & 48 & Ramos Polychrome & unassigned \\
\hline CASO46 & 48 & Ramos Polychrome & $\mathrm{R} 2$ \\
\hline CASO47 & 48 & Ramos Polychrome & $\mathrm{R} 2$ \\
\hline CASO48 & 48 & Ramos Polychrome & $\mathrm{R} 1$ \\
\hline CASO49 & 55 & Ramos Polychrome & R1 \\
\hline CAS050 & 55 & Ramos Polychrome & R3 \\
\hline CAS051 & 65 & Ramos Polychrome & R1 \\
\hline CAS052 & 66 & Ramos Polychrome & $\mathrm{R} 1$ \\
\hline CASO53 & 68 & Ramos Polychrome & $\mathrm{R} 1$ \\
\hline CAS054 & 73 & Ramos Polychrome & $\mathrm{R} 2$ \\
\hline CAS055 & 73 & Ramos Polychrome & R3 \\
\hline CAS056 & 73 & Ramos Polychrome & $\mathrm{R} 2$ \\
\hline CAS057 & 81 & Ramos Polychrome & $\mathrm{R} 1$ \\
\hline CAS058 & 81 & Ramos Polychrome & $\mathrm{R} 2$ \\
\hline CAS059 & 93 & Ramos Polychrome & unassigned \\
\hline CASO60 & 108 & Ramos Polychrome & $\mathrm{R} 1$ \\
\hline CAS061 & 130 & Ramos Polychrome & $\mathrm{R} 1$ \\
\hline CAS062 & 130 & Ramos Polychrome & R3 \\
\hline CASO63 & 130 & Ramos Polychrome & R3 \\
\hline CAS064 & 133 & Ramos Polychrome & $\mathrm{R} 1$ \\
\hline CAS065 & 1020 & Ramos Polychrome & unassigned \\
\hline CAS066 & 1020 & Ramos Polychrome & R3 \\
\hline CAS067 & 1022 & Ramos Polychrome & R3 \\
\hline CAS068 & 17 & Gila Polychrome & G \\
\hline CASO69 & 20 & Gila Polychrome & G \\
\hline CAS070 & 23 & Gila Polychrome & G \\
\hline CAS071 & 23 & Gila Polychrome & G \\
\hline CASO72 & 26 & Gila Polychrome & G \\
\hline CAS073 & 26 & Gila Polychrome & G \\
\hline CASO74 & 26 & Gila Polychrome & $\mathrm{G}$ \\
\hline CAS075 & 26 & Gila Polychrome & G \\
\hline CASO76 & 26 & Gila Polychrome & G \\
\hline CAS077 & 48 & Gila Polychrome & G \\
\hline CAS078 & 48 & Gila Polychrome & G \\
\hline CAS079 & 48 & Gila Polychrome & $\mathrm{G}$ \\
\hline
\end{tabular}




\begin{tabular}{|l|c|l|l|}
\hline CAS080 & 55 & Gila Polychrome & G \\
\hline CAS081 & 62 & Gila Polychrome & G \\
\hline CAS082 & 62 & Gila Polychrome & G \\
\hline CAS083 & 62 & Gila Polychrome & G \\
\hline CAS084 & 62 & Gila Polychrome & G \\
\hline CAS085 & 62 & Gila Polychrome & G \\
\hline CAS086 & 65 & Gila Polychrome & G \\
\hline CAS087 & 66 & Gila Polychrome & G \\
\hline CAS088 & 66 & Gila Polychrome & G \\
\hline CAS089 & 66 & Gila Polychrome & G \\
\hline CAS090 & 66 & Gila Polychrome & G \\
\hline CAS091 & 73 & Gila Polychrome & G \\
\hline CAS092 & 73 & Gila Polychrome & G \\
\hline CAS093 & 73 & Gila Polychrome & G \\
\hline CAS094 & 73 & Gila Polychrome & G \\
\hline CAS095 & 74 & Gila Polychrome & G \\
\hline CAS096 & 93 & Gila Polychrome & G \\
\hline CAS097 & 102 & Gila Polychrome & G \\
\hline CAS098 & 130 & Gila Polychrome & G \\
\hline CAS099 & 130 & Gila Polychrome & G \\
\hline CAS100 & 133 & Gila Polychrome & G \\
\hline CAS101 & 1022 & Gila Polychrome & G \\
\hline CAS102 & 65 & Chupadero B/W & unassigned \\
\hline CAS103 & 102 & Tonto Polychrome & G \\
\hline CAS104 & 13 & Villa Ahumada Poly & G \\
\hline & & $\begin{array}{l}\text { Possible clay sample, } \\
\text { turned out to be } \\
\text { unworkable }\end{array}$ & \\
\hline CAS105 & & & P1 \\
\hline & & & \\
\hline
\end{tabular}




\section{Appendix D}

Scatterplots of Ramos groups using the same elements as Triadan et al. 2018:156-157. Group R3 would fit inside Triadan et al.'s Core Group 2 suggesting that the samples were made at the same production location.

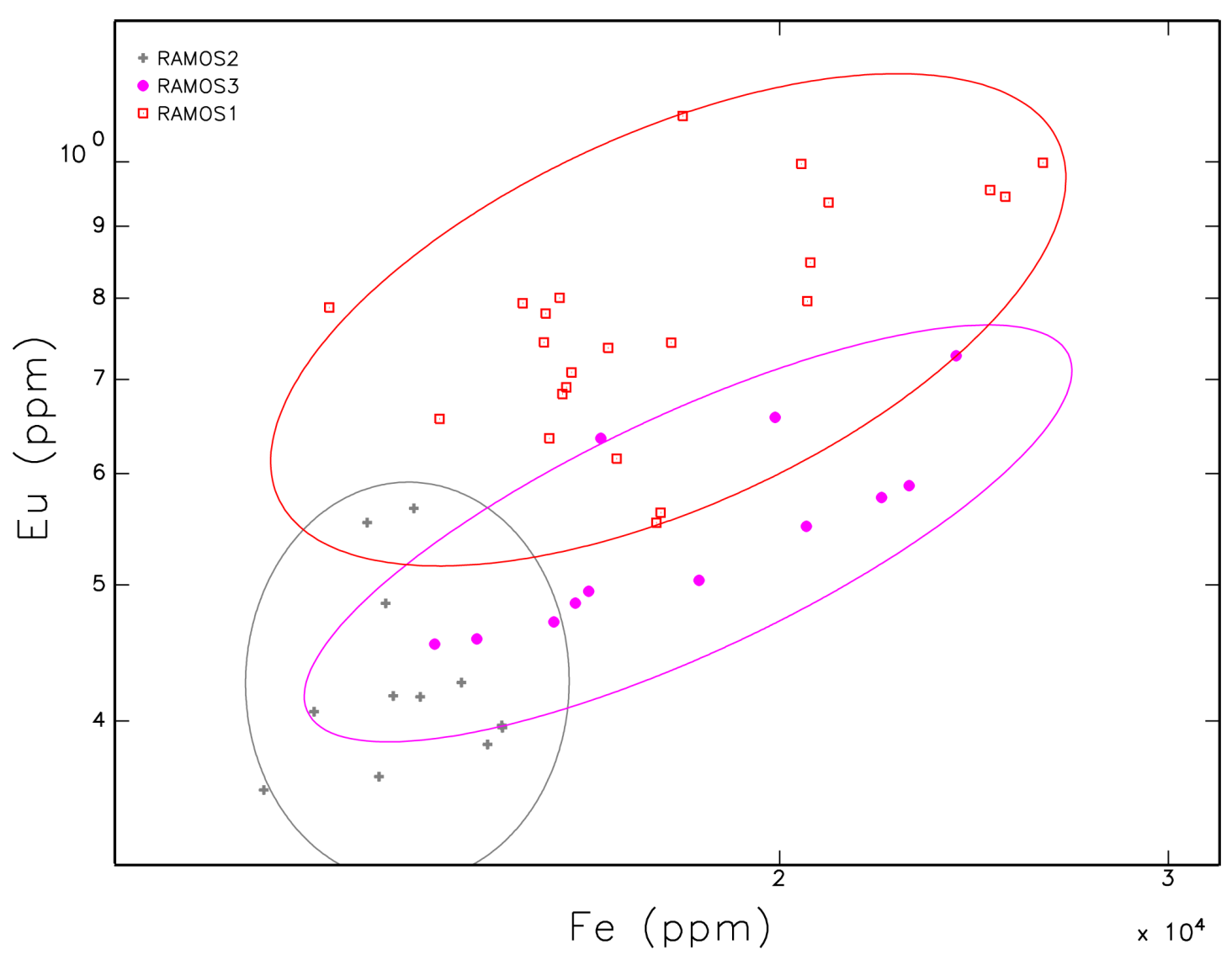

Scatterplot of iron and europium showing the three Ramos Polychrome groups. 


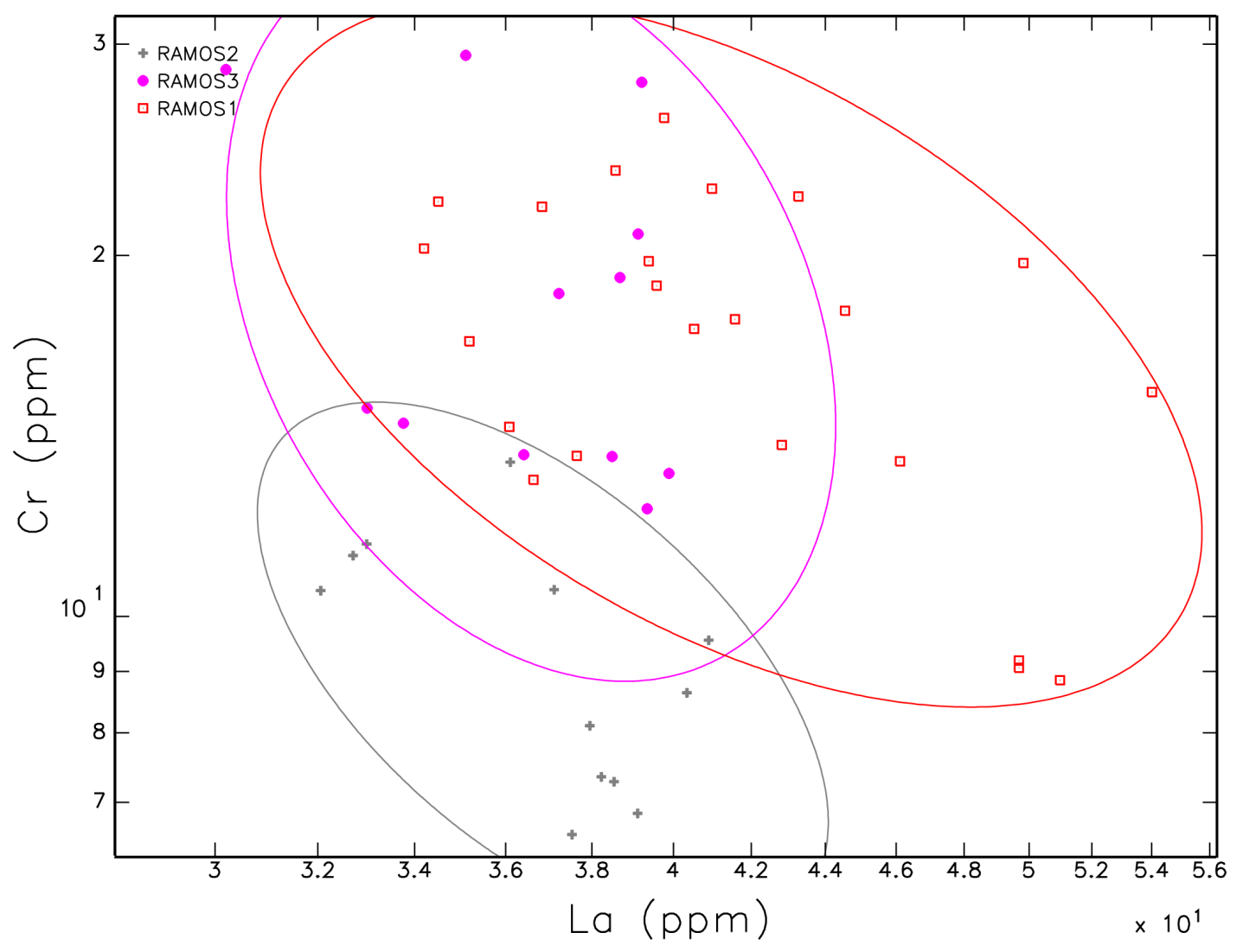

Scatterplot of lanthanum and chromium showing the three Ramos Polychrome groups. 


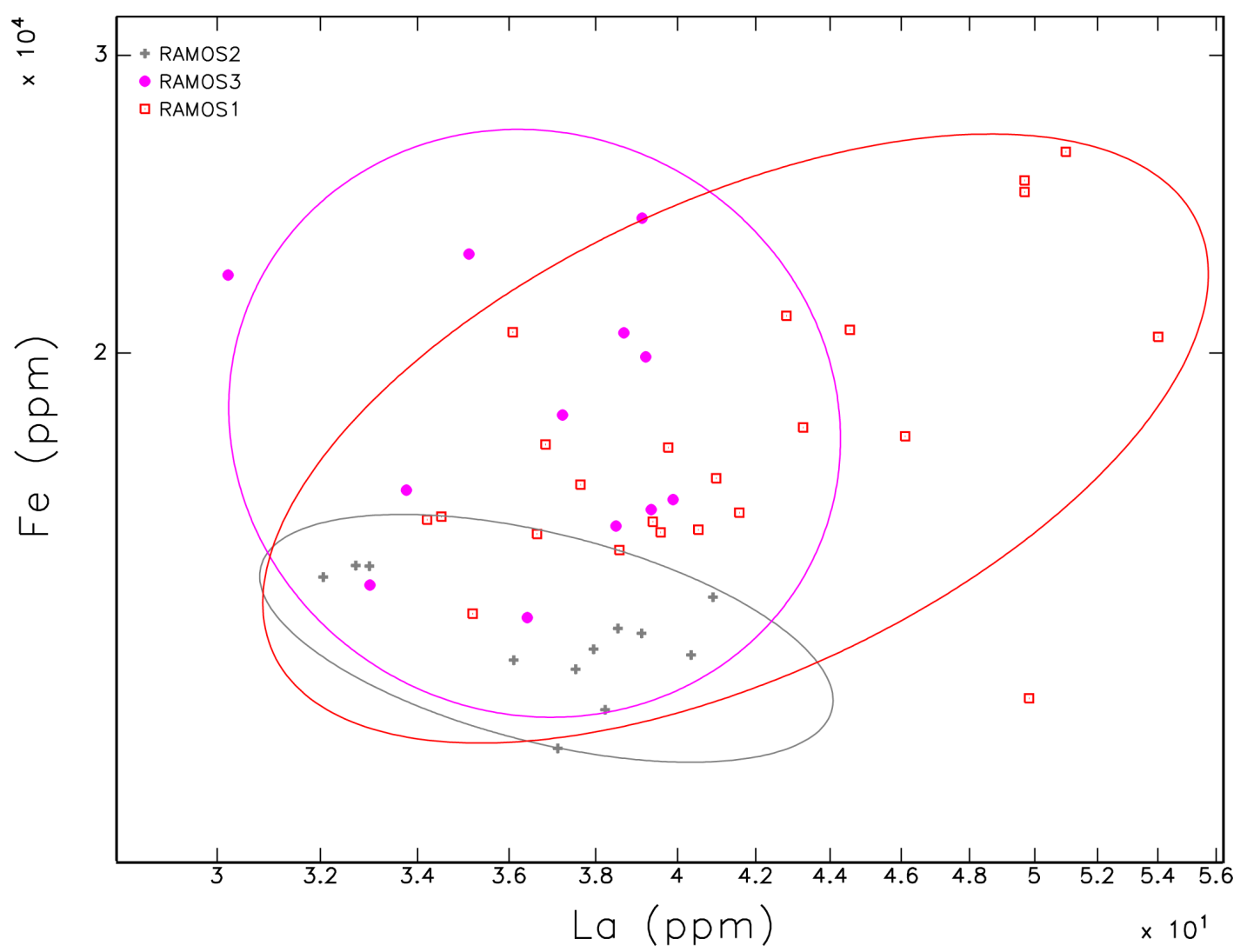

Scatterplot of lanthanum and iron showing the three Ramos Polychrome groups. 


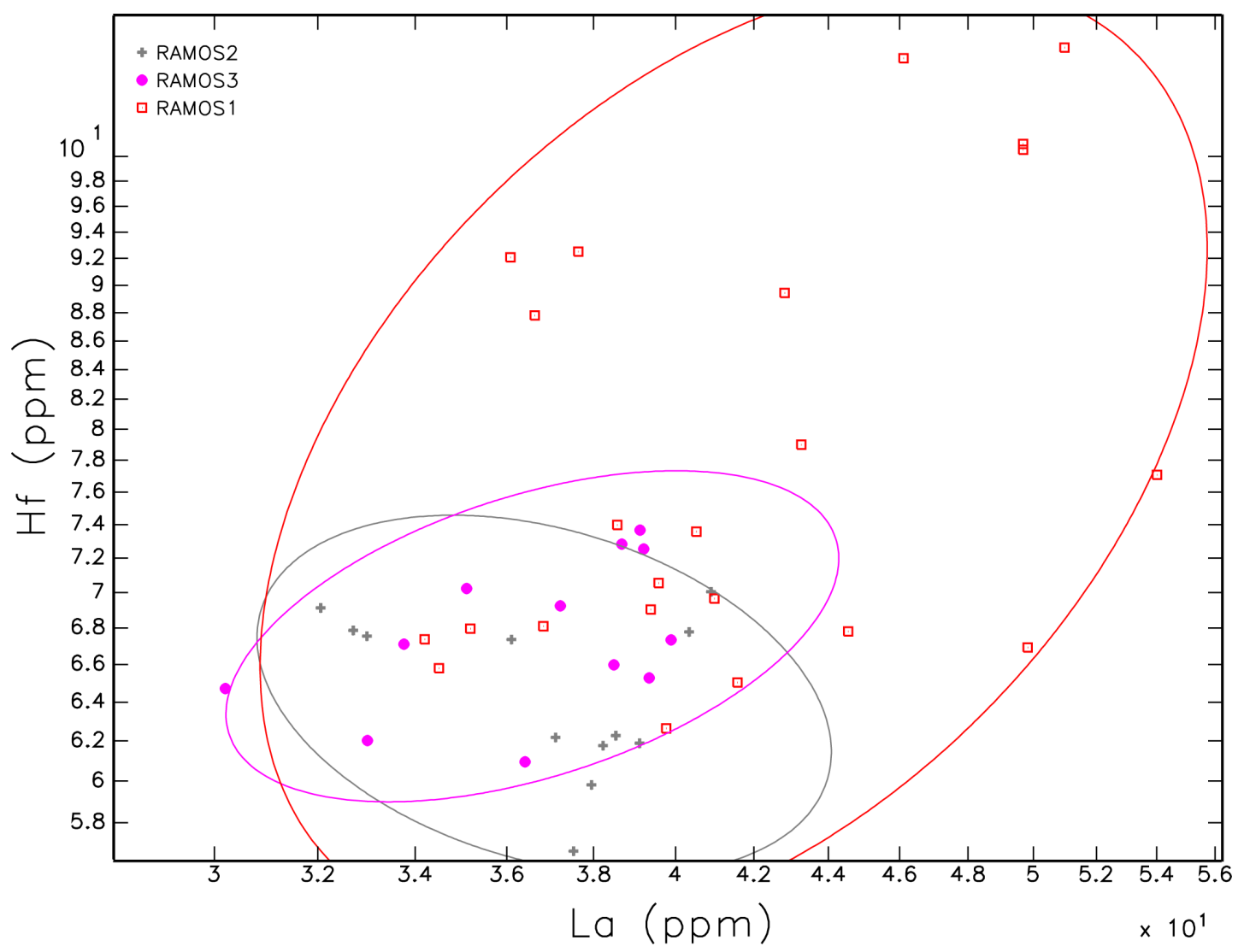

Scatterplot of lanthanum and hafnium showing the three Ramos Polychrome groups. 
Appendix E

Raw NAA Data of samples from 76 Draw (LA156980), Luna County, New Mexico.

\begin{tabular}{|c|c|c|c|c|c|c|c|c|}
\hline ANID & As & La & Lu & Nd & Sm & U & $\mathrm{Yb}$ & $\mathrm{Ce}$ \\
\hline CASO02 & 4.3035 & 33.0064 & 0.6240 & 25.2106 & 5.9258 & 4.3502 & 4.1302 & 67.1301 \\
\hline CASO03 & 5.7207 & 66.2184 & 0.5243 & 53.4470 & 10.1367 & 4.5107 & 3.6366 & 127.0161 \\
\hline CASO04 & 5.9759 & 66.0344 & 0.5458 & 53.9908 & 10.3434 & 4.4750 & 3.6827 & 126.2962 \\
\hline CASO05 & 2.0906 & 36.1012 & 0.6068 & 28.8424 & 6.2860 & 5.1074 & 4.5630 & 65.6048 \\
\hline CASO06 & 4.1865 & 46.6943 & 0.4501 & 36.1433 & 7.5057 & 4.0144 & 2.9926 & 83.1822 \\
\hline CASO07 & 7.3931 & 80.0884 & 1.0088 & 68.7374 & 14.5227 & 3.7377 & 8.0842 & 117.7934 \\
\hline CASO08 & 2.2343 & 38.2289 & 0.5825 & 31.1301 & 6.7308 & 4.1123 & 4.4440 & 67.8534 \\
\hline CASO09 & 4.1137 & 49.6779 & 0.6056 & 35.2532 & 6.7086 & 5.3820 & 3.8050 & 87.1870 \\
\hline CASO10 & 7.7915 & 50.3789 & 0.6025 & 43.6571 & 8.9440 & 3.2571 & 4.0166 & 97.9586 \\
\hline CAS011 & 7.8294 & 64.3332 & 0.4827 & 52.6040 & 10.4748 & 3.9363 & 3.3312 & 126.1947 \\
\hline CAS012 & 3.6046 & 25.8357 & 0.5131 & 25.4540 & 6.5150 & 1.6241 & 4.1319 & 55.4960 \\
\hline CAS013 & 4.3977 & 30.0787 & 0.5425 & 28.1691 & 6.6920 & 2.2606 & 4.3784 & 64.1537 \\
\hline CAS014 & 9.1270 & 63.5516 & 0.4905 & 53.1458 & 10.0403 & 3.9386 & 3.2909 & 124.4923 \\
\hline CAS015 & 5.3493 & 50.1817 & 0.4405 & 44.6225 & 9.1853 & 3.5988 & 3.2057 & 103.3521 \\
\hline CAS016 & 6.6782 & 47.5629 & 0.5156 & 40.5628 & 8.4307 & 4.0258 & 3.2767 & 92.1130 \\
\hline CAS017 & 1.7434 & 44.9195 & 0.6951 & 33.7995 & 7.4066 & 3.7131 & 5.2115 & 93.4893 \\
\hline CAS018 & 5.9374 & 64.7495 & 0.5506 & 49.7901 & 10.0308 & 4.9461 & 3.6668 & 122.4604 \\
\hline CAS019 & 5.4103 & 64.6537 & 0.5482 & 52.8296 & 10.1396 & 4.8146 & 3.6047 & 123.8691 \\
\hline CASO20 & 6.5439 & 62.7125 & 0.4109 & 56.7978 & 10.4931 & 2.8839 & 2.9727 & 90.1325 \\
\hline CAS021 & 3.4361 & 50.9824 & 0.6482 & 36.5601 & 6.8971 & 5.9688 & 4.0157 & 90.8562 \\
\hline CASO22 & 5.5532 & 61.9456 & 0.5937 & 51.3729 & 9.8759 & 6.0521 & 3.8157 & 123.0384 \\
\hline CAS023 & 5.7470 & 64.0732 & 0.5796 & 53.5923 & 9.9823 & 4.7785 & 3.5903 & 122.2792 \\
\hline CASO24 & 3.2801 & 49.6823 & 0.5910 & 35.2256 & 6.8077 & 5.6300 & 3.7877 & 89.0977 \\
\hline CASO25 & 2.7360 & 110.3492 & 0.9143 & 94.5293 & 17.5664 & 6.9789 & 6.2914 & 222.6434 \\
\hline CASO26 & 7.4166 & 38.4911 & 0.6165 & 31.6271 & 6.7342 & 4.8725 & 4.5036 & 69.0108 \\
\hline CASO27 & 3.8804 & 38.7956 & 0.4918 & 33.2943 & 7.8133 & 2.8614 & 3.8868 & 77.8838 \\
\hline CASO28 & 8.3029 & 43.6139 & 0.4176 & 39.3204 & 7.7970 & 3.5695 & 3.3549 & 90.1429 \\
\hline CASO29 & 1.8933 & 39.8705 & 0.4199 & 30.0651 & 6.1763 & 2.9201 & 2.7587 & 80.1764 \\
\hline CASO30 & 3.7239 & 95.5847 & 0.6484 & 92.4559 & 18.5106 & 4.6080 & 5.2813 & 170.7277 \\
\hline CAS031 & 6.3107 & 77.4067 & 0.5937 & 72.8916 & 13.4540 & 3.5278 & 4.3066 & 145.4996 \\
\hline CASO32 & 7.5283 & 68.5924 & 0.6358 & 53.8518 & 10.6352 & 3.4005 & 4.2529 & 126.0966 \\
\hline CAS033 & 3.0261 & 44.5426 & 0.6876 & 38.1044 & 8.7062 & 4.7261 & 5.1736 & 83.3379 \\
\hline CAS034 & 2.2985 & 61.5173 & 0.6990 & 50.1350 & 10.0191 & 5.8376 & 5.1494 & 101.0545 \\
\hline CAS035 & 3.1696 & 46.1109 & 0.6113 & 35.2010 & 7.6362 & 5.3878 & 3.9653 & 93.3254 \\
\hline CAS036 & 6.8043 & 33.7672 & 0.5224 & 24.5168 & 5.0871 & 4.0719 & 3.7013 & 56.4149 \\
\hline CAS037 & 6.2753 & 37.2250 & 0.5792 & 28.9802 & 6.0481 & 5.3971 & 4.2746 & 75.8326 \\
\hline CAS038 & 2.4960 & 31.9006 & 0.5834 & 26.8919 & 5.7410 & 5.8880 & 4.1870 & 49.8078 \\
\hline CAS039 & 6.9302 & 36.4147 & 0.6039 & 29.2151 & 6.3442 & 5.0619 & 4.3915 & 72.9589 \\
\hline CASO40 & 2.0526 & 47.5439 & 0.6598 & 34.7670 & 7.6514 & 5.1242 & 5.0278 & 82.9635 \\
\hline
\end{tabular}




\begin{tabular}{|c|c|c|c|c|c|c|c|c|c|}
\hline ANID & Co & $\mathrm{Cr}$ & Cs & $\mathrm{Eu}$ & $\mathrm{Fe}$ & $\mathrm{Hf}$ & $\mathbf{R b}$ & Sb & Sc \\
\hline CASO02 & 2.5383 & 14.9150 & 5.6874 & 0.4576 & 14579.7 & 6.2021 & 189.69 & 0.4842 & 5.0829 \\
\hline CASO03 & 7.1326 & 19.5151 & 2.9067 & 2.1712 & 33863.8 & 9.6632 & 120.90 & 0.5456 & 12.4906 \\
\hline CASO04 & 7.1057 & 19.9458 & 2.9452 & 2.1613 & 34350.6 & 9.7351 & 120.42 & 0.6089 & 12.7063 \\
\hline CASO05 & 2.1171 & 13.4471 & 4.0485 & 0.3651 & 13163.3 & 6.7357 & 205.33 & 0.4256 & 4.2980 \\
\hline CASO06 & 8.9193 & 38.0812 & 5.0082 & 1.7415 & 39545.4 & 9.5069 & 137.97 & 0.6909 & 10.9924 \\
\hline CASO07 & 7.2030 & 40.9106 & 4.9183 & 1.7325 & 37440.8 & 13.2718 & 128.60 & 0.7062 & 9.5774 \\
\hline CAS008 & 2.0137 & 7.3485 & 2.9052 & 0.4062 & 12301.7 & 6.1759 & 199.87 & 0.2523 & 4.0441 \\
\hline CASO09 & 4.7831 & 9.1912 & 5.4267 & 0.9442 & 25301.7 & 10.1019 & 163.13 & 0.4663 & 6.1757 \\
\hline CAS010 & 5.4106 & 29.1864 & 6.1231 & 2.0019 & 41472.2 & 12.3798 & 128.57 & 1.2250 & 12.6881 \\
\hline CAS011 & 5.1516 & 16.9742 & 2.8324 & 2.2523 & 25909.2 & 11.2456 & 88.36 & 0.9171 & 11.7736 \\
\hline CAS012 & 35.5222 & 160.9653 & 5.8336 & 1.6202 & 85316.1 & 5.9163 & 56.88 & 0.4224 & 29.5908 \\
\hline CAS013 & 23.4174 & 191.4950 & 6.2003 & 1.2008 & 61102.6 & 7.0283 & 100.90 & 0.4709 & 21.7184 \\
\hline CAS014 & 5.3187 & 16.5611 & 2.7334 & 2.1359 & 24560.5 & 10.8960 & 87.74 & 0.8938 & 11.5327 \\
\hline CAS015 & 5.8365 & 29.5327 & 4.8056 & 1.9092 & 40468.1 & 6.5881 & 106.31 & 1.0459 & 11.8135 \\
\hline CAS016 & 5.0131 & 24.3523 & 5.0588 & 1.8021 & 37388.0 & 8.2033 & 119.94 & 1.1430 & 11.2478 \\
\hline CAS017 & 2.0260 & 5.2589 & 11.5615 & 0.6498 & 9416.9 & 7.8803 & 232.06 & 0.2703 & 3.3729 \\
\hline CAS018 & 5.4094 & 18.7505 & 2.8901 & 2.0765 & 30874.1 & 10.2503 & 112.39 & 0.5628 & 11.1700 \\
\hline CAS019 & 7.6825 & 19.2412 & 2.8226 & 2.1377 & 33420.1 & 9.6504 & 119.61 & 0.5363 & 12.3153 \\
\hline CASO20 & 3.3296 & 22.3638 & 4.7304 & 2.2600 & 39596.0 & 6.7209 & 94.69 & 0.9640 & 12.2440 \\
\hline CAS021 & 4.5404 & 8.8475 & 5.7970 & 0.9986 & 26312.7 & 10.9308 & 174.23 & 0.6228 & 6.3812 \\
\hline CASO22 & 5.5207 & 16.2768 & 3.1254 & 2.0247 & 29407.0 & 10.8899 & 127.54 & 0.6364 & 11.2745 \\
\hline CASO23 & 7.2631 & 18.6785 & 2.9108 & 2.1168 & 33192.8 & 9.4973 & 121.28 & 0.5610 & 12.1789 \\
\hline CASO24 & 4.6940 & 9.0640 & 5.6172 & 0.9546 & 24908.1 & 10.0543 & 172.78 & 0.4839 & 6.0955 \\
\hline CAS025 & 5.2434 & 11.5325 & 2.7092 & 2.3670 & 40888.7 & 18.3852 & 101.87 & 0.6025 & 10.4770 \\
\hline CASO26 & 2.0507 & 13.5922 & 4.0852 & 0.4704 & 15800.2 & 6.5978 & 190.43 & 0.4620 & 5.6567 \\
\hline CAS027 & 13.4020 & 64.7024 & 4.6937 & 1.3169 & 36690.7 & 7.6007 & 105.60 & 0.5980 & 10.8452 \\
\hline CASO28 & 16.6786 & 71.9223 & 5.8822 & 1.4501 & 39664.5 & 7.8754 & 107.73 & 0.6477 & 11.9434 \\
\hline CAS029 & 12.5751 & 36.3454 & 3.8002 & 1.3016 & 32035.5 & 6.2164 & 122.94 & 0.4095 & 9.2260 \\
\hline CAS030 & 12.2834 & 41.0795 & 5.1971 & 3.6357 & 32973.8 & 10.4821 & 104.11 & 0.4149 & 14.5049 \\
\hline CAS031 & 5.3498 & 27.8806 & 5.4501 & 2.3371 & 41932.7 & 12.2523 & 112.33 & 0.6708 & 12.8970 \\
\hline CAS032 & 8.6839 & 34.9481 & 4.3063 & 2.0518 & 42519.3 & 11.8065 & 122.03 & 0.6737 & 11.1597 \\
\hline CAS033 & 3.5127 & 17.9866 & 6.6469 & 0.8476 & 20644.8 & 6.7820 & 192.85 & 0.3737 & 5.9585 \\
\hline CASO34 & 1.7385 & 7.4546 & 2.1487 & 0.9465 & 12330.3 & 8.8750 & 189.32 & 0.2538 & 4.6709 \\
\hline CASO35 & 2.8141 & 13.4692 & 5.1005 & 0.7434 & 17854.4 & 10.8372 & 177.86 & 0.7022 & 6.6613 \\
\hline CAS036 & 3.1369 & 14.4902 & 7.6311 & 0.6357 & 16590.3 & 6.7110 & 188.05 & 0.6123 & 5.1028 \\
\hline CASO37 & 3.2240 & 18.5912 & 5.3652 & 0.5036 & 18383.9 & 6.9248 & 196.42 & 0.6176 & 6.1743 \\
\hline CAS038 & 2.3919 & 20.1967 & 7.1092 & 0.4665 & 17530.4 & 6.9796 & 209.71 & 0.4023 & 6.6769 \\
\hline CAS039 & 2.3695 & 13.6382 & 4.6172 & 0.4538 & 13950.5 & 6.0947 & 192.85 & 0.5492 & 5.1028 \\
\hline CASO40 & 2.1667 & 7.8411 & 2.8852 & 0.7904 & 14907.8 & 7.8946 & 199.32 & 0.3603 & 5.4640 \\
\hline
\end{tabular}




\begin{tabular}{|c|c|c|c|c|c|c|c|c|c|}
\hline ANID & Sr & $\mathrm{Ta}$ & Tb & Th & $\mathrm{Zn}$ & Al & $\mathrm{Ba}$ & $\mathrm{Ca}$ & Dy \\
\hline CASO02 & 48.41 & 1.8319 & 0.9295 & 24.8320 & 56.29 & 82083.0 & 299.1 & 7291.1 & 5.9211 \\
\hline CASOO3 & 92.91 & .4169 & 2674 & 0.0489 & 86.40 & 99808.5 & 1175.5 & 9341.7 & 6.5038 \\
\hline CASO04 & 294.83 & 1.4596 & 1.3834 & 19.9762 & 86.99 & 100017.2 & 1130.9 & 9436.4 & 6.5637 \\
\hline CASO05 & 200.35 & 2.1133 & 1.0328 & 30.4172 & 64.48 & 82468.9 & 282.1 & 6543.2 & 6.4364 \\
\hline CAS006 & 298.17 & 1.5126 & 0.8843 & 16.5091 & 93.27 & 104048.6 & 1143.3 & 8510.8 & 4.5388 \\
\hline CASO07 & 414.22 & 2.0948 & 2.2184 & 25.9862 & 77.49 & 84468.8 & 849.8 & 10595.3 & 12.6335 \\
\hline CASO08 & 203.78 & 1.7973 & 1.0472 & 27.7162 & 66.00 & 74396.8 & 338.3 & 7548.4 & 6.8361 \\
\hline CASO09 & 257.93 & 1.7476 & 0.8442 & 28.5483 & 58.76 & 87136.7 & 707.0 & 8234.0 & 5.3466 \\
\hline CASO10 & 133.47 & 3.1893 & 1.1779 & 15.3162 & 134.75 & 96093.5 & 359.4 & 7882.8 & 6.2169 \\
\hline CAS011 & 555.01 & 1.5616 & 1.1248 & 19.2397 & 63.23 & 111943.0 & 1403.0 & 12159.9 & 6.2035 \\
\hline CASO12 & 235.44 & 1.0116 & 1.0639 & 7.5146 & 111.38 & 87339.2 & 476.0 & 33800.3 & 6.8158 \\
\hline CAS013 & 315.13 & 1.1617 & 1.0646 & 14.4072 & 97.13 & 83783.9 & 516.1 & 24834.7 & 5.8162 \\
\hline CASO14 & 534.61 & 1.5550 & 1.0933 & 18.8650 & 59.78 & 113451.6 & 1397.7 & 11551.7 & 6.2827 \\
\hline CAS015 & 327.62 & 3.1619 & 1.1432 & 13.7236 & 138.80 & 96772.6 & 418.3 & 8579.0 & 5.3625 \\
\hline CAS016 & 204.87 & 3.0366 & 1.0634 & 16.1554 & 138.02 & 91139.5 & 430.0 & 6487.2 & 5.6858 \\
\hline CAS017 & 86.28 & 2.0427 & 1.0971 & 28.4710 & 56.11 & 79712.0 & 151.7 & 5682.1 & 6.5807 \\
\hline CAS018 & 321.18 & 1.5005 & 1.1977 & 20.7783 & 77.13 & 96670.4 & 1305.5 & 10655.4 & 6.6201 \\
\hline CASO1 & .44 & 242 & 2258 & 19.7353 & 80.29 & 96611.1 & 1186.5 & 9989.1 & 6.8647 \\
\hline CASO20 & 158.37 & 4.0848 & 1.1634 & 13.2007 & 112.07 & 94241.3 & 325.6 & 6950.7 & 6.5946 \\
\hline CAS021 & 201.25 & 1.8119 & 0.8651 & 29.7721 & 58.66 & 87365.4 & 705.4 & 6792.6 & 5.4845 \\
\hline CASO22 & 304.64 & 1.6031 & 1.3189 & 22.6661 & 83.94 & 94983.3 & 1195.9 & 10598.8 & 6.5615 \\
\hline CASO23 & 305.83 & 1.4348 & 1.2497 & 19.5601 & 83.88 & 95438.6 & 1114.5 & 9640.8 & 6.8525 \\
\hline CASO24 & 260.98 & 1.7660 & 0.8765 & 28.3914 & 56.77 & 89571.4 & 630.4 & 9201.3 & 5.5367 \\
\hline CAS025 & 36.38 & 6.5309 & 2.1219 & 15.1677 & 114.36 & 87625.8 & 704.7 & 5283.2 & 10.9773 \\
\hline CASO26 & 137.35 & 1.9428 & 1.0090 & 26.6687 & 68.79 & 84789.8 & 286.4 & 6711.9 & 6.4157 \\
\hline CASO27 & 44.45 & 1.2631 & 1.1432 & 12.6823 & 85.41 & 71883.9 & 561.1 & 29498.8 & 5.9287 \\
\hline CASO28 & 476.82 & 1.2142 & 1.0086 & 12.7849 & 108.25 & 75068.3 & 534.0 & 39002.3 & 6.3823 \\
\hline CASO29 & 487.13 & 1.2545 & 0.8232 & 15.0044 & 94.09 & 80121.4 & 707.1 & 15321.4 & 4.6841 \\
\hline CASO30 & 447.36 & 1.6171 & 2.2219 & 21.1302 & 92.91 & 108388.6 & 1322.2 & 11822.1 & 11.4911 \\
\hline CAS031 & 214.72 & 3.7206 & 1.6724 & 11.5371 & 150.92 & 88710.7 & 450.6 & 6411.8 & 7.9806 \\
\hline CAS032 & 324.88 & 2.5647 & 1.4049 & 22.4343 & 93.71 & 93163.8 & 738.4 & 11565.7 & 7.2946 \\
\hline CASO33 & 123.13 & 1.9120 & 1.3847 & 23.3661 & 66.81 & 83216.3 & 321.7 & 7850.9 & 7.6667 \\
\hline CAS034 & 113.44 & 1.9257 & 1.3580 & 25.2202 & 54.99 & 82648.8 & 577.2 & 6460.2 & 7.4984 \\
\hline CAS035 & 152.06 & 2.1194 & 1.0789 & 24.9137 & 71.72 & 90040.7 & 440.8 & 7377.5 & 5.7711 \\
\hline CAS036 & 166.48 & 1.8154 & 0.7532 & 24.3528 & 53.01 & 82785.0 & 455.2 & 8126.1 & 4.4096 \\
\hline CAS037 & 181.82 & 1.8825 & 0.9023 & 27.7583 & 59.75 & 88808.3 & 387.5 & 6514.1 & 5.6199 \\
\hline CAS038 & 83.96 & 2.0437 & 0.8812 & 26.7256 & 59.94 & 91272.0 & 213.5 & 4615.3 & 5.2367 \\
\hline CASO39 & 189.18 & 1.8407 & 0.9757 & 26.0773 & 68.54 & 81475.0 & 296.1 & 7432.5 & 6.0014 \\
\hline CASO40 & 77.67 & 1.7788 & 1.2118 & 25.1908 & 61.11 & 84078.0 & 394.0 & 7090.8 & 6.8147 \\
\hline
\end{tabular}




\begin{tabular}{|c|c|c|c|c|c|}
\hline ANID & $K$ & $M n$ & $\mathrm{Na}$ & $\mathrm{Ti}$ & V \\
\hline CASO02 & 36126.1 & 414.84 & 12619.4 & 2533.1 & 22.70 \\
\hline CASO03 & 28684.4 & 435.96 & 19386.0 & 5358.6 & 62.92 \\
\hline CASO04 & 29619.3 & 439.04 & 19140.8 & 5169.0 & 65.95 \\
\hline CASO05 & 39561.6 & 382.21 & 13205.8 & 2408.5 & 18.15 \\
\hline CAS006 & 33990.3 & 350.86 & 18244.4 & 5617.4 & 90.05 \\
\hline CASO07 & 27074.3 & 265.06 & 10488.4 & 4182.4 & 77.10 \\
\hline CAS008 & 37896.9 & 412.36 & 11042.4 & 2112.3 & 12.84 \\
\hline CASO09 & 37476.6 & 416.68 & 13969.7 & 3943.0 & 36.33 \\
\hline CASO10 & 41651.1 & 780.43 & 17381.3 & 4444.3 & 40.37 \\
\hline CAS011 & 26726.1 & 226.94 & 15527.3 & 6823.4 & 68.32 \\
\hline CAS012 & 11577.3 & 1194.74 & 10428.8 & 10138.2 & 193.54 \\
\hline CASO13 & 19706.4 & 729.55 & 11903.9 & 6481.2 & 158.16 \\
\hline CASO14 & 26772.0 & 230.78 & 14981.1 & 6650.2 & 54.55 \\
\hline CASO15 & 41484.8 & 940.62 & 15284.7 & 4749.2 & 71.54 \\
\hline CASO16 & 50006.1 & 752.97 & 17640.5 & 4410.7 & 50.64 \\
\hline CASO17 & 41170.6 & 414.06 & 7952.5 & 1963.3 & 14.38 \\
\hline CAS018 & 32043.9 & 379.27 & 19654.8 & 5037.0 & 53.52 \\
\hline CAS019 & 29893.7 & 454.04 & 19473.9 & 5207.8 & 62.16 \\
\hline CASO20 & 41660.9 & 655.10 & 21820.1 & 6497.8 & 34.82 \\
\hline CASO21 & 35851.6 & 422.69 & 14501.7 & 4029.8 & 35.87 \\
\hline CASO22 & 30681.1 & 369.90 & 19602.7 & 4388.3 & 46.17 \\
\hline CASO23 & 29130.3 & 437.48 & 18801.2 & 5295.1 & 53.57 \\
\hline CASO24 & 37422.1 & 471.57 & 13273.1 & 4022.5 & 34.41 \\
\hline CASO25 & 47090.9 & 773.99 & 19366.4 & 4827.6 & 31.03 \\
\hline CASO26 & 39879.3 & 402.11 & 13746.3 & 2433.9 & 24.49 \\
\hline CASO27 & 29540.3 & 753.87 & 15208.9 & 4752.2 & 100.91 \\
\hline CASO28 & 27916.6 & 748.83 & 14406.1 & 4794.5 & 136.12 \\
\hline CASO29 & 34516.8 & 782.51 & 16779.6 & 4069.3 & 68.58 \\
\hline CASO30 & 25198.9 & 542.35 & 16401.8 & 7232.0 & 90.38 \\
\hline CAS031 & 42308.7 & 506.49 & 17716.1 & 5954.8 & 57.75 \\
\hline CAS032 & 28430.6 & 522.69 & 13921.8 & 5692.8 & 76.68 \\
\hline CASO33 & 34859.7 & 496.77 & 12871.3 & 3002.9 & 41.53 \\
\hline CAS034 & 42976.5 & 373.19 & 9155.8 & 2908.8 & 19.48 \\
\hline CASO35 & 36224.8 & 464.56 & 17987.1 & 2834.5 & 26.73 \\
\hline CAS036 & 35818.5 & 219.29 & 13917.3 & 3380.4 & 28.14 \\
\hline CAS037 & 38914.4 & 303.90 & 9941.8 & 2443.7 & 31.26 \\
\hline CAS038 & 35965.5 & 332.59 & 6889.3 & 3123.1 & 25.00 \\
\hline CAS039 & 39135.2 & 423.31 & 13127.5 & 1896.6 & 21.50 \\
\hline CASO40 & 39613.7 & 419.08 & 11811.9 & 2428.5 & 23.35 \\
\hline
\end{tabular}




\begin{tabular}{|c|c|c|c|c|c|c|c|c|}
\hline ANID & As & La & Lu & Nd & Sm & U & $\mathrm{Yb}$ & $\mathrm{Ce}$ \\
\hline CASO41 & 3.2567 & 45.0193 & 0.5536 & 37.9102 & 7.9043 & 4.7343 & 4.1929 & 80.7354 \\
\hline CASO42 & 1.5478 & 37.5285 & 0.4972 & 31.2248 & 6.6945 & 4.5188 & 3.7543 & 65.6032 \\
\hline CASO43 & 1.6295 & 39.1035 & 0.5550 & 31.4127 & 6.9166 & 4.3725 & 4.2427 & 70.1096 \\
\hline CASO44 & 2.4606 & 36.8307 & 0.5947 & 28.2859 & 6.3763 & 4.8727 & 4.3325 & 62.2083 \\
\hline CASO45 & 2.5502 & 34.9428 & 0.5983 & 28.8165 & 6.4620 & 5.4574 & 4.4118 & 69.6595 \\
\hline CASO46 & 2.9666 & 40.8907 & 0.6926 & 33.2217 & 7.3458 & 4.9846 & 5.4537 & 72.9857 \\
\hline CASO47 & 3.1781 & 32.7138 & 0.5346 & 25.6587 & 5.7744 & 4.8364 & 4.1817 & 61.9670 \\
\hline CASO48 & 2.5946 & 36.0805 & 0.5368 & 30.7454 & 6.3073 & 5.0124 & 3.8307 & 70.4656 \\
\hline CASO49 & 3.0651 & 54.0091 & 0.6093 & 42.0786 & 8.4105 & 4.4109 & 4.8363 & 104.2245 \\
\hline CAS050 & 7.7814 & 39.8896 & 0.6229 & 32.7279 & 6.8886 & 5.2073 & 4.6298 & 70.8538 \\
\hline CAS051 & 3.7791 & 39.3791 & 0.6391 & 31.5388 & 7.0034 & 5.5287 & 4.6901 & 74.0770 \\
\hline CAS052 & 4.0377 & 42.8105 & 0.6071 & 36.1186 & 7.1286 & 4.8259 & 3.9070 & 83.0928 \\
\hline CAS053 & 2.5428 & 34.2001 & 0.5957 & 28.4411 & 5.7862 & 4.7363 & 3.7454 & 61.0421 \\
\hline CAS054 & 2.6542 & 32.9917 & 0.6397 & 26.8868 & 5.7772 & 4.2746 & 4.2425 & 62.5286 \\
\hline CASO55 & 4.0059 & 39.2077 & 0.7348 & 32.0476 & 7.3133 & 6.1930 & 4.4881 & 65.7202 \\
\hline CAS056 & 3.2415 & 32.0561 & 0.6483 & 24.5985 & 5.6080 & 4.1938 & 4.1265 & 61.4972 \\
\hline CAS057 & 2.9603 & 49.8171 & 0.8155 & 43.1566 & 9.4965 & 6.0965 & 5.7969 & 94.9566 \\
\hline CAS058 & 3.0637 & 37.1135 & 0.6800 & 30.1970 & 6.4587 & 5.5246 & 4.5045 & 70.9804 \\
\hline CAS059 & 1.4346 & 48.7052 & 0.6229 & 41.9861 & 8.6542 & 4.3385 & 4.4426 & 91.5952 \\
\hline CAS060 & 2.9549 & 38.5691 & 0.6796 & 31.5548 & 6.7967 & 5.5286 & 4.4509 & 75.7370 \\
\hline CAS061 & 2.5992 & 41.5749 & 0.6749 & 36.1724 & 8.2182 & 4.4730 & 4.7126 & 112.3982 \\
\hline CAS062 & 7.7180 & 39.3435 & 0.6739 & 31.0128 & 6.8628 & 4.7610 & 4.6074 & 70.2389 \\
\hline CAS063 & 7.0851 & 38.6793 & 0.6777 & 33.8929 & 6.7195 & 5.3611 & 4.5624 & 74.5202 \\
\hline CAS064 & 2.2147 & 34.5124 & 0.5757 & 27.6535 & 5.8921 & 5.0531 & 3.8002 & 63.7504 \\
\hline CAS065 & 2.5456 & 44.5873 & 0.8297 & 38.9253 & 8.6277 & 6.1241 & 5.7396 & 98.0491 \\
\hline CAS066 & 7.6652 & 35.1128 & 0.6657 & 32.4116 & 6.8535 & 4.7807 & 4.7061 & 68.7809 \\
\hline CAS067 & 2.0046 & 43.2627 & 0.7237 & 34.9967 & 7.8354 & 5.3271 & 4.8742 & 83.3271 \\
\hline CAS068 & 3.9817 & 36.3291 & 0.4337 & 34.1488 & 6.9712 & 2.6885 & 3.0520 & 76.9473 \\
\hline CAS069 & 5.1702 & 40.2858 & 0.4559 & 37.0773 & 7.7031 & 3.0868 & 3.0770 & 83.7292 \\
\hline CAS070 & 2.8569 & 40.9554 & 0.4377 & 34.2549 & 7.7391 & 2.6380 & 3.1649 & 86.5593 \\
\hline CAS071 & 3.6893 & 38.9225 & 0.3940 & 36.1679 & 7.1428 & 2.1047 & 3.0625 & 79.4199 \\
\hline CASO72 & 5.3270 & 39.6621 & 0.4669 & 36.5692 & 7.5784 & 3.3256 & 3.3720 & 81.4441 \\
\hline CAS073 & 4.3895 & 39.6505 & 0.4536 & 36.3135 & 7.3678 & 3.0196 & 3.2329 & 81.3707 \\
\hline CAS074 & 3.9556 & 41.3004 & 0.4697 & 36.8098 & 7.5848 & 3.1230 & 3.2918 & 83.4626 \\
\hline CAS075 & 3.4757 & 45.8015 & 0.4700 & 39.9881 & 8.4968 & 3.0660 & 3.3450 & 95.2332 \\
\hline CAS076 & 4.1431 & 48.5116 & 0.4737 & 41.8735 & 8.6024 & 3.2179 & 3.6557 & 99.0317 \\
\hline CASO77 & 6.9161 & 40.0512 & 0.4626 & 34.8813 & 7.4935 & 3.2874 & 3.1752 & 82.6078 \\
\hline CAS078 & 3.9976 & 43.7138 & 0.4588 & 40.4610 & 7.9037 & 3.6529 & 3.3632 & 89.4359 \\
\hline CAS079 & 4.9811 & 40.2944 & 0.4225 & 37.4224 & 7.5872 & 2.9997 & 3.1989 & 86.1608 \\
\hline CAS080 & 3.6005 & 41.2242 & 0.4023 & 36.0601 & 7.4143 & 2.3590 & 3.0853 & 82.4682 \\
\hline
\end{tabular}




\begin{tabular}{|c|c|c|c|c|c|c|c|c|c|}
\hline ANID & Co & $\mathrm{Cr}$ & Cs & Eu & $\mathrm{Fe}$ & $\mathrm{Hf}$ & $\mathrm{Rb}$ & Sb & Sc \\
\hline CAS041 & 3.7589 & 27.5035 & 7.2523 & 0.7822 & 22084.3 & 8.7514 & 127.86 & 0.3880 & 8.7979 \\
\hline CAS042 & 1.7587 & 6.5777 & 4.6127 & 0.5537 & 13001.5 & 5.6657 & 184.65 & 0.1824 & 4.0588 \\
\hline CASO43 & 1.7816 & 6.8522 & 4.7533 & 0.5666 & 13650.1 & 6.1885 & 187.63 & 0.2088 & 4.1526 \\
\hline CASO44 & 2.8516 & 21.9524 & 6.6954 & 0.5629 & 17659.2 & 6.8106 & 214.63 & 0.5559 & 6.6800 \\
\hline CASO45 & 2.6856 & 13.5603 & 6.5970 & 0.3972 & 12392.3 & 5.7215 & 204.77 & 0.4339 & 4.0116 \\
\hline CASO46 & 1.8163 & 9.5558 & 3.7163 & 0.4260 & 14343.9 & 7.0037 & 200.95 & 0.3016 & 5.0194 \\
\hline CAS047 & 2.4125 & 11.2386 & 3.4586 & 0.3956 & 14971.4 & 6.7870 & 194.88 & 0.3052 & 5.1668 \\
\hline CASO48 & 4.5540 & 14.3923 & 5.7043 & 0.7958 & 20579.9 & 9.2070 & 163.41 & 0.6447 & 5.4604 \\
\hline CASO49 & 5.0390 & 15.3821 & 2.7040 & 0.9966 & 20450.2 & 7.7078 & 198.44 & 0.4980 & 6.7098 \\
\hline CAS050 & 2.1186 & 13.1589 & 4.2163 & 0.4948 & 16383.2 & 6.7338 & 196.63 & 0.5921 & 5.8415 \\
\hline CAS051 & 2.5119 & 19.7764 & 9.5277 & 0.8003 & 15893.6 & 6.9039 & 182.74 & 0.4272 & 6.0611 \\
\hline CAS052 & 4.0721 & 13.8964 & 6.2793 & 0.9355 & 21044.1 & 8.9434 & 166.51 & 0.6573 & 6.0522 \\
\hline CAS053 & 2.8990 & 20.2635 & 5.8160 & 0.6834 & 15941.6 & 6.7378 & 154.25 & 0.3568 & 6.1329 \\
\hline CAS054 & 2.3122 & 11.4905 & 3.6206 & 0.3971 & 14962.0 & 6.7549 & 193.24 & 0.3101 & 5.2085 \\
\hline CAS055 & 2.9253 & 27.8753 & 8.1440 & 0.6580 & 19900.2 & 7.2544 & 203.11 & 0.4696 & 8.2744 \\
\hline CAS056 & 1.7283 & 10.5063 & 3.7204 & 0.3849 & 14740.8 & 6.9117 & 200.81 & 0.3184 & 5.1749 \\
\hline CAS057 & 2.8840 & 19.7078 & 7.0942 & 0.7877 & 12497.2 & 6.6922 & 231.19 & 0.3307 & 6.7613 \\
\hline CAS058 & 1.9895 & 10.5271 & 4.3699 & 0.3572 & 11673.1 & 6.2172 & 216.01 & 0.3006 & 3.9174 \\
\hline CAS059 & 3.4420 & 20.8617 & 2.2335 & & 21961.1 & 10.9397 & & 0.4428 & 6.8855 \\
\hline CASO60 & 2.5250 & 23.5322 & 9.2732 & 0.7932 & 15294.0 & 7.3989 & 179.68 & 0.4748 & 5.9831 \\
\hline CAS061 & 3.4180 & 17.6954 & 4.8162 & 0.7080 & 16091.2 & 6.5036 & 200.94 & 0.4087 & 5.8880 \\
\hline CAS062 & 1.9244 & 12.2982 & 4.3027 & 0.4852 & 16158.5 & 6.5278 & 198.07 & 0.5049 & 5.7849 \\
\hline CAS063 & 2.9491 & 19.1632 & 6.5839 & 0.5503 & 20562.0 & 7.2834 & 213.93 & 0.8273 & 6.9413 \\
\hline CAS064 & 2.7171 & 22.1709 & 6.1667 & 0.6912 & 16005.9 & 6.5797 & 169.58 & 0.3910 & 6.1375 \\
\hline CAS065 & 2.6760 & 12.0675 & 4.8835 & 0.5300 & 8651.3 & 6.4381 & 231.74 & 0.2600 & 5.0009 \\
\hline CAS066 & 3.5286 & 29.3509 & 5.1366 & 0.5881 & 22888.3 & 7.0241 & 201.18 & 0.5538 & 7.3848 \\
\hline CAS067 & 3.6772 & 22.3859 & 8.2508 & 1.0782 & 18074.6 & 7.8992 & 178.36 & 0.4302 & 5.9467 \\
\hline CAS068 & 14.5958 & 50.8329 & 6.7711 & 1.4355 & 34967.5 & 6.0586 & 124.73 & 0.5591 & 12.1798 \\
\hline CAS069 & 16.0887 & 72.3237 & 5.5181 & 1.4392 & 39045.6 & 6.6338 & 107.26 & 0.6613 & 11.8476 \\
\hline CAS070 & 14.5419 & 60.1179 & 5.3344 & 1.5112 & 37156.0 & 6.9278 & 107.70 & 0.5111 & 12.1694 \\
\hline CAS071 & 14.4387 & 56.1791 & 4.9281 & 1.4325 & 34996.8 & 6.3750 & 112.22 & 0.4735 & 11.6816 \\
\hline CAS072 & 15.8863 & 74.1064 & 6.5874 & 1.4135 & 39818.2 & 7.7022 & 126.68 & 0.7131 & 11.6147 \\
\hline CAS073 & 15.7665 & 70.1695 & 6.1340 & 1.4092 & 38255.3 & 7.1050 & 122.43 & 0.6120 & 11.9023 \\
\hline CAS074 & 15.0065 & 65.6922 & 5.9128 & 1.4262 & 38231.8 & 7.4339 & 121.27 & 0.6886 & 11.4398 \\
\hline CAS075 & 17.2256 & 63.4972 & 9.3607 & 1.5616 & 39948.0 & 7.5041 & 143.12 & 0.7694 & 12.8352 \\
\hline CAS076 & 16.0381 & 77.5221 & 7.6475 & 1.5008 & 43605.1 & 9.1458 & 134.24 & 0.8033 & 12.2455 \\
\hline CAS077 & 15.7534 & 67.1214 & 7.9480 & 1.4170 & 37601.5 & 6.9847 & 137.21 & 0.7010 & 11.8132 \\
\hline CAS078 & 17.1140 & 62.6466 & 9.1207 & 1.5016 & 39522.1 & 7.3420 & 144.66 & 0.6824 & 12.7273 \\
\hline CAS079 & 15.4464 & 59.3737 & 6.6639 & 1.5024 & 39227.6 & 7.5016 & 117.94 & 0.7114 & 13.2301 \\
\hline CAS080 & 15.0688 & 48.7977 & 5.5735 & 1.4667 & 35651.9 & 5.8608 & 114.38 & 0.5464 & 12.5338 \\
\hline
\end{tabular}




\begin{tabular}{|c|c|c|c|c|c|c|c|c|c|}
\hline & $\mathrm{Sr}$ & Ta & $\mathrm{Tb}$ & Th & $\mathrm{Zn}$ & Al & $\mathrm{Ba}$ & $\mathrm{Ca}$ & Dy \\
\hline CAS041 & 196.50 & 1.8913 & 1.0431 & 25.9421 & 98.41 & 94370.1 & 919.9 & 15916.8 & 6.1914 \\
\hline CASO42 & 5.69 & 7936 & 9754 & .0078 & 52.37 & 79758.7 & 289.4 & 1755.4 & 5.7268 \\
\hline CASO43 & .52 & 8249 & 0170 & 4.4885 & 56.03 & 77985.0 & 295.0 & 8937.1 & 5.3509 \\
\hline CASO44 & & 9240 & 1.0480 & & & 88158.5 & 560.0 & 6608.7 & 5.2666 \\
\hline CASO45 & 78.35 & 1.8137 & 0.9699 & 24.7052 & 52.03 & 82608.1 & 338.9 & 7941.4 & 6.3131 \\
\hline CASO46 & 138.60 & 1.8668 & 1.2344 & 29.5629 & 69.86 & 79200.4 & 188.0 & 6327.1 & 7.1762 \\
\hline CAS047 & 50.67 & 8829 & 0.8936 & 24.8260 & 65.54 & 75060.2 & 233.7 & 6341.6 & 5.5155 \\
\hline CASO48 & 0.36 & 7094 & 0.9471 & 18.8067 & .31 & 80289.2 & 612.7 & 7071.5 & 5.2285 \\
\hline CASO49 & 143.39 & 1.8047 & 1.2067 & 22.7597 & 65.04 & 88121.0 & 411.1 & 6661.5 & 7.0862 \\
\hline CAS050 & 48.13 & 9418 & 1.0412 & 7.2205 & 67.57 & 84615.1 & 336.3 & 6425.8 & 6.7814 \\
\hline CAS051 & 119.34 & 1.8204 & 1.0410 & 24.4960 & 58.49 & 77329.9 & 521.5 & 6174.0 & 6.2199 \\
\hline CAS052 & 222.77 & 1.6430 & 1.0104 & 21.3991 & 63.07 & 80720.5 & 602.1 & 7699.9 & 5.3126 \\
\hline CAS053 & 262.60 & 1.6859 & 0.8651 & 365 & 60.32 & 80243.5 & 622.9 & 3618.8 & 5.2013 \\
\hline CAS054 & 138.32 & 1.8334 & 0.9217 & 24.9571 & 65.88 & 73978.8 & 203.7 & 5219.3 & 5.2242 \\
\hline CASO55 & 128.52 & 1.9017 & 1.0332 & 27.2405 & 2.59 & 89494.5 & 280.7 & 185.9 & 6.0212 \\
\hline CAS056 & 99.78 & 1.8898 & 1.0345 & 24.8018 & 61.01 & 74105.1 & 135.4 & 5491.1 & 5.3958 \\
\hline CAS057 & 107.12 & 2.0862 & 1.4500 & 29.7064 & 65.61 & 87693.1 & 377.0 & 7633.4 & 8.4756 \\
\hline CAS058 & 4.29 & 1.8420 & .9689 & 26.0820 & 1.81 & 75281.0 & 239.2 & 591.7 & 5.5567 \\
\hline CAS059 & 348.30 & 1.8194 & 1.1625 & 22.0739 & 71.22 & 89872.9 & 929.6 & 10690.4 & 6.9483 \\
\hline CAS060 & 150.13 & 1.7022 & 0.9524 & 24.2636 & 66.40 & 77962.7 & 577.0 & 6931.7 & 5.8363 \\
\hline & & & 1132 & 26.7798 & 57.09 & 83043.8 & 39.5 & 38.4 & 7726 \\
\hline CAS062 & 175.09 & 1.8890 & 1.0752 & 27.2233 & 72.12 & 85031.9 & 291.2 & 5241.6 & 6.2963 \\
\hline CAS063 & 116.04 & 1.9680 & 0.9393 & 27.8094 & 74.61 & 92898.5 & 298.2 & 5021.3 & 6.7894 \\
\hline CAS064 & 214.82 & 1.6817 & 0.8324 & 23.2604 & 58.59 & 80187.1 & 535.8 & 7946.9 & 5.1171 \\
\hline CAS065 & 79.84 & 2.0706 & 1.2860 & 28.9751 & 57.83 & 78238.6 & 341.4 & 6724.9 & 8.3114 \\
\hline CAS066 & 84.74 & 1.7889 & 0.9830 & 24.7935 & 91.18 & 86528.8 & 288.6 & 6006.0 & 6.5696 \\
\hline CAS067 & 6.26 & 1.7107 & 1.1359 & 24.2742 & 56.02 & 73661.7 & 598.8 & 6176.0 & 7.2100 \\
\hline CAS068 & 536.18 & 1.0194 & 0.8930 & 11.6915 & 96.76 & 83436.2 & 862.6 & 30324.8 & 5.2250 \\
\hline CAS069 & 541.18 & 1.1470 & 0.9842 & 11.9963 & 111.76 & 69733.8 & 696.0 & 38770.0 & 5.3413 \\
\hline CASO70 & 472.50 & 1.0298 & 1.0492 & 12.3000 & 93.89 & 78649.9 & 759.2 & 27536.4 & 5.5774 \\
\hline CAS071 & 476.77 & 1.0857 & 0.8929 & 12.2713 & 91.06 & 80091.3 & 766.3 & 20157.1 & 5.4282 \\
\hline CAS072 & 466.87 & 1.1746 & 0.9874 & 12.0333 & 108.35 & 74139.3 & 656.0 & 30429.0 & 5.6989 \\
\hline CAS073 & 573.99 & 1.1886 & 0.9560 & 12.4616 & 108.14 & 75717.1 & 614.8 & 29046.4 & 5.8255 \\
\hline CAS074 & 9.88 & 1.1421 & 0.9503 & 14.6466 & 102.41 & 73605.3 & 712.0 & 35197.8 & 4.9233 \\
\hline CAS075 & 46.82 & 1.1851 & 1.0407 & 14.4949 & 119.02 & 76083.2 & 647.2 & 27828.8 & 5.4885 \\
\hline CAS076 & 464.03 & 1.2794 & 1.0493 & 15.2760 & 114.50 & 70313.1 & 561.3 & 37505.2 & 7.1314 \\
\hline CAS077 & 494.38 & 1.2190 & 0.9688 & 12.2216 & 114.90 & 73031.3 & 635.0 & 40083.1 & 5.2889 \\
\hline CAS078 & 407.76 & 1.1396 & 0.9965 & 12.9615 & 118.38 & 77762.8 & 601.7 & 31608.7 & 5.3788 \\
\hline CAS079 & 455.10 & 1.0349 & 1.0221 & 11.3313 & 100.28 & 79809.1 & 706.8 & 29807.9 & 5.7545 \\
\hline CASO80 & 486.79 & 0.9144 & 0.9335 & 11.6357 & 100.88 & 81958.1 & 795.2 & 29842.1 & 4.8546 \\
\hline
\end{tabular}




\begin{tabular}{|c|c|c|c|c|c|}
\hline ANID & $\mathrm{K}$ & Mn & $\mathrm{Na}$ & $\mathrm{Ti}$ & $\bar{v}$ \\
\hline CAS041 & 24436.2 & 411.72 & 6242.6 & 3981.8 & 40.32 \\
\hline CAS042 & 36489.4 & 410.46 & 11328.4 & 2391.9 & 16.94 \\
\hline CASO43 & 36368.6 & 431.78 & 11443.4 & 3075.5 & 10.90 \\
\hline CASO44 & 36779.6 & 376.84 & 10238.8 & 2849.1 & 23.68 \\
\hline CASO45 & 53187.0 & 384.61 & 10953.2 & 1949.0 & 17.34 \\
\hline CASO46 & 39229.9 & 367.84 & 10501.2 & 2422.9 & 21.10 \\
\hline CASO47 & 39520.4 & 414.98 & 10696.9 & 2182.8 & 24.43 \\
\hline CASO48 & 38003.7 & 498.13 & 15305.0 & 4097.7 & 30.34 \\
\hline CASO49 & 46550.0 & 530.40 & 11230.4 & 2929.3 & 26.44 \\
\hline CAS050 & 38011.6 & 461.61 & 14073.8 & 2274.0 & 22.92 \\
\hline CAS051 & 35114.7 & 302.66 & 11669.8 & 2944.4 & 22.24 \\
\hline CAS052 & 37931.7 & 437.34 & 15199.8 & 3725.3 & 32.94 \\
\hline CAS053 & 38772.9 & 344.46 & 12783.0 & 3460.6 & 23.04 \\
\hline CAS054 & 39080.5 & 381.20 & 10773.0 & 2114.6 & 17.83 \\
\hline CAS055 & 35242.2 & 339.30 & 10025.4 & 3064.4 & 45.38 \\
\hline CAS056 & 37180.9 & 404.54 & 11018.5 & 2012.9 & 18.36 \\
\hline CAS057 & 37739.3 & 317.97 & 10492.3 & 2245.9 & 22.42 \\
\hline CAS058 & 39459.6 & 468.54 & 11659.9 & 2105.2 & 11.26 \\
\hline CAS059 & 36051.2 & 501.48 & 17436.0 & 3602.2 & 25.31 \\
\hline CASO60 & 33159.5 & 309.58 & 11352.4 & 2549.0 & 27.11 \\
\hline CAS061 & 35741.8 & 339.44 & 11185.4 & 2200.7 & 29.11 \\
\hline CAS062 & 37268.7 & 377.62 & 13824.4 & 2706.9 & 22.77 \\
\hline CAS063 & 36505.0 & 357.33 & 12345.1 & 2510.3 & 32.99 \\
\hline CAS064 & 34825.7 & 304.72 & 12057.7 & 3661.1 & 21.55 \\
\hline CAS065 & 40128.0 & 507.56 & 11144.8 & 1423.6 & 0.00 \\
\hline CAS066 & 34842.6 & 361.11 & 12604.0 & 2522.1 & 42.42 \\
\hline CAS067 & 36114.7 & 394.44 & 12511.7 & 3407.4 & 24.91 \\
\hline CAS068 & 28267.5 & 678.20 & 13900.3 & 4504.4 & 73.53 \\
\hline CASO69 & 27240.3 & 706.40 & 14819.4 & 4685.1 & 100.43 \\
\hline CAS070 & 30050.6 & 718.16 & 13258.9 & 4465.9 & 86.17 \\
\hline CAS071 & 27833.3 & 727.09 & 14981.4 & 4000.3 & 90.10 \\
\hline CAS072 & 28860.0 & 647.07 & 15856.8 & 4838.2 & 105.54 \\
\hline CAS073 & 28797.0 & 634.52 & 15267.7 & 5899.4 & 130.17 \\
\hline CASO74 & 28737.1 & 651.12 & 15592.0 & 5219.5 & 100.03 \\
\hline CAS075 & 27644.1 & 621.20 & 14270.4 & 4920.2 & 90.55 \\
\hline CAS076 & 26414.6 & 941.55 & 15536.4 & 5439.1 & 104.52 \\
\hline CASO77 & 25399.7 & 637.46 & 14732.6 & 4384.8 & 141.67 \\
\hline CAS078 & 26819.6 & 625.08 & 13995.7 & 4390.1 & 101.84 \\
\hline CAS079 & 28175.3 & 748.16 & 12571.7 & 5523.6 & 86.13 \\
\hline CAS080 & 29659.3 & 711.54 & 13233.5 & 4275.1 & 77.38 \\
\hline
\end{tabular}




\begin{tabular}{|l|r|r|r|r|r|r|r|r|}
\hline ANID & As & La & Lu & Nd & Sm & $\mathbf{U}$ & Yb & Ce \\
\hline CAS081 & 3.6851 & 39.1086 & 0.4473 & 34.0483 & 7.4974 & 2.5831 & 3.3973 & 81.2889 \\
\hline CAS082 & 7.1054 & 41.2911 & 0.4562 & 41.7365 & 7.4914 & 3.2174 & 3.2382 & 84.1780 \\
\hline CAS083 & 4.3863 & 38.6509 & 0.4283 & 37.5167 & 7.4191 & 2.5651 & 3.0554 & 80.9157 \\
\hline CAS084 & 6.1969 & 49.3827 & 0.5000 & 43.1117 & 8.8766 & 3.1259 & 3.6296 & 99.7811 \\
\hline CAS085 & 3.7020 & 40.1128 & 0.4420 & 33.8419 & 7.4079 & 2.3173 & 3.1453 & 83.4515 \\
\hline CAS086 & 6.6370 & 38.8142 & 0.4518 & 35.6631 & 7.5176 & 2.6328 & 3.4481 & 80.1049 \\
\hline CAS087 & 5.1610 & 42.5902 & 0.4636 & 37.5684 & 7.6168 & 3.1799 & 3.3764 & 86.5102 \\
\hline CAS088 & 5.7476 & 40.7753 & 0.4758 & 35.1990 & 7.8482 & 3.2933 & 3.4916 & 82.7529 \\
\hline CAS089 & 3.2028 & 43.3508 & 0.4436 & 38.3824 & 7.5042 & 2.7743 & 3.2383 & 88.9082 \\
\hline CAS090 & 6.7879 & 40.1618 & 0.4543 & 34.2774 & 7.5744 & 2.8738 & 3.3344 & 83.1536 \\
\hline CAS091 & 5.6633 & 46.2563 & 0.4802 & 40.9469 & 8.2093 & 3.1697 & 3.4242 & 93.5024 \\
\hline CAS092 & 7.7555 & 43.8382 & 0.4519 & 39.4264 & 8.0353 & 2.6522 & 3.2753 & 90.1325 \\
\hline CAS093 & 4.1875 & 40.0710 & 0.4451 & 39.7193 & 7.2856 & 2.4951 & 3.2047 & 84.0900 \\
\hline CAS094 & 3.1792 & 41.5925 & 0.4919 & 39.6154 & 7.9952 & 2.9073 & 3.7340 & 86.7034 \\
\hline CAS095 & 5.2690 & 42.0422 & 0.4467 & 41.0927 & 8.1287 & 3.0530 & 3.4097 & 86.6034 \\
\hline CAS096 & 3.6293 & 43.9737 & 0.4488 & 38.1235 & 7.9268 & 3.0744 & 3.2803 & 89.4531 \\
\hline CAS097 & 3.4831 & 39.2574 & 0.4532 & 37.3028 & 7.6029 & 2.5296 & 3.2929 & 82.4704 \\
\hline CAS098 & 4.3516 & 43.1891 & 0.4326 & 36.5334 & 7.7279 & 2.8091 & 3.3476 & 86.5664 \\
\hline CAS099 & 3.3134 & 37.8189 & 0.4451 & 32.9778 & 6.9974 & 1.9533 & 3.3259 & 78.9371 \\
\hline CAS100 & 3.3392 & 39.1526 & 0.4581 & 35.6262 & 7.5271 & 2.6277 & 3.3303 & 79.8365 \\
\hline CAS101 & 5.2333 & 41.0193 & 0.4922 & 37.0943 & 7.8903 & 2.5289 & 3.6353 & 84.6106 \\
\hline CAS103 & 6.6741 & 41.7337 & 0.4675 & 37.6224 & 8.1326 & 3.3790 & 3.5279 & 86.5038 \\
\hline CAS104 & 2.8271 & 38.2995 & 0.4169 & 34.0389 & 7.1434 & 2.6167 & 3.1051 & 79.7034 \\
\hline CAS105 & 2.3918 & 42.0998 & 0.4121 & 31.8250 & 6.3417 & 2.8379 & 2.9056 & 82.7726 \\
\hline
\end{tabular}




\begin{tabular}{|c|c|c|c|c|c|c|c|c|c|}
\hline ANID & Co & $\mathrm{Cr}$ & Cs & & $\mathrm{Fe}$ & $\mathrm{Hf}$ & $\mathbf{R b}$ & Sb & Sc \\
\hline CAS081 & 14.8230 & 62.2538 & 5.0307 & 1.4099 & 37361.0 & 6.9778 & 112.22 & 0.5765 & 11.2425 \\
\hline CAS082 & 15.6326 & 58.9846 & 7.0923 & 1.4385 & 36157.4 & 6.5448 & 134.38 & 0.7394 & 11.4682 \\
\hline CAS083 & 16.1516 & 67.4426 & 5.7292 & 1.4661 & 41232.2 & 7.3855 & 106.86 & 0.5919 & 13.0716 \\
\hline CAS084 & 16.0105 & 71.9727 & 6.6652 & 1.4848 & 40458.1 & 8.5409 & 129.48 & 0.7466 & 11.9738 \\
\hline CAS085 & 15.0448 & 62.7594 & 7.4592 & 1.4587 & 37854.1 & 7.1014 & 127.03 & 0.5777 & 12.7303 \\
\hline CAS086 & 13.1768 & 57.3245 & 4.5619 & 1.3580 & 35513.8 & 6.4317 & 107.91 & 0.5827 & 11.5002 \\
\hline CAS087 & 15.7209 & 69.1795 & 5.8885 & 1.4300 & 39017.7 & 8.1446 & 123.71 & 0.6461 & 11.6344 \\
\hline CAS088 & 15.9298 & 68.8718 & 8.5095 & 1.4584 & 39117.4 & 7.0734 & 145.32 & 0.7327 & 12.1605 \\
\hline CAS089 & 15.0671 & 56.6372 & 5.7641 & 1.4378 & 35013.2 & 6.6190 & 114.68 & 0.5556 & 10.7773 \\
\hline CAS090 & 16.4648 & 73.4819 & 8.4288 & 1.4480 & 38964.2 & 7.6309 & 143.91 & 0.7428 & 12.1845 \\
\hline CAS091 & 15.5546 & 70.1077 & 6.9628 & 1.4548 & 39777.3 & 7.8008 & 131.51 & 0.6867 & 11.7979 \\
\hline CASO92 & 16.4191 & 74.7115 & 5.7211 & 1.5011 & 41441.1 & 7.9607 & 108.52 & 0.7664 & 12.5149 \\
\hline CAS093 & 14.8137 & 54.6318 & 7.2986 & 1.4653 & 36769.0 & 6.9620 & 127.54 & 0.5684 & 12.4682 \\
\hline CASO94 & 13.4128 & 59.9706 & 4.7463 & 1.4530 & 36997.5 & 8.4553 & 108.74 & 0.6033 & 11.5715 \\
\hline CAS095 & 16.5054 & 73.3579 & 5.6361 & 1.5055 & 41137.6 & 8.1801 & 112.49 & 0.6975 & 12.4756 \\
\hline CAS096 & 16.9531 & 62.6889 & 9.1359 & 1.4715 & 39684.0 & 7.4093 & 143.03 & 0.6992 & 12.7919 \\
\hline CAS097 & 16.1364 & 68.4002 & 5.0817 & 1.4967 & 40422.7 & 8.0960 & 102.47 & 0.5242 & 12.9993 \\
\hline CAS098 & 15.6601 & 70.3519 & 7.7281 & 1.4811 & 39878.8 & 7.9184 & 140.85 & 0.7244 & 11.9495 \\
\hline CAS099 & 14.2234 & 60.8175 & 5.2839 & 1.4008 & 37081.1 & 7.3625 & 108.63 & 0.5116 & 12.1382 \\
\hline CAS100 & 14.9320 & 63.5200 & 5.9519 & 1.4086 & 38011.1 & 7.2893 & 123.06 & 0.6805 & 11.3162 \\
\hline CAS101 & 13.5555 & 57.7728 & 6.5165 & 1.4457 & 35954.4 & 7.4965 & 125.49 & 0.6657 & 11.6067 \\
\hline CAS103 & 16.0669 & 75.0013 & 7.4806 & 1.4819 & 40655.3 & 8.3219 & 134.69 & 0.7702 & 11.9650 \\
\hline CAS104 & 14.7362 & 58.6146 & 5.0016 & 1.4844 & 37019.5 & 6.5340 & 106.91 & 0.5683 & 12.7727 \\
\hline CAS105 & 11.6354 & 33.8347 & 5.1433 & 1.3024 & 28742.7 & 6.3231 & 147.83 & 0.4962 & 8.1241 \\
\hline
\end{tabular}




\begin{tabular}{|c|c|c|c|c|c|c|c|c|c|c|}
\hline ANID & Sc & $\mathrm{Sr}$ & Ta & Tb & Th & $\mathrm{Zn}$ & Al & $\mathrm{Ba}$ & $\mathrm{Ca}$ & Dy \\
\hline CAS081 & 11.2425 & 580.55 & 1.1637 & 1.0356 & 11.9793 & 106.97 & 76676.6 & 700.8 & 35315.6 & 5.7289 \\
\hline CAS082 & 11.4682 & 536.23 & 1.1788 & 0.9224 & 12.7406 & 105.41 & 71392.0 & 776.1 & 37126.5 & 5.4204 \\
\hline CAS083 & 13.0716 & 495.97 & 1.0848 & 0.9284 & 11.3504 & 101.05 & 77739.2 & 813.1 & 29617.2 & 5.7035 \\
\hline CAS084 & 11.9738 & 467.58 & 1.1897 & 1.1178 & 14.4440 & 109.11 & 74164.1 & 762.1 & 31942.5 & 5.8522 \\
\hline CAS085 & 12.7303 & 460.74 & 1.0912 & 0.9591 & 11.7992 & 94.21 & 81088.3 & 715.0 & 28828.0 & 5.2102 \\
\hline CAS086 & 11.5002 & 411.63 & 1.1681 & 0.9929 & 12.9243 & 88.97 & 71935.1 & 694.7 & 31723.0 & 6.2925 \\
\hline CAS087 & 11.6344 & 498.78 & 1.2433 & 0.9960 & 12.4447 & 111.05 & 74214.5 & 743.9 & 28793.2 & 5.4872 \\
\hline CAS088 & 12.1605 & 450.78 & 1.2436 & 0.9831 & 12.2976 & 109.87 & 82578.0 & 612.4 & 29972.1 & 5.1623 \\
\hline CAS089 & 10.7773 & 507.60 & 1.1334 & 0.9553 & 12.4586 & 104.18 & 74536.5 & 654.2 & 22795.5 & 5.3135 \\
\hline CAS090 & 12.1845 & 477.40 & 1.2155 & 0.9631 & 12.8599 & 104.74 & 75606.2 & 529.6 & 33114.9 & 5.1284 \\
\hline CAS091 & 11.7979 & 480.37 & 1.1950 & 1.0273 & 13.2924 & 107.36 & 76491.6 & 655.9 & 31176.4 & 5.5006 \\
\hline CAS092 & 12.5149 & 432.79 & 1.2690 & 1.0982 & 13.8535 & 111.30 & 72637.6 & 651.4 & 31572.6 & 5.5856 \\
\hline CAS093 & 12.4682 & 490.33 & 1.0350 & 0.9047 & 12.0409 & 89.95 & 79608.7 & 715.3 & 30098.1 & 5.5631 \\
\hline CAS094 & 11.5715 & 492.02 & 1.1725 & 1.0825 & 13.3951 & 90.75 & 71485.5 & 722.2 & 32239.6 & 6.6542 \\
\hline CAS095 & 12.4756 & 508.29 & 1.1588 & 1.1093 & 13.8884 & 122.87 & 74683.7 & 716.7 & 23905.0 & 6.6831 \\
\hline CAS096 & 12.7919 & 463.11 & 1.1371 & 1.0216 & 13.0914 & 123.02 & 80345.5 & 691.9 & 29256.1 & 5.7476 \\
\hline CAS097 & 12.9993 & 464.36 & 1.0854 & 1.1884 & 11.2612 & 102.48 & 82462.7 & 703.6 & 27226.0 & 5.9876 \\
\hline CAS098 & 11.9495 & 429.04 & 1.1608 & 1.0151 & 13.6360 & 118.61 & 76745.3 & 603.1 & 35841.4 & 5.6067 \\
\hline CAS099 & 12.1382 & 470.45 & 1.0014 & 0.9211 & 11.3287 & 101.03 & 82737.1 & 757.6 & 26059.5 & 5.4690 \\
\hline CAS100 & 11.3162 & 545.75 & 1.1632 & 1.0222 & 11.9406 & 110.60 & 73699.6 & 761.9 & 37338.3 & 5.6278 \\
\hline CAS101 & 11.6067 & 414.80 & 1.1673 & 1.1020 & 13.6890 & 94.19 & 77810.0 & 813.0 & 30954.4 & 6.2015 \\
\hline CAS103 & 11.9650 & 465.62 & 1.2361 & 1.0358 & 12.7923 & 105.13 & 78188.1 & 696.6 & 27515.4 & 6.3571 \\
\hline CAS104 & 12.7727 & 540.43 & 1.0274 & 0.9271 & 13.2637 & 101.66 & 86346.7 & 957.7 & 21783.0 & 6.0790 \\
\hline CAS105 & 8.1241 & 338.04 & 1.2792 & 0.7607 & 15.3642 & 97.10 & 79586.6 & 674.5 & 13083.1 & 5.1854 \\
\hline
\end{tabular}




\begin{tabular}{|l|r|r|r|r|r|}
\hline ANID & $\mathbf{K}$ & $\mathbf{M n}$ & $\mathbf{N a}$ & $\mathbf{T i}$ & $\mathbf{V}$ \\
\hline CAS081 & 27912.5 & 621.60 & 14825.9 & 4125.6 & 91.91 \\
\hline CAS082 & 27061.7 & 660.80 & 15219.1 & 4689.4 & 117.76 \\
\hline CAS083 & 27156.9 & 780.07 & 12733.2 & 5314.9 & 86.02 \\
\hline CAS084 & 28175.6 & 674.14 & 15866.3 & 5354.0 & 113.95 \\
\hline CAS085 & 27839.6 & 718.26 & 14080.8 & 4554.1 & 91.32 \\
\hline CAS086 & 27901.8 & 769.28 & 13368.1 & 4580.6 & 91.86 \\
\hline CAS087 & 27874.0 & 652.04 & 15633.7 & 4606.2 & 110.22 \\
\hline CAS088 & 26058.2 & 632.35 & 15454.9 & 5240.1 & 157.27 \\
\hline CAS089 & 30135.5 & 592.84 & 16000.3 & 4861.7 & 79.05 \\
\hline CAS090 & 26345.9 & 698.26 & 15603.0 & 4675.7 & 140.94 \\
\hline CAS091 & 25942.3 & 668.88 & 16412.1 & 4857.4 & 117.37 \\
\hline CAS092 & 26560.6 & 711.67 & 14406.7 & 5927.9 & 105.55 \\
\hline CAS093 & 28528.7 & 707.50 & 13894.3 & 4610.7 & 78.34 \\
\hline CAS094 & 28033.9 & 759.07 & 13631.3 & 4791.3 & 75.03 \\
\hline CAS095 & 27779.7 & 904.11 & 15072.9 & 5136.8 & 127.93 \\
\hline CAS096 & 29543.2 & 571.26 & 14928.4 & 4744.0 & 109.53 \\
\hline CAS097 & 27885.8 & 853.87 & 14315.7 & 4863.7 & 96.40 \\
\hline CAS098 & 28051.1 & 673.53 & 15333.4 & 5456.3 & 108.50 \\
\hline CAS099 & 29939.3 & 805.89 & 14026.3 & 5077.1 & 81.66 \\
\hline CAS100 & 31463.7 & 691.60 & 15135.6 & 4767.2 & 108.04 \\
\hline CAS101 & 30050.0 & 757.54 & 14108.6 & 4878.1 & 88.40 \\
\hline CAS103 & 30642.9 & 680.19 & 17935.1 & 5473.9 & 119.74 \\
\hline CAS104 & 32632.9 & 816.14 & 13605.0 & 4240.0 & 81.98 \\
\hline CAS105 & 36202.5 & 978.44 & 17908.5 & 3774.8 & 49.52 \\
\hline
\end{tabular}




\section{References Cited}

Amsden, Monroe

1928 Archaeological Reconnaissance in Sonora. Southwest Museum Paper No.

1. Highland Park, California.

Arnold, Dean E.

1989 Ceramic Theory and Cultural Process. New Studies in Archaeology.

Cambridge University Press, Cambridge.

Bandelier, Alfred F.

1892 Final Report of Investigations Among the Indians of the Southwestern

United States, Carried on Mainly in the Years from 1880-1885, Part 2. Papers of the Archaeological Institute of America, American Series 4, Cambridge.

Bishop, Ronald L., Robert L. Rands, and George R. Holley

1992 Ceramic Compositional Analysis in Archaeology. In Advances in

Archaeological Method and Theory, Vol. 5, edited by Michael B. Schiffer, pp. 275-330. Academic Press, New York.

Blackiston, A. Hooten

1909 Recently Discovered Cliff-Dwellings of the Sierra Madres. Records of the Past 8(5):20-32.

Brand, Donald D.

1933 The Historical Geography of Northwestern Chihuahua. PhD dissertation, Department of Geography, University of California.

Brand, Donald D.

1935 The Distribution of Pottery Types in Northwest Mexico. American Anthropologist 37:287-305.

Britton, Emma L.

2018 Mineralogical and Chemical Variability of Casas Grandes Polychromes Throughout the International Four Corners. PhD dissertation, Anthropology, University of California, Santa Cruz.

Carey, Henry A.

1931 An Analysis of the Northwestern Chihuahua Culture. American Anthropologist 33:325-374. 
Carpenter, John P.

2002 The Animas Phase and Paquime: Regional Differentiation and Integration at Joyce Well. In The Joyce Well Site: On the Frontier of the Casas Grandes World, edited by James M. Skibo, Eugene B. McCluney, and William H. Walker, pp. 149-166. The University of Utah Press, Salt Lake City.

Cecil, Leslie, and Hector Neff

2006 Postclassic Maya Slips and Paints and Their Relationship to Socio-Political Groups in El Peten, Guatamala. Journal of Archaeological Science 33:14821491.

Cordell, Linda

1997 Archaeology of the Southwest. Academic Press, New York.

Creel, Darrell, Matthew Williams, Hector Neff, and Michael D. Glascock

2002 Black Mountain Phase Ceramics and Implications for Manufacture and Exchange Patterns. In Ceramic Production and Circulation in the Greater Southwest, edited by Donna Glowacki and Hector Neff, pp. 37-46. vol. 44. Costen Institute of Archaeology, University of California, Los Angeles.

Crown, Patricia L.

1994 Ceramics and Ideology: Salado Polychrome Pottery. University of New Mexico Press, Albuquerque.

Cruz Antillón, Rafael, Robert Leonard, Tim Maxwell, Todd L. VanPool, Marcel Harmon, Christine S. VanPool, David Hyndman, and Sidney Brandwein

2004 Galeana, Villa Ahumada, and Casa Chica: Diverse Sites in the Casas Grandes Region. In Surveying the Archaeology of Northwest Mexico, edited by Gillian E. Newell and Emiliano Gallaga, pp. 149-175. The University of Utah Press, Salt Lake City.

Dean, Jeffrey S., and John C. Ravesloot

1993 The Chronology of Cultural Interaction in the Gran Chichimeca. In Culture and Contact: Charles C. Di Peso's Gran Chichimeca, edited by Anne I. Woosley and John C. Ravesloot, pp. 83-104. Amerind Foundation, Dragoon, Arizona, and the University of New Mexico Press, Albuquerque.

Dean, Jeffrey S., and Anne I. Woosley (editors)

2000 Salado. University of New Mexico Press.

Di Peso, Charles C.

1974 Casas Grandes: A Fallen Trading Center of the Gran Chichimeca, Vol. 13. Amerind Foundation, Dragoon, and Northland Press, Flagstaff, Arizona. 
Di Peso, Charles C., John B. Rinaldo, and Gloria J. Fenner (editors)

1974 Casas Grandes: A Fallen Trading Center of the Gran Chichimeca, Vol.

4-8. Amerind Foundation, Dragoon, and Northland Press, Flagstaff, Arizona.

Doser, Diane I., and Jason Rodriguez

1993 The Seismicity of Chihuahua, Mexico, and the 1928 Parral Earthquake.

Physics of the Earth and Planetary Interiors 78:97-104.

Douglas, John E.

1995 Autonomy and Regional Systems in the Late Prehistoric Southern Southwest. American Antiquity 60:240-257.

Fenner, Gloria J.

1974 Chapter 3: Medio Period Ceramics. In Casas Grandes: A Fallen Trading Center of the Grand Chichimeca, edited by Charles C. Di Peso, John B. Rinaldo, and Gloria J. Fenner, pp. 77-316. Amerind Foundation, Dragoon, and Northland Press, Flagstaff, Arizona.

Fish, Paul R., and Suzanne K. Fish

1999 Reflections on the Casas Grandes Regional System from the Northwestern Periphery. In The Casas Grandes World, edited by Curtis F. Schaafsma and Carroll L. Riley, pp. 27-42. The University of Utah Press, Salt Lake City.

Gamboa, Eduardo

2002 Casas Grandes Culture. In Talking Birds, Plumed Serpents, and Painted Women: The Ceramics of Casas Grandes, edited by Joanne Stuhr, pp. 41-43. Tucson Museum of Art and Historick Block, Tucson.

Gladwin, Winifred, and Harold Gladwin

1934 A Method for Designation of Cultures and Their Variation. In Medallion Papers, pp. 1-10. Lancaster Press, Pennsylvania.

Glascock, Michael D.

1992 Characterization of Archaeological Ceramics at MURR by Neutron Activation Analysis and Multivariate Statistics. In Chemical Characterization of Ceramic Pastes in Archaeology, Monographs in World Archaeology No. 7, edited by Hector Neff, pp. 11-26. Prehistory Press, Madison, Wisconsin.

2014 Geochemical Sourcing. In Encyclopedia of Geoarchaeology, edited by Allan S. Gilbert. Springer, Netherlands. 
Glascock, Michael D., and Hector Neff

2003 Neutron Activation Analysis and Provenience Research in Archaeology.

Measurement Science and Technology 14:1516-1526.

Glowacki, Donna, and Hector Neff (editors)

2002 Ceramic Production and Circulation in the Greater Southwest: Source

Determination by INAA and Complementary Mineralogical Investigations.

Monograph 44. Costen Institute of Archaeology, Los Angeles.

Harbottle, Garmin

1976 Activation Analysis in Archaeology. Radiochemistry 3:33-72.

Harmon, Marcel

2006 Religion and the Mesoamerican Ball Game in the Casas Grandes Region of Northern Mexico. In Religion in the Prehispanic Southwest, edited by Todd L. VanPool, Christine S. VanPool, and David A. Phillips Jr., pp. 185-218. AltaMira Press, Walnut Creek, CA.

Hendrickson, Mitchell J.

2003 Design Analysis of Chihuahuan Polychromes Jars from North American

Museum Collections, BAR International Studies 1125. Archaeopress, Oxford.

Hill, David V.

2010 Petrographic Analysis of Ten Sherds from the 76 Draw Site, Luna County, New Mexico. Report submitted to Christine VanPool, University of Missouri. Copies available from Christine VanPool, University of Missouri.

Huntley, Deborah, Jeffrey Clark, and Mary F. Ownby

2013 Movement of People and Pots in the Upper Gila Region of the American Southwest. In Exploring Cause and Explanation, Historical Ecology,

Demography and Movement in the American Southwest, edited by Cynthia Herhahn and Ann F. Ramenosfky, pp. 275-295. University Press of Colorado, Boulder.

Jelinek, Arthur J.

1967 A Prehistoric Sequence in the Middle Pecos Valley, New Mexico.

Anthropological Papers No. 31. Museum of Anthropology, University of

Michigan, Ann Arbor.

Jennings, Jesse D.

1940 A Variation of Southwestern Pueblo Culture. Technical Series Bulletin No.

19. Laboratory of Anthropology, Museum of New Mexico, Santa Fe. 
Kelley, J. Charles

1993 Zenith Passage: The View from Chalchihuites. In Culture and Contact:

Charles C. Di Peso's Gran Chichimeca, edited by Anne I. Woosley and John C. Ravesloot, pp. 227-250. Amerind Foundation and University of New Mexico Press, Albuquerque.

2000 The Aztatlán Mercantile System: Mobile Traders and the Northwestern Expansion of Mesoamerican Civilization. In Greater Mesoamerica: The Archaeology of West and Northwest Mexico, edited by Michael Foster and Shirley Gorenstein, pp. 137-154. University of Utah Press, Salt Lake City.

Kelley, Jane Holden

1984 The Archaeology of the Sierra Blanca Region of Southeastern New Mexico. Anthropological Papers No. 74. Museum of Anthropology, University of Michigan, Ann Arbor.

Kidder, Alfred V.

1916 The Pottery of the Casas Grandes District, Chihuahua. In Holmes Anniversary Volume: Anthropoogical Essays, pp. 253-268, Washington D.C.

Kidder, Alfred V., Harriet S. Cosgrove, and C. Burton Cosgrove

1949 The Pendleton Ruin, Hidalgo County, New Mexico. Contributions to American Anthropology and History. Carnegie Institution of Washington, Washington, D.C.

Kidder, Alfred V., and Anna O. Shepard 1936 The Pottery of Pecos, Volume 2: The Glaze Paint, Culinary, and Other Wares. Papers of the Southwestern Expedition. Yale University Press, New Haven.

Krug, Andrew

2018 Sourcing of Marine Shell from 76 Draw, New Mexico. Master's thesis. Department of Anthropology, University of Missouri.

Krug, Andrew R., Kyle D. Waller, and Christine S. VanPool

2016 Isotopic Approaches to Animas Phase Marine Shell Exhcange. Paper presented at the 81st Annual Meeting of the Society for American Archaeology, Orlando, Florida.

Lally, Joseph R.

2006 A Critical Mass of Archaeologists. Fire and Arson Investigator:22-24. 
Lekson, Stephen $\mathrm{H}$.

1999 Was Casas a Pueblo? In The Casas Grandes World, edited by Curtis F.

Schaafsma and Carroll L. Riley, pp. 84-92. The University of Utah Press, Salt Lake City.

2000 Salado in Chihuahua. In Salado, edited by Jeffrey S. Dean, pp. 275-294. University of New Mexico Press.

2002 Salado Archaeology of the Upper Gila, New Mexico. Athropological Papers of the University of Arizona. No. 67. The University of Arizona Press, Tucson.

Lieber, Mallary, Christine S. VanPool, and Todd L. VanPool

2014 Pottery and Social Interaction at 76 Draw, New Mexico. The Artifact 52:31-36.

Lowell, Julia C.

2007 Women and Men in Warfare and Migration: Implications of Gender Imbalance in the Grasshopper Region of Arizona. American Antiquity 72:95123.

Lumholtz, Carl

1902 Unknown Mexico: Explorations in the Sierra Madre and Other Regions, 1890-1898, Vol. 1-2. Charles Scribner, New York.

Lyons, Patrick, and Alexander J. Lindsay

2006 Perforated Plates and the Salado Phenomenon. Kiva 72:5-54.

McCarthy, Elizabeth M., Christine S. VanPool, and Andrew Fernandez 2014 The 76 Draw Bird Burial. The Artifact 52:139-145.

McCluney, Eugene B.

1962 Clanton Draw and Box Canyon: An Interim Report on Two Prehistoric Sites in Hidalgo County, New Mexico, and Related Surveys. Monograph No. 26. School of American Research, Santa Fe.

2002 The 1963 Excavation. In The Joyce Well Site: On the Frontier of the Casas Grandes World, edited by James M. Skibo, Eugene B. McCluney, and William H. Walker, pp. 11-96. The University of Utah Press, Salt Lake City.

Mera, Harry P.

1943 An Outline of Ceramic Development in Southern and Southeastern New Mexico. Technical Series Bulletin No. 11. Laboratory of Anthropology, Museum of New Mexico, Santa Fe. 
Minnis, Paul E.

1988 Four Examples of Specialized Production at Casas Grandes, Northwestern Chihuahua. Kiva 53:181-193.

Minnis, Paul E., and Michael E. Whalen

2015 Introduction: The Joint Casas Grandes Expedition in Historical Context. In Ancient Paquimé and the Casas Grandes World, edited by Paul E. Minnis and Michael E. Whalen, pp. 3-16. The University of Arizona Press, Tucson.

Neff, Hector

2002 Quantitative Techniques for Analyzing Ceramic Compositional Data. In Ceramic Production and Circulation in the Greater Southwest, edited by Donna Glowacki and Hector Neff, pp. 15-36. vol. Monograph 44. Costen Institute of Archaeology, Los Angeles.

2014 Pots as Signals: Explaining the Enigma of Long-Distance Ceramic Exchange. In Craft and Science: International Perspectives on Archaeological Ceramics, edited by Marcos Martinón-Torres, pp. 1-11. Bloomsbury Qatar Foundation, Doha, Qatar.

Neff, Hector, and Donna Glowacki

2002 Ceramic Source Determination by Instrumental Neutron Activation Analysis in the American Southwest. In Ceramic Production and Circulation in the Greater Southwest, Monograph 44, edited by Donna Glowacki and Hector Neff, pp. 1-14. The Costen Institute of Archaeology, Los Angeles.

Nelson, Ben A., and Steven LeBlanc

1986 Short-Term Sedentism in the American Southwest: The Mimbres Valley Salado. Maxwell Museum of Anthropology and the University of New Mexico Press, Albuquerque.

Noneman, Heidi, Christine S. VanPool, Andrew Fernandez, and Todd L. VanPool 2017 Experimental Casas Grandes Archaeology of Pottery to Examine Tribochemical Processes of Corn Beer and Hominy. Paper presented at the $82^{\text {nd }}$ Annual Meeting of the Society for American Archaeology, Vancouver, British Columbia.

Ownby, Mary F., Huntley, Deborah L., and Matthew Peeples

2014 A Combined Approach: Using NAA and Petrography to Examine Ceramic Production and Exchange in the American Southwest. Journal of Archaeological Science 52:152-162. 
Peeples, Matthew A.

2011 Identity and Social Transformation in the Prehispanic Cibola World: A.D. 1150-1325, Arizona State University.

Pierce, Daniel E.

2017 Finding Class in the Glass: Obsidian Source as a Costly Signal. Journal of Anthropological Archaeology 48:217-232.

Pitezel, Todd

2011 From Archaeology to Ideology in Northwest Mexico: Cerro de Moctezuma in the Casas Grandes Ritual Landscape. PhD dissertation, School of Anthropology, University of Arizona, Tucson. https://repository.arizona.edu/handle/10150/145310?mode=full

Putsavage, Kathryn J.

2015 Social Reorganization in the Mimbres Region of Southwestern New Mexico: The Classic to Postclassic Mimbres Transition (A.D. 1150 to 1450), PhD dissertion, Department of Anthropology, University of Colorado. https://scholar.colorado.edu/anth_gradetds/49/

Rakita, Gordon F. M.

2009 Ancestors and Elites: Emergent Complexity and Ritual Practices in the Casas Grandes Polity. AltaMira Press, Lanham, Maryland.

Rakita, Gordon F. M., and Rafael Cruz

2015 Organization of Production at Paquimé. In Ancient Paquimé and the Casas Grandes World, edited by Paul E. Minnis and Michael E. Whalen, pp. 58-82. University of Arizona Press.

Rakita, Gordon F.M., and Gerry R. Raymond 2003 The Temporal Sensitivity of Casas Grandes Polychrome Ceramics. Kiva 68:153-184.

Rakita, Gordon F. M., Christine S. VanPool, Todd L. VanPool, and Sarah Sterling 2011 An Introduction to the 76 Draw Site, Luna County, New Mexico. In Patterns in Transition: Papers from the 16th Bienniel Jornada Mogollon Conference, edited by Melinda R. Landreth, pp. 29-64. El Paso Museum of Archaeology, El Paso, Texas.

Rice, Prudence M.

1987 Pottery Analysis: A Sourcebook. University of Chicago Press, Chicago. 
Rinaldo, John B.

1974 Chapter 3: Medio Period Ceramics. In Casas Grandes: A Fallen Trading Center of the Grand Chichimeca, edited by Charles C. Di Peso, John B. Rinaldo, and Gloria J. Fenner, pp. 77-316. Amerind Foundation, Dragoon, and Northland Press, Flagstaff, Arizona.

Sall, Candace A., Robert J. Speakman, and Michael D. Glascock

2001 Geochemical Sourcing of Obsidian Artifacts to Support CRM. Paper

presented at the 66th Annual Meeting of the Society for American Archaeology, New Orleans.

Sall, Candace A., Maria Nieves Zedeño, and Robert J. Speakman

2005 A Preliminary Analysis of Pigments Used in Redware Pottery Production at Point of Pines, Arizona. In Laser Ablation-ICP-MS in Archaeological Research, edited by Robert J. Speakman and Hector Neff, pp. 155-166. University of New Mexico Press, Albuquerque.

Sauer, Carl, and Donald D. Brand

1931 Prehistoric Settlements of Sonora, with Special Reference to Cerros de Trincheras. University of California Publications in Geography 5(3). University of California Press, Berkley.

Sayles, Edwin B.

1936 An Archaeological Survey of Chihuahua, Mexico. Medallion Papers 22. Gila Pueblo Foundation, Globe, Arizona.

Schaafsma, Curtis F., and Carroll L. Riley (editors)

1999a The Casas Grandes World. The University of Utah Press, Salt Lake City.

1999b The Casas Grandes World: Analysis and Conclusion. In The Casas Grandes World, edited by Curtis F. Schaafsma and Carroll L. Riley, pp. 237-249. The University of Utah Press, Salt Lake City.

Shepard, Anna O.

1995 Ceramics for the Archaeologist. Edition No. 5. Carnegie Institution, Washington D. C.

Skibo, James M., Eugene B. McCluney, and William H. Walker 2002 The Joyce Well Site. The University of Utah Press, Salt Lake City.

Speakman, Robert J.

2013 Mimbres-Mogollon Pottery Production and Distribution in the American Southwest, USA, PhD dissertation, Department of History and Archaeology, University of Barcelona. 
Sprehn, Maria S.

2003 Social Complexity and the Specialist Potters of Casas Grandes in Northern

Mexico. PhD Dissertation, Department of Anthropology, University of New

Mexico, Albuquerque.

2006 The Specialist Potters of Casas Grandes. In Secrets of Casas Grandes:

Precolumbian Art and Archaeology of Northern Mexico, edited by Melissa S.

Powell, pp. 38-73. Museum of New Mexico Press, Santa Fe.

Stallings, W. S.

1931 El Paso Polychrome. Technical Series. No. 3. Laboratory of Anthropology, Santa Fe.

Taliaferro, Matthew S.

2014 The Black Mountain Phase Occupation at Old Town: an Examination of Social and Technological Organization in the Mimbres Valley of Southwestern New Mexico, ca. A.D. 1150-1300. PhD dissertation, The University of Texas at Austin.

Topi, John R., Christine S. VanPool, Kyle D. Waller, and Todd L. VanPool

2018 The Economy of Specialized Ceramic Craft Production in the Casas

Grandes Region. Latin American Antiquity 29:122-142.

Triadan, Daniela

1997 Ceramic Commodities and Common Containers: Production and

Distribution of White Mountain Red Ware in the Grasshopper Region, Arizona.

No. 61. The University of Arizona Press, Tucson.

Triadan, Daniela, Eduardo Gamboa Carrera, M. James Blackman and Ronald L. Bishop 2005 Sourcing Casas Grandes Polychrome Ceramics. Paper presented the 70th Annual Meeting of the Society for American Archaeology, Salt Lake City.

2018 Sourcing Chihuahuan Polychrome Ceramics: Assessing Medio Period Economic Organization. Latin American Antiquity 29:143-168.

Turner, Christy G.

1999 The Dentition of Casas Grandes with Suggestions on Epigenetic

Relationships among Mexican and Southwestern U.S. Populations. In The Casas Grandes World, edited by Curtis F. Schaafsma and Carroll L. Riley, pp.

229-236. University of Utah Press, Salt Lake City.

USGS

2005 New Mexico geologic map data. USGS. 
VanPool, Christine S.

2003 The Symbolism of Casas Grandes. PhD dissertation, Department of Anthropology, University of New Mexico, Albuquerque.

VanPool, Christine S., Gordon F. M. Rakita, Rafael Cruz Antillon, and Robert Leonard 2008 Field Guide to the Ceramic Types of the Casas Grandes Region. In Touching the Past: Ritual, Religion, and Trade of Casas Grandes, edited by Glenna Neilsen-Grimm, pp. 59-67. Popular Series 5. Museum of Peoples and Cultures, Provo, Utah.

VanPool, Christine S., and Todd L. VanPool

2002 Dichotomy and Duality: The Structure of Casas Grandes Art. In Talking Birds, Plumed Serpents, and Painted Women: Ceramics of Casas Grandes, edited by Joanne Stuhr, pp. 71-75. Tucson Museum of Art and Arizona Lithographers, Tucson.

2012 Casas Grandes Phenomenon. In The Oxford Handbook of North American Archaeology, edited by Timothy P. Pauketat, pp. 645-657. Oxford University Press.

VanPool, Todd L., and Robert D. Leonard 2002 Specialized Groundstone Production in the Casas Grandes Region of Northern Chihuahua, Mexico. American Antiquity 67:710-730.

VanPool, Todd L., Christopher Oswald, Jason Christy, Jeffrey R. Ferguson, Gordon F. M. Rakita, and Christine S. VanPool

2013 Provenance Studies of Obsidian at 76 Draw. In Advances in Jornada Mogollon Archaeology: Proceedings of the 17th Jornada Mogollon Conference, edited by Todd L. VanPool, Elizabeth M. McCarthy, and Christine S. VanPool, pp. 163-183. El Paso Museum of Archaeology, El Paso.

VanPool, Todd L., and Christine S. VanPool

2018 Visiting the Serpent's Home: A Relational Analysis of Paquimé as a

Pilgrimage Site in the North American Southwest. Journal of Social

Archaeology 18:306-324.

VanPool, Todd L., Christine S. VanPool, and Robert D. Leonard 2005 The Casas Grandes Core and Periphery. In Archaeology Between the Borders, edited by Marc Thompson, Jason Jurgena, and Lora Jackson, pp. 2535. El Paso Museum of Archaeology, El Paso. 
VanPool, Todd L., Christine S. VanPool, and David A. Phillips Jr.

2006 The Casas Grandes and Salado Phenomena: Evidence for a Religious

Schism in the Greater Southwest. In Religion in the Prehispanic Southwest, edited by Christine S. VanPool, Todd L. VanPool, and David A. Phillips Jr., pp. 235-251. AltaMira Press, Lanham, Maryland.

VanPool, Todd L., Christine S. VanPool, and Gordon F. M. Rakita

2014 Medio Period Architecture and Archaeology at 76 Draw. The Artifact

52:1-29.

Vargas, Victoria D.

1995 Copper Bell Trade Patterns in the Prehispanic U.S. Southwest and

Northwest Mexico. Arizona State Museum Archaeological Series No. 187.

Arizona State Museum, University of Arizona, Tucson.

Walker, William H., and Gaea McGahe

2006 Animated Waters: Ritual Technology at Casas Grandes, Chihuahua. In:

Precolumbian Water Management: Ideology, Ritual, and Power, edited by

Lisa J. Lucero and Barbara W. Fash, pp. 189-204. University of Arizona Press, Tucson.

Waller, Kyle D.

2017 Bioarchaeological Analyses of Paleodemography and Violence at Paquimé, Chihuahua, Mexico. PhD dissertation, Anthropology, University of Missouri.

Weigand, P.C., Garmin Harbottle, and E. V. Sayre

1977 Turquoise Sources and Source Analysis: Mesoamerica and the

Southwestern U.S.A. In Exchange Systems in Prehistory, edited by Timothy K. Earle and Jonathan E. Ericson, pp. 15-34. Academic Press, New York.

Whalen, Michael E., and Paul E. Minnis

1999 Investigating the Paquimé Regional System. In The Casas Grandes World, edited by Curtis F. Schaafsma and Carroll L. Riley, pp. 54-62. The University of Utah Press, Salt Lake City.

2001 Casas Grandes and its Hinterlands: Prehistoric Regional Organization in Northwest Mexico. University of Arizona Press, Tucson.

2009 The Neighbors of Casas Grandes: Excavating Medio Period Communities of Northwest Chihuahua, Mexico. University of Arizona Press, Tucson. 
Wiseman, Reggie N.

2014 Introduction to Mera's Ceramic Developments in Southern and

Southeastern New Mexico. In: Since Mera: The Original Eleven Bulletins, With Essays and Opinions Derived from Recent Research, edited by Emily J. Brown, Reggie N. Wiseman, and Rory P. Gauthier, pp. 375-383. Archaeological Society of New Mexico, Albuquerque.

Woosley, Anne I., and Bart Olinger

1993 The Casas Grandes Ceramic Tradition: Production and Interregional Exchange of Ramos Polychrome. In Culture and Contact: Charles C. Di Peso's Gran Chichimeca, edited by Anne I. Woosley and John C. Ravesloot, pp. 105131. Amerind Foundation, Dragoon. 
Candace Ann (Lindsey) Sall was born in Kansas City, Missouri, to Nancy and Duane Lindsey in 1974. Her father was in the United States Air Force and the family moved as the Air Force called: two bases in Missouri, one in Louisiana, one in California, and some tours where her father traveled without the family. Candace, or Candy as she is usually called, graduated from Northeast Law, Public Service, and Military Magnet High School in Kansas City, Missouri, and was a member of the National Honor Society.

Candace worked her way through college along with her husband, Joseph C. Sall. She graduated from the University of Missouri with two Bachelor of Arts degrees: Anthropology, and Art History and Archaeology in 2001. Candace completed her Master of Arts degree in Anthropology at the University of New Mexico in 2003.

The University of Missouri's Research Reactor (MURR) provides powerful scientific techniques that are not available in many parts of the United States. Candace returned to the University of Missouri to complete her Ph.D. in Anthropology using several of the techniques available in the Archaeometry Lab at MURR.

Candace has been the Associate Curator at the Museum of Anthropology at the University of Missouri since 2007, and she managed the archaeology collections at the Museum from 2004 to 2007. She continues to do fieldwork in the U.S. Southwest and Northwest Mexico.

Candace is also a flight archer and holds two current world records in the primitive simple composite 50- and 35-pound categories. She loves talking about archaeology and archery with people that visit the museum. 